Master Thesis

TVVR 19/5002

\title{
Study on future storm surge around Suo-nada Sea
}

\section{Ayano Sonoda}

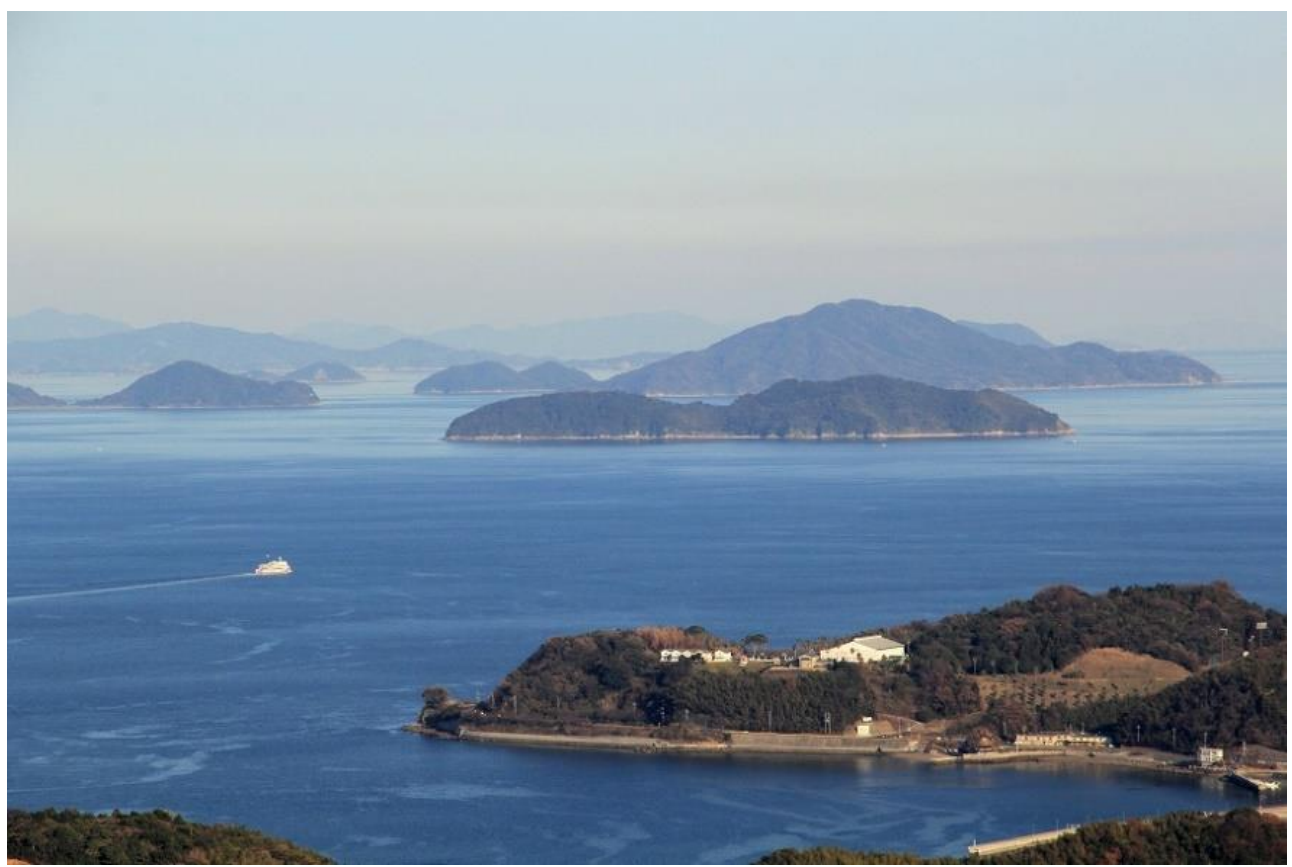

Division of Water Resources Engineering

Department of Building and Environmental Technology

Lund University 


\section{Study on future storm surge around Suo-nada Sea}

By:
Ayano Sonoda

Master Thesis

Division of Water Resources Engineering

Department of Building \& Environmental Technology

Lund University

Box 118

22100 Lund, Sweden 
Water Resources Engineering TVVR-19/5002

ISSN 1101-9824

Lund 2019

www.tvrl.lth.se 


\author{
Master Thesis \\ Division of Water Resources Engineering \\ Department of Building \& Environmental Technology \\ Lund University
}

English title:

Author:

Supervisor:

Examiner:

Language

Year:

Keywords:
Study on future storm surge around Suo-nada Sea Ayano Sonoda

Magnus Larson

Hans Hanson

English

2019

Storm surge; Suo-nada Sea; FVCOM; Japan; numerical simulation 


\section{Acknowledgement}

This project is a part of my big challenges in a double degree project and I could finish my thesis work with so many helps and supports.

Firstly, I would like to thank my supervisor, Prof. Noriaki Hashimoto for his extraordinary patience and consistent encouragement. He gave me great help by providing me with necessary materials, valuable advices and inspiration of new ideas.

I also would like to show my special thanks to Prof. Yasuyuki Nakagawa for his helps to improve my research work. He always gave me new perspectives and valuable advices.

My heartfelt thanks also go to Dr. Masaru Yamashiro, an associate professor. He always gave me valuable advices and showed me the way of proceeding this project. Without his help, my thesis could not be the present form and moreover I could not finish it.

I also would like to show my special thanks to my assistant lecturer Mr. Yoshihiko Ide, who always taught me how to solve technical problems I faced about programing etc. Besides, he gave me a lot of advices and new point of view. Thanks to his supports, I could discuss more deeply in my thesis.

I would like to show my thanks to Mr. Mitsuyoshi Kodama, who is a technical assistant in my laboratory. He arranged an environment for studying and whenever I had problems in my computer or other electronic devices, he fixed them promptly.

I would like to show my thanks to Mr. Suzuyama, who is working in Environmental Consultant of Ocean and Human. He provided me the data of WRF on four typhoons and without his helps, this project has not been the same as the present. Thanks to him, main part of this project could be completed.

Special thanks to my supervisor in Sweden, Magnus Larson, who gave me valuable advices. Owing to his advices, my thesis could be improved a lot. Many thanks to Hans Hanson for his review and contribution to the improvement of this report.

Special thanks to my laboratory members in Japan. They always encouraged me whenever I had a big problem and got depressed. Also especially Taiki Shibata and Seizi Takeda supported me technically on how to deal with the data of d4PDF. Without their helps, main part of this project could not be completed.

Special thanks to my colleagues in Sweden. They always helped me and taught me anything I could not understand especially because of language problem and also encouraged me whenever I needed. With their helps, I could finish all my projects.

Finally, for my parents, thank you for all of your love and support during my time of 
being a double degree student. They provided me an incredible experiment in Sweden and Japan, which is never forgettable for me. Thanks to them, I could challenge anything even which I thought I could not realize and finally completed my degree project. I would like to share this big achievement with them. 


\begin{abstract}
Japan lies on an area frequently hit by typhoons while city functions are clustered along the flat coastal areas, hence Japan has experienced lots of storm surge disasters up to the present. Coastal areas along the Suo-nada Sea also have the vulnerability against storm surge and in the past Typhoon 18 in 1999, Typhoon 16 and 18 in 2004 made remarkable damages in the areas. Furthermore, due to global warming, there are growing concerns about possible tremendous storm surge disasters caused by more furious typhoons than ever. Thus it is necessary to estimate the future storm surge for the coastal disaster prevention. The Suo-nada Sea, however, has some topographical factors which make storm surge estimations difficult. In this study, numerical simulations for storm surge around the Suo-nada Sea were performed by using a coastal circulation model FVCOM (Finite Volume Coastal Ocean Model) developed by Chen et al. (2003). FVCOM employs an unstructured grid system so as to accurately compute tidal currents even in complicated inner bays. First, appropriate computational domain was investigated. Then influences of various input data; calculation results by an empirical typhoon model, simulation results by a regional meteorological model and Grid Point Value, on the accuracy of simulations were examined. Next, future changes of typhoon characteristics around the sea area was investigated on the basis of Database for Policy Decision making for Future climate change (d4PDF). Finally, the future storm surge in Suo-nada Sea was estimated. From the simulations, it was found that more intense typhoons would strike the Suonada Sea and the direction of typhoon tracks would change toward the north in the future due to the global warming. It was also shown that the storm surge around the sea area can be more developed and cause more severe damages around the region in the future.
\end{abstract}




\section{TABLE OF CONTENTS}

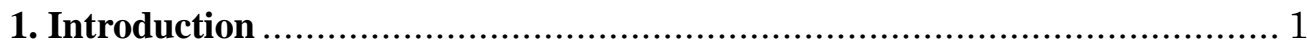

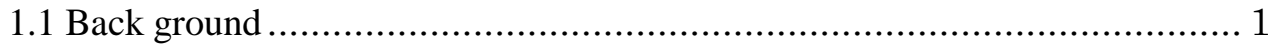

1.2 Characteristics on topography and storm surge simulations in Suo-nada Sea.. 2

1.3 Past typhoons which made severe damages in the region along Suo-nada Sea 4

1) Suo-nada typhoon $(1942.8 / 27 \sim 29)$............................................. 4

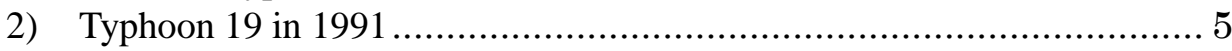

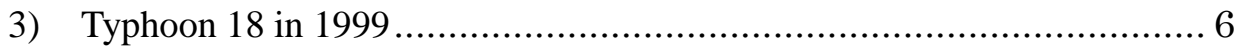

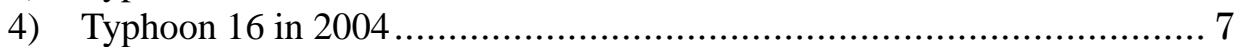

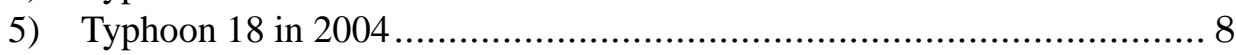

1.4 Past studies on storm surge simulation in Suo-nada Sea .......................... 9

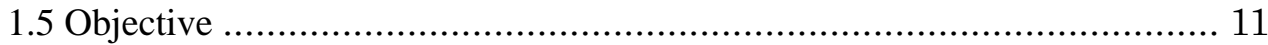

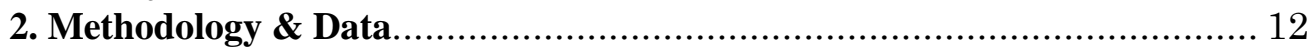

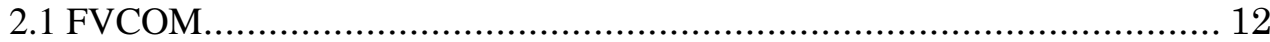

2.1.1 Characteristic of FVCOM .................................................... 12

1) 3-dimensional finite volume method..................................... 12

2) Unstructured- grid system ......................................... 14

3) Location of the model variables .......................................... 15

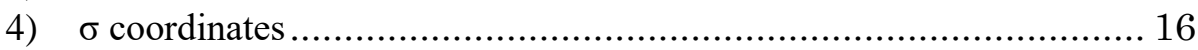

2.1.2 Example of use of FVCOM in other studies............................. 17

2.2 Procedure of estimation on storm surge height ................................. 20

2.3 Estimation of central atmospheric pressure and wind speed of typhoon....... 21

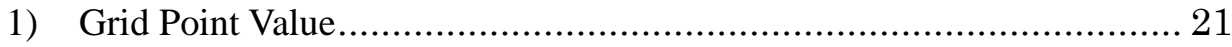

2) Typhoon model ............................................................. 22

3) The Weather Research \& Forecasting Model, WRF ......................... 24

2.4 Database for Policy Decision making for Future climate change (d4PDF) ... 25

2.5 Other data used in the study ..................................................... 27

3. Numerical simulations on storm surge in Suo-nada Sea ......................... 28

3.1 Investigation on the computational domain size ............................... 28

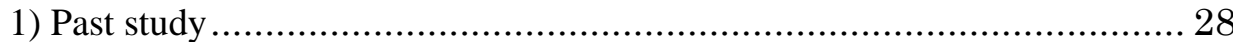

2) Examination of computational domain for FVCOM .........................29

3) Comparison of 5 kinds of computational domain with storm surge ........... 31

4) Investigation on Kii-Channel ................................................ 34

3.2 Verification of numerical simulations on storm surge with several kinds of data

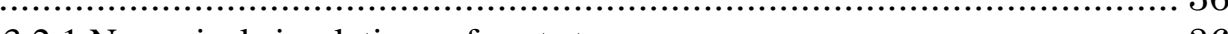

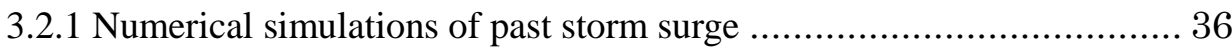

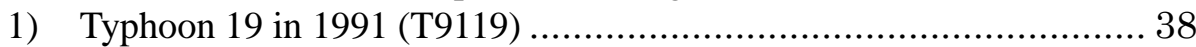

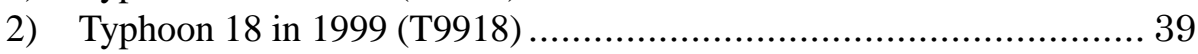

3) Typhoon 16 in 2004 (T0416) ............................................ 40

4) Typhoon 18 in 2004 (T0418) ............................................ 41

3.2.2 Discussion ............................................................ 42

1) Comparison of the results obtained by three different kinds of data ... 42

2) Investigation on relationship between the results of storm surge and typhoon track ............................................................... 43 
3) Comparison of the results between only surge and tide ................. 46

4) Computational conditions for the simulations ............................ 50

5) Accuracy of Best track (BT) .....................................53

4. Future risk of storm surge in Suo-nada Sea ...................................... 54

4.1 Change of the trend on typhoon struck the region along Suo-nada Sea ....... 54

1) Extraction of dangerous future typhoon................................... 54

2) Change of the trend on typhoons going through around Suo-nada Sea..... 55

4.2 Storm surge simulation with future typhoons from d4PDF .................... 57

1) Strongest 10 typhoons passing around Suo-nada Sea ....................... 57

2) Bias correction on central air pressure of future typhoons extracted from d4PDF ............................................................................ 58

3) Typhoon model for the future typhoons ................................... 59

i) Typhoon central pressure ................................................. 59

ii) Radius of maximum wind speed .................................... 59

4.3 Storm surge simulations with future typhoon using typhoon model ........... 62

1) Damped effects of typhoons by passing through the land......................6 62

2) Simulations on future storm surge in Suo-nada Sea...........................6 66

i) Comparison before and after the bias correction on central pressure of typhoon ..................................................................... 66

a) Fifth strongest typhoon ................................................ 66

b) Strongest typhoon ....................................................... 68

ii) Simulations using hypothetical tracks with considering damped effect of typhoons.................................................................... 70

3) Discussion on future storm surge in Suo-nada Sea .......................... 78

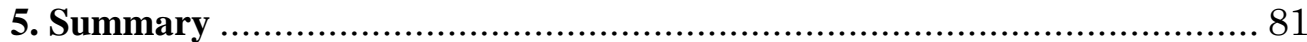

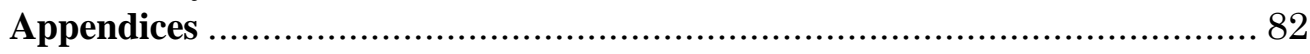

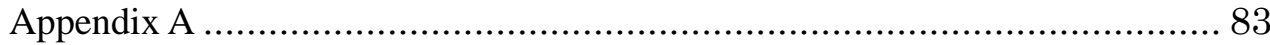

Appendix B ......................................................................... 85

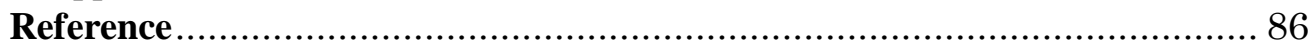




\section{Introduction}

\subsection{Back ground}

Japan is surrounded by sea and lies on an area frequently struck by typhoons. According to Japan Meteorological Agency, 25.6 typhoons are generated on ocean around Japan and among them 11.4 typhoons are approaching while 2.7 typhoons land on Japan every year on an average. Especially in summer season (August and September) a lot of typhoons strike Japan and many damages are reported all over the country. On the other hands the city functions are clustered along the flat coastal area and also there are many reclaimed land since most of Japan is occupied by hills or mountains. For example, it is still fresh for many Japanese that in 2018, Typhoon 21 went across Kinki area and it led to huge damages, especially Osaka Kansai International airport which was built on reclaimed ground was flooded and it became a big news. (See Figure 1.1.1) In this way, Japan has experienced the damages caused by storm surge many times up to the present and it can be said that a coastal disaster prevention is essential for this country. Furthermore, due to global warming, there are growing concerns about possible tremendous storm surge disasters which might be caused by more furious typhoons than ever at the coastal areas throughout Japan.

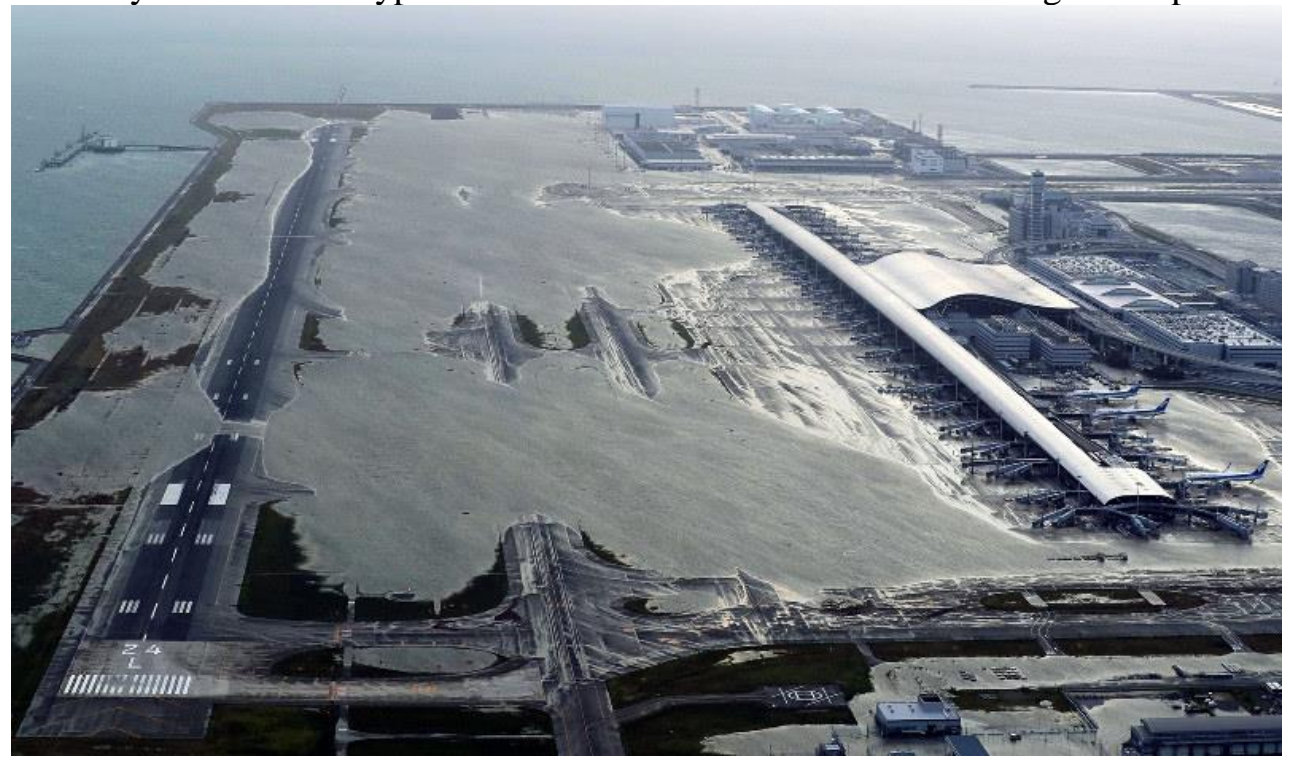

Figure 1.1.1 Flooded Kansai International Airport caused by Typhoon 21 in 2018 (Navva, 2018)

In Kyushu area, Ariake Sea and Yatsushiro Sea are the most dangerous part against storm surge and focused as an objective sea area for storm surge simulations frequently. A region along Suo-nada Sea which is the largest part of Seto Inland Sea also has a vulnerability against storm surge due to a long fetch. For example, in the past Typhoon 18 in 1999, Typhoons 16 and 18 in 2004 hit Suo-nada Sea when high tide and made remarkable damages around the region yet there are less investigations on storm surge in this sea area compared to Ariake and Yatsushiro Sea. Furthermore, 
since Suo-nada Sea is surrounded by land area and has a complicated topography, it has been known that the surge simulation with high accuracy is quite difficult. However due to the global warming it is assumed that the risk of storm surge will rise in the future so that it is strongly expected to study future storm surge in the sea area for the coastal disaster prevention.

\subsection{Characteristics on topography and storm surge simulations in Suo-nada Sea} Suo-nada Sea is located between northern part of Kyushu Island and Yamaguchi prefecture (See Figure 1.2.1) and has almost S-shape. Suo-nada Sea stretches from west to east as opposed to many bays for instance Ariake Sea, Yatsushiro Sea and Kagoshima Bay which are long from north to south. Suo-nada Sea is around $90 \mathrm{~km}$ long from west to east and the width is around $50 \mathrm{~km}$. The sea area is the largest part of Seto-Inland Sea and connecting to Hibiki-nada Sea by Kanmon Strait and also Pacific Ocean through Bungo and Kii-Channel. Moreover, the region around Suonada Sea has been developed as a coastal industrial region. The water depth of the sea area is getting shallower as going to west side; some spots have around $50 \mathrm{~m}$ as water depth in east side whereas in west side it becomes around less than $20 \mathrm{~m}$ especially in the sea area which is around $10 \sim 15 \mathrm{~km}$ away from the coastal line (See Figure 1.2.2). Also the tidal variation in Suo-nada Sea is quite large, around $3.8 \mathrm{~m}$. Since the tidal variation in Hibiki-nada Sea is $1.5 \mathrm{~m}$, this tidal variation gap between Suo-nada and Hibiki-nada Sea leads to a rapid current and complicated tide in Kanmon Strait. The tidal current in Kanmon Strait becomes around 9.4 nots (around $17 \mathrm{~km} / \mathrm{hour}$ ) as the fastest and flows westward when high tide while flowing eastward when low tide. The current direction changes four times in one day, every around 6 hours (Kanmon waterway Office, 2008).

In terms of numerical simulations on storm surge in Suo-nada Sea, it has been known that it is quite difficult to realize it with high accuracy in the sea area because of several topographical factors. Firstly, the water depth in Suo-nada Sea is not so deep (See Figure 1.2.2) that wind effects more strongly contributes to generating the storm surge compared to other sea areas (Nadao, et al., 2006). Secondly the seawater flowing into the region from Pacific Ocean through Bungo Channel and also Kii Channel might influence to the level of storm surge. Also as wind-driven flow is blocked by the Kanmon Strait (see Figure 1.2.1), it can make storm surge even higher. Moreover, Suo-nada Sea is a part of Seto Inland Sea which is composed of several sea areas e.g. Suo-nada Sea, Hiroshima bay and Osaka bay (See Figure 1.2.1) and those areas connect and affect each other. Hence sea areas of Seto-Inland Sea have another unique reason for developing storm surge except for two common reasons; wind effects and low pressure of typhoons. Because of their connection, the high tidal levels caused by typhoons is propagated to the other sea areas. And while the tidal levels going through complicated characteristic topography, another surge will be generated (Takamatsu Port Airport Technical Research Office, 2007). These topographical characteristics make storm surge estimations difficult in Suo-nada Sea and indeed in the past studies, storm surge height tended to be underestimated by numerical simulations, which is described below. 


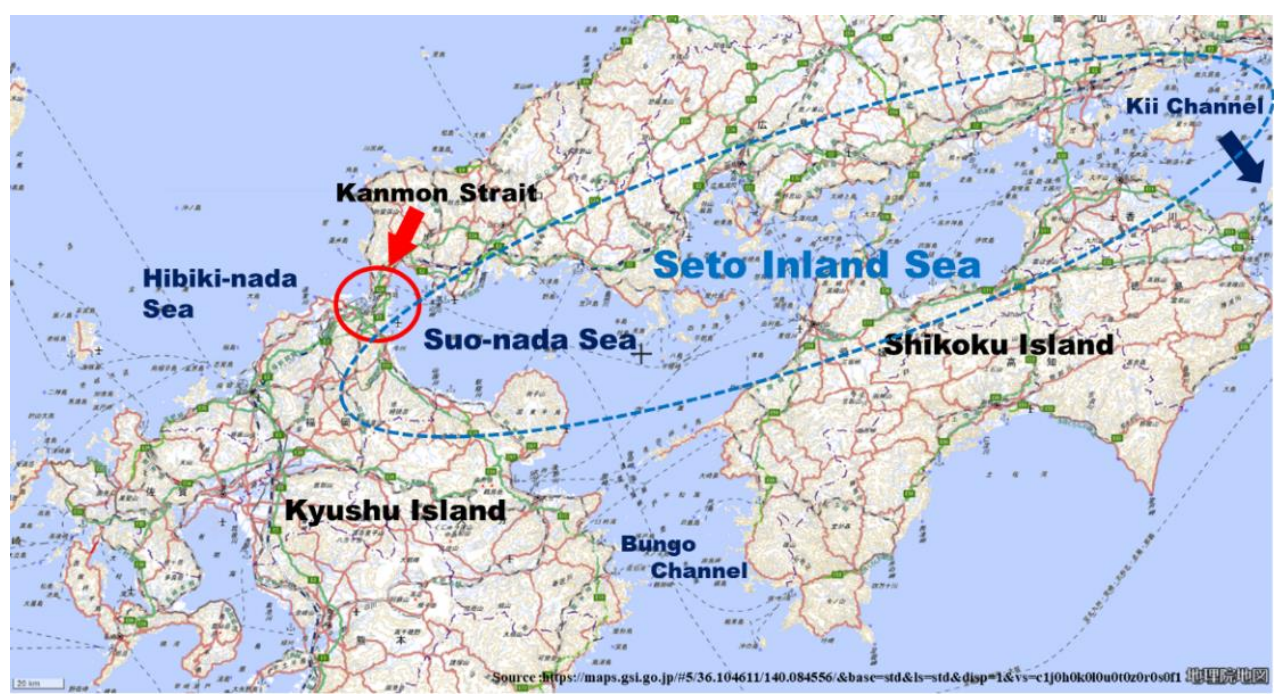

Figure 1.2.1. Map of the region around Suo-nada Sea (Geospatial Information Authority of Japan, 2018)

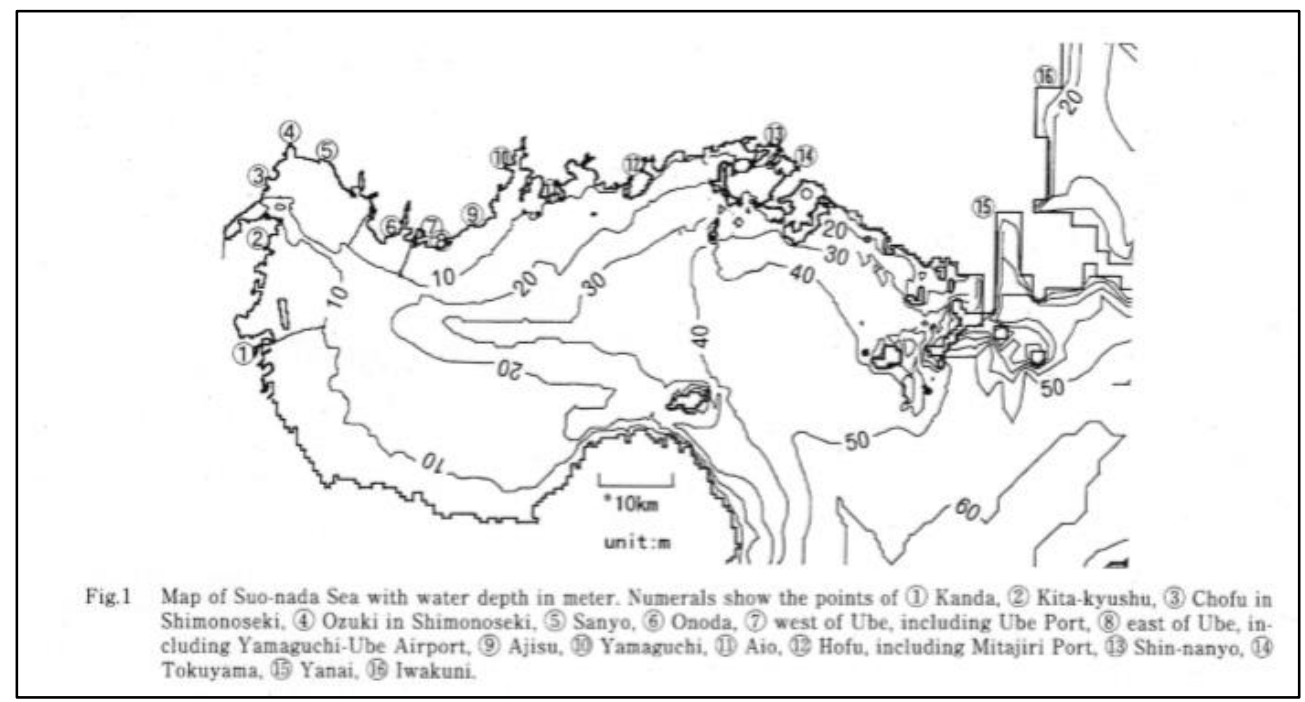

Figure 1.2.2 Map of Suo-nada Sea with water depth in meter (Hiroyasu, 2000) 
1.3 Past typhoons which made severe damages in the region along Suo-nada Sea The past typhoons which led to remarkable storm surge and caused to severe damages around the region along Suo-nada are as follows.

\section{1) Suo-nada typhoon (1942. 8/27 29)}

This typhoon struck Suo-nada Sea and gave tremendous damages to the region hence it was named "Suo-nada typhoon". Suo-nada typhoon has similar track to Typhoon 18 in 1999. Suo-nada typhoon was originated on August $27^{\text {th }}$ and after went across Kyushu Island from south to north, disappeared on $29^{\text {th }}$. The typhoon was short-lived however intensity of the typhoon was the highest when its going through west side of Kyushu Island. Besides since its traveling speed was slow, a state of strong wind and low pressure had been kept in the region around on the path including Suo-nada Sea and Aki-nada Sea. The lowest air pressure was recorded at Akune in Kagoshima, 946.3hPa. As it struck the region along Suo-nada Sea when high tide, it caused high storm surge especially at western coast and northern coast of the sea (See Table 1.3.1) and 1158 people were killed in Yamaguchi prefecture. Moreover, at Kanmon strait, sea level of east side

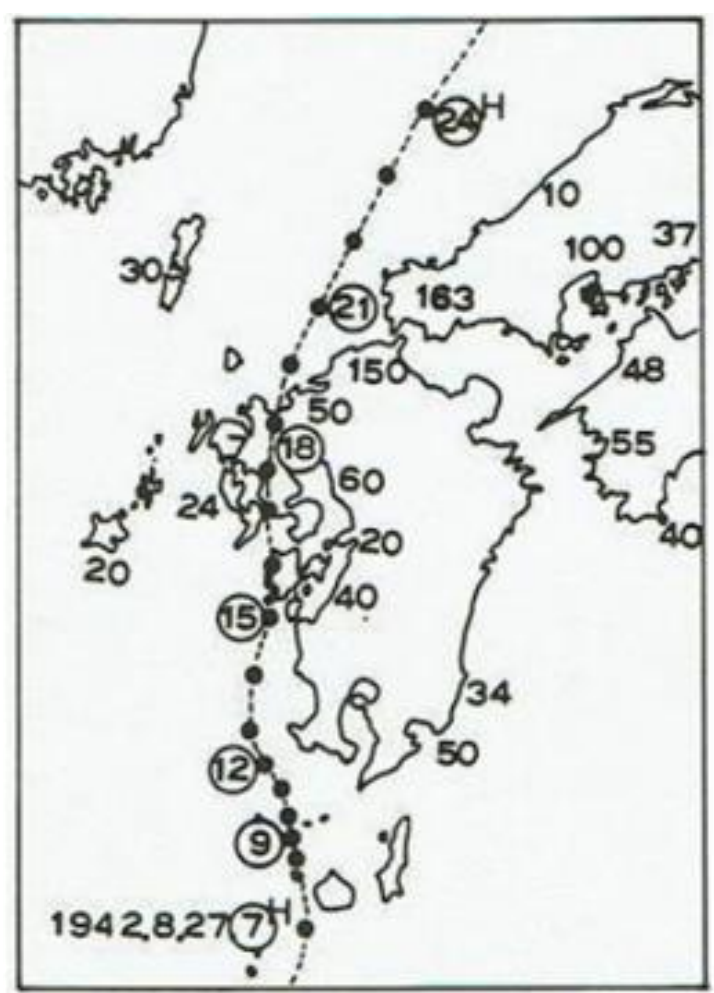

Figure 1.3.1 Track of Suo-nada typhoon (Yo, 1986) became $3 \mathrm{~m}$ higher than west side because of storm surge and it generated unusual tidal current. At that time, the region along Suo-nada Sea had developed as industrial city and also reclaimed land were spread hence these land use factors also contributed to enlargement of the damage. (Masamori, 2003)

Table 1.3.1 Observed values of storm surge caused by Suo-nada typhoon at the coastal area along Suo-nada Sea (Masamori, 2003)

\begin{tabular}{|l|l|}
\hline Location & Height of storm surge $(\mathrm{m})$ \\
\hline Shimonoseki & 0.8 \\
\hline Kanda & 1.3 \\
\hline Ube & 1.9 \\
\hline Mitaziri & 1.9 \\
\hline Tokuyama & 1.9 \\
\hline
\end{tabular}




\section{2) Typhoon 19 in 1991}

Typhoon 19 in 1991 (T9119) went across the west side sea of Kyushu island with speeding up and landed on Sasebo city in Nagasaki prefecture at past 16:00 on September $27^{\text {th }}$. And after that it passed through the central part of Saga prefecture, the region near Fukuoka city, Kita-kyushu city and northwest side of Yamaguchi prefecture then reached to Sea of Japan. (See Figure 1.3.2) While the time when typhoon going through the region around Kyushu island, the central atmospheric pressure was $940 \mathrm{hPa}$ and maximum wind speed was $50 \mathrm{~m} / \mathrm{s}$. Besides the range of strong wind, which is above $25 \mathrm{~m} / \mathrm{s}$ was $300 \mathrm{~km}$; the intensity of the typhoon had been so strong so that west coast of Kyushu island, Suo-nada Sea which were located on the right side of the typhoon were struck by huge storm surge. Especially in Suo-nada Sea, the storm surge height was remarkably developed. The maximum surge height on the north coast of Kyushu island was more than $1.9 \mathrm{~m}$ and the one on the south coast of Kyushu island was around $1.1 \sim 1.8 \mathrm{~m}$. This typhoon made severe damages not only Kyushu area but also in whole Japan island, especially in the northeast area, which is famous for producing apples, the cost of damage became tremendous since its strong wind threw down many apples. Therefore, the typhoon is called "apple typhoon" in that region. (Masamori, 2003)

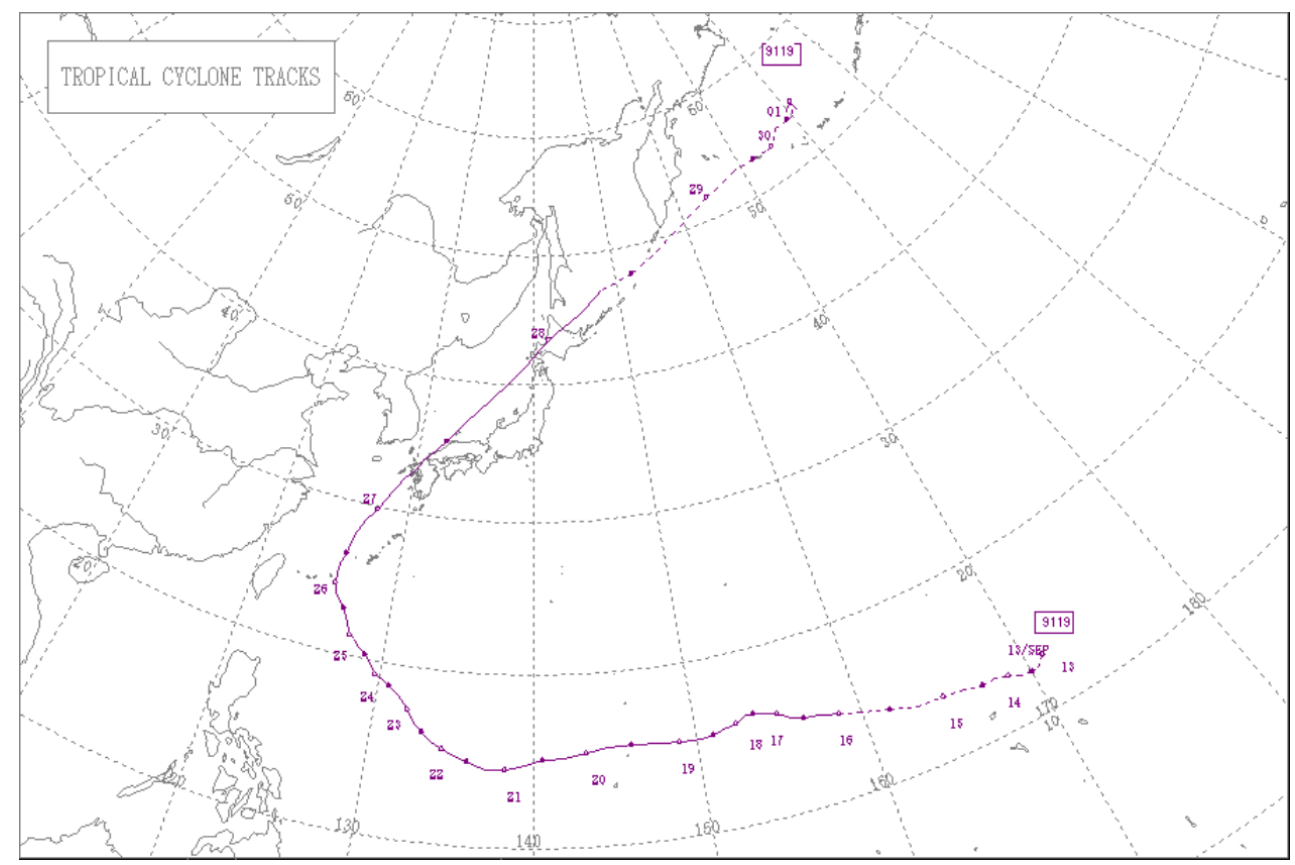

Figure 1.3.2 Track of the typhoon 19 in 1991 (Japan Meteorological Agency, 1991) 


\section{3) Typhoon 18 in 1999}

Typhoon 18 in 1999 (T9918) was generated around Okinawa and went up north slowly, landed on north of Kumamoto prefecture on September $24^{\text {th }}$. Thereafter it crossed Kyushu island and hit Yamaguchi prefecture then it reached Hokkaido in the end after going through Japanese Sea. (See Figure 1.3.3) A south wind blew strongly especially around Kyushu and Chugoku area and over $30 \mathrm{~m} / \mathrm{s}$ was observed as a wind speed everywhere. At Kumamoto $60.2 \mathrm{~m} / \mathrm{s}$ was recorded as the maximum instantaneous wind speed and this was the highest record though the recording was started in 1949. With strong wind, storm surge was developed mainly at the coastal area located on western Japan and especially at Kumamoto and Yamaguchi prefecture the damages became huge since it came around high tide in Autumn Tide. (Ministry of Construction, n.d.) 12 people were killed by the storm surge at Kumamoto and it made many coastal engineers shocked since no one thought storm surge would kill people in the twentieth century with improvement of coastal preventions. Also in Yamaguchi the damages became the largest though a standard for establishing embankment was improved before the typhoon hit the region so that the municipality needed to give a second look for the standard. (Tomihide, et al., 2003)

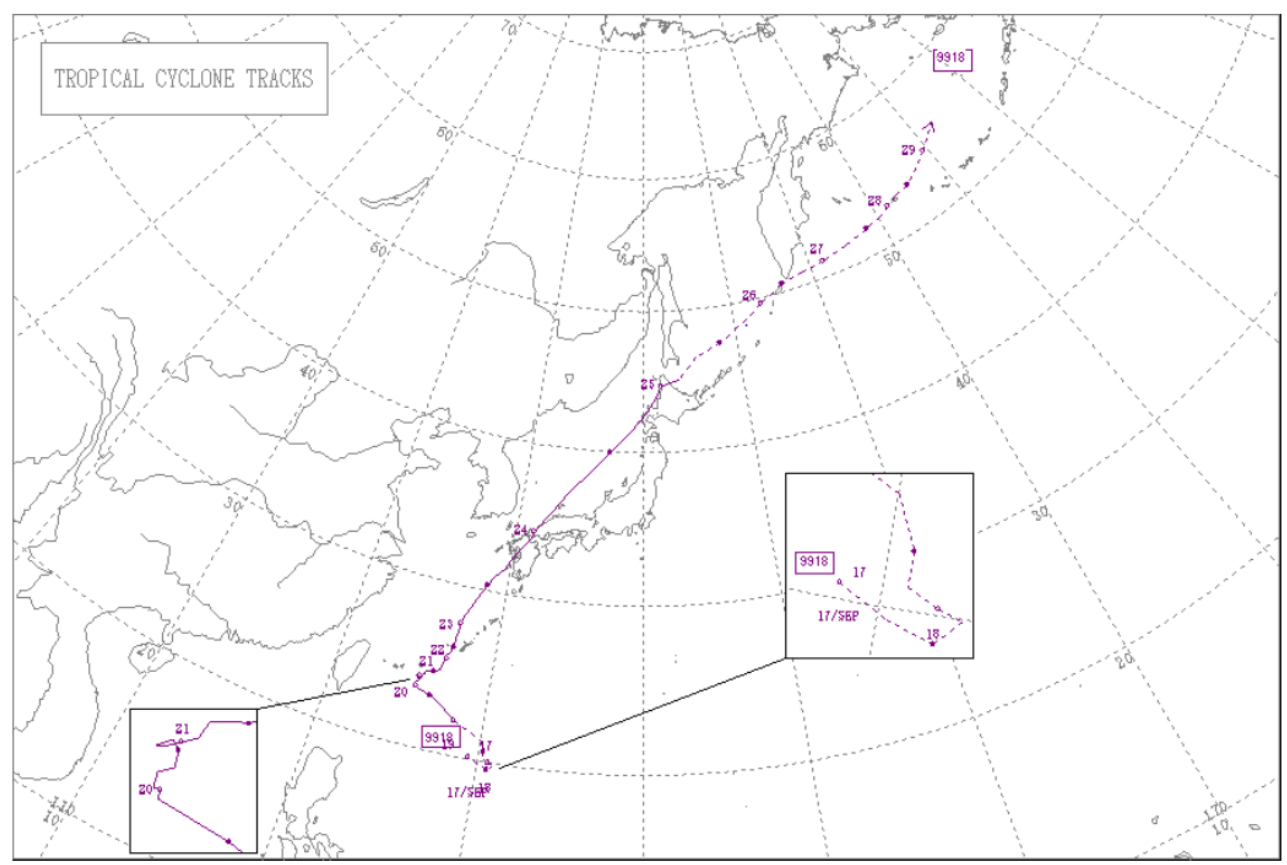

Figure 1.3.3 Track of the typhoon 18 in 1999 (Japan Meteorological Agency, 1999) 


\section{4) Typhoon 16 in 2004}

Typhoon 16 in 2004 (T0416) landed on Kagoshima prefecture on August $30^{\text {th }}$ and went through Yamaguchi prefecture after running through Kyushu Island. (See Figure 1.3.4) The typhoon caused storm surge which grew more than $1 \mathrm{~m}$ along Seto-Inland Sea especially at Takamatsu port in Kagawa prefecture the wave height reached $2.46 \mathrm{~m}$ which exceeded the original highest record $1.94 \mathrm{~m}$. At Uno port in Okayama prefecture also the highest height was recorded. At Takamatsu in Kagawa prefecture over 15000 houses, $980 \mathrm{ha}$ were flooded and some lives were lost. The life lines such as electricity, gas and waterworks were stopped and a blackout caused by inundation affected about 28000 households in the prefecture. (Ministry of Land, Infrastructure, Transport and Tourism ,2005) This was occurred since lots of sea water from Pacific Ocean was driven and flew into this region through the Bungo-Channel by strong wind whose direction is from south to south-west. Moreover, it was also one of the reasons that the typhoon came when the highest tide through a year and it contributed a lot to generating the huge wave.

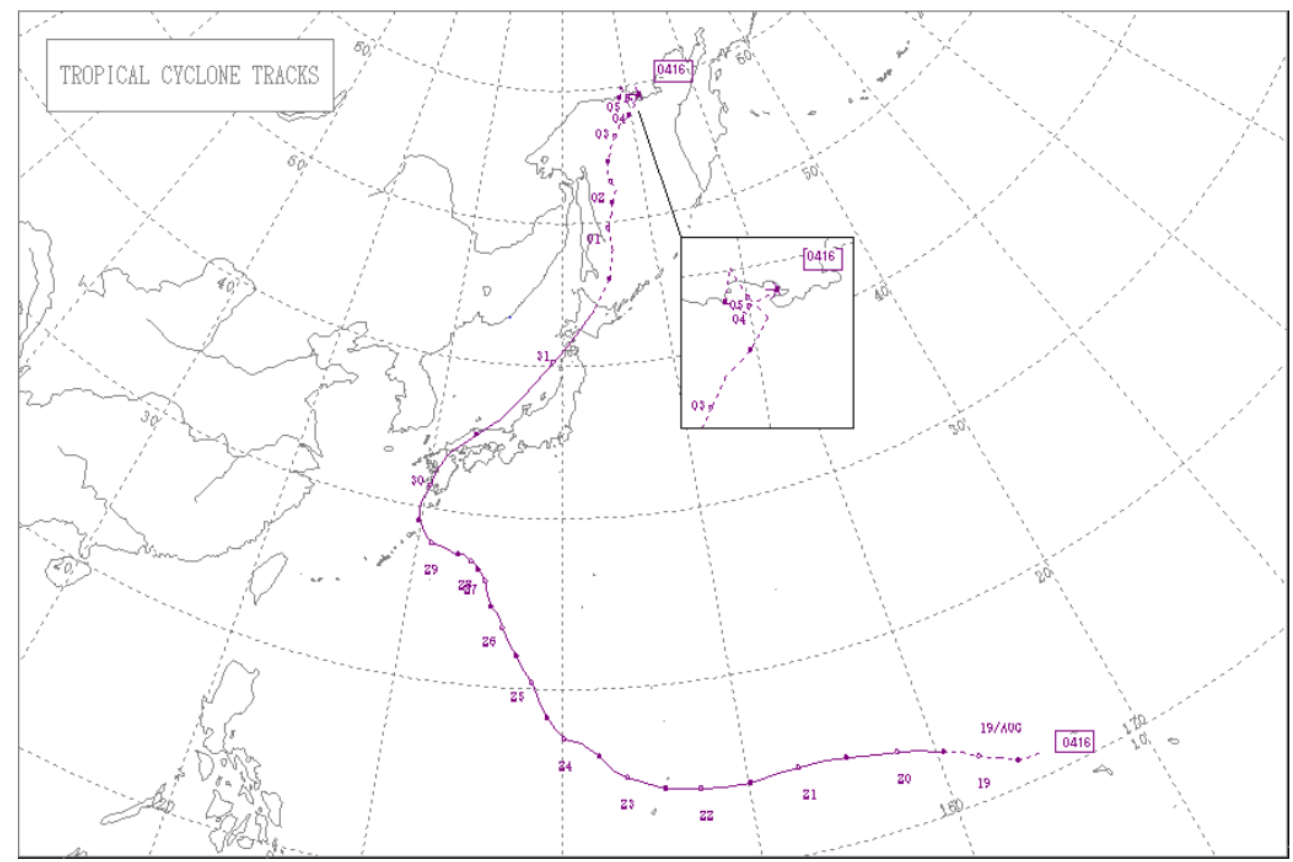

Figure 1.3.4 Track of the typhoon 16 in 2004 (Japan Meteorological Agency, 2004) 


\section{5) Typhoon 18 in 2004}

Typhoon 18 in 2004 (T0418) landed on Okinawa prefecture on September $5^{\text {th }}$ and in two days it went through Nagasaki prefecture. This typhoon went up north along Sea of Japan and caused a lot of damages in the whole country. (See Figure 1.3.5) The record-breaking strong wind was one of the notable characteristics of this typhoon and indeed in some cities the record of the maximum instantaneous wind speed was updated. Especially at Hiroshima prefecture, $60.2 \mathrm{~m} / \mathrm{s}$ was recorded as the maximum instantaneous wind speed and moreover, the typhoon also hit the region when high tide so that many areas affected the damage caused by storm surge. Since the typhoon went through only one week after typhoon 16, many people evacuated before finish cleaning, which raised people's anxiety. Itsukushima shrine which is a world heritage in Hiroshima was also one of the most afflicted sites and the expense for repairing rose to 790000000 Japanese yen. Besides the typhoon broke a common sense because it reached Hokkaido with keeping the same intensity and caused the huge damages in the prefecture also. (Ministry of Land, Infrastructure, Transport and Tourism ,2005)

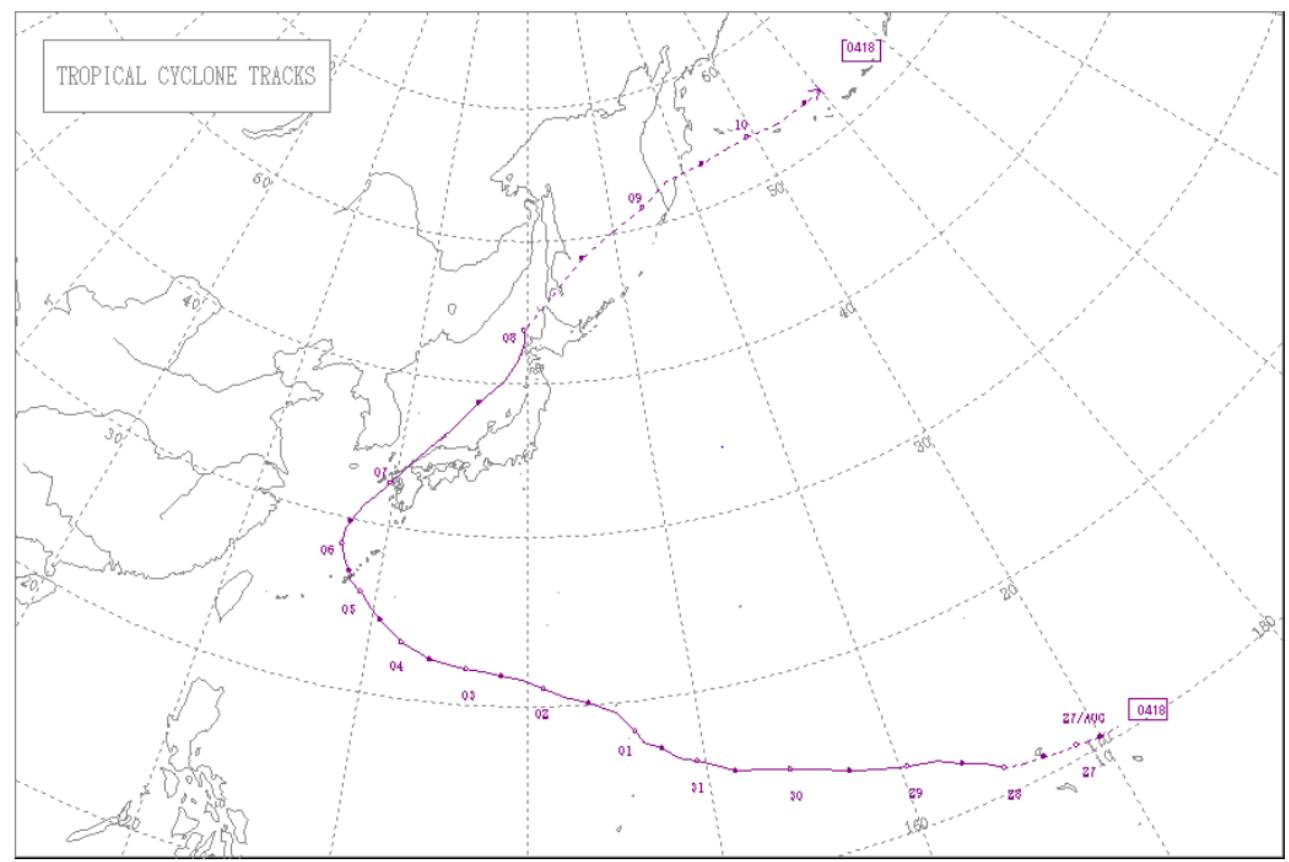

Figure 1.3.5 Track of the typhoon 18 in 2004 (Japan Meteorological Agency, 2004) 


\subsection{Past studies on storm surge simulation in Suo-nada Sea}

Storm surge simulations in Suo-nada Sea have been performed in many past studies. For example, Haruyuki and Hisato (2002) carried out the simulation on storm surge caused by T9918 estimating pressure distribution with Myers model and using gradient wind. However, as seen from Figure 1.4.1, they reported that their estimations became quite smaller than observed data; only $50 \%$ of observed value at Kanda and $60 \%$ in Ube. (The location of each station is shown in Figure 1.4.4) Moreover, they obtained the similar results about T9119 as well and pointed out the problem on estimation of wind speed above sea as a main reason.
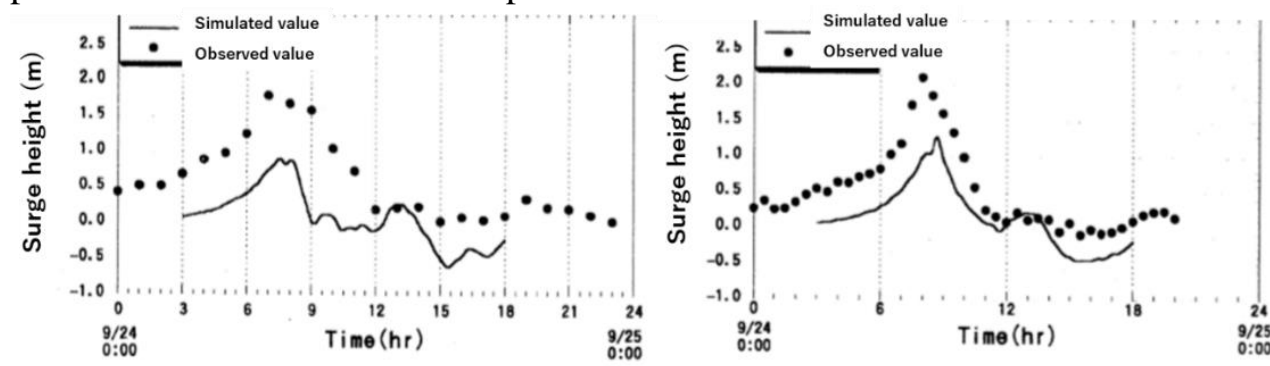

Figure 1.4.1 Comparison simulated value on storm surge by T9918 with observed one at Kanda (left side) and Ube (right side), (Haruyuki and Hisato, 2002)

In order to improve the estimation on storm surge in Suo-nada Sea, Veltcheva and Hiroyasu (2002) consider both a distortion of pressure distribution for Myers model and super gradient wind with Mitsuta $\cdot$ Fujii model, and performed simulations about T9918. The result at Kanda is as shown in Figure 1.4.2. From the figure, it can be seen that the estimation after modifying the external forces became better than before though still it was unable to represent second peak which was between 8 and 10 hours.

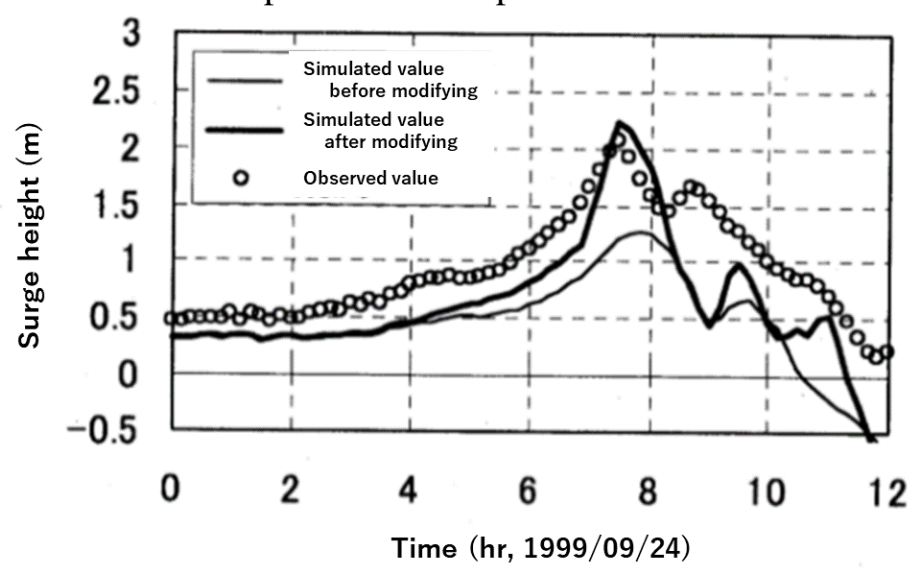

Figure 1.4.2 Comparison simulated value of storm surge before and after modifying external forces by T9918 with observed one at Kanda (Veltcheva \& Hiroyasu, 2002)

Moemi, et al. (2006) carried out simulations based on the study by Veltcheva and Hiroyasu (2002); they attempted to estimate the surge by both T9918 and T0416 with not only a combination of Myers model and super gradient winds but also the one of 
Holland model which adds one more parameter to the Myers model and just gradient winds, then compared the results of two combinations. Since the station of wind speed at Kanda was located near the sea, the parameters to correct wind speed were determined as fitting with the observed data at Kanda and by using the parameters the surge simulations were performed. The results were as shown in Figure 1.4.3. Wind speed at Kanda could obtain almost similar value with observed data especially before central typhoon was passing through the point for both cases although surge height at Ube of these cases were underestimated around $0.2 \sim 0.3 \mathrm{~m}$. More inverstigations are needed for it, however they conculded that both cases were able to improve the simulations on storm surge comparing with the original way i.e. using Myers model and gradient winds, and it was important to have good wind estimation for realizing the accurate storm surge simulations.
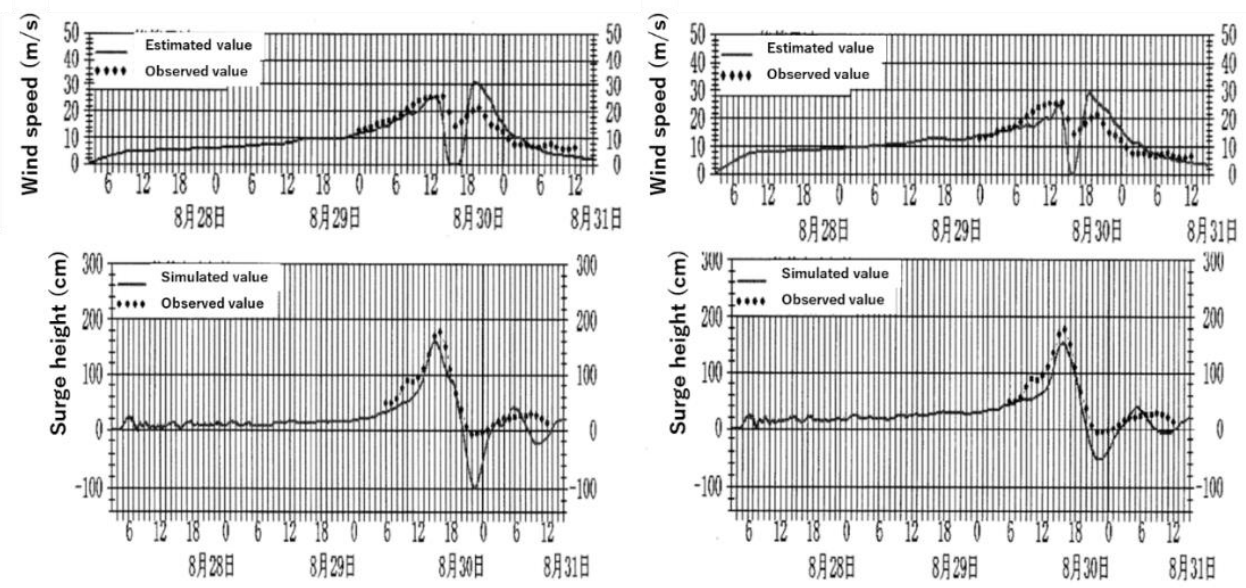

Figure 1.4.3 Results of wind speed at Kanda and surge height at Ube using Holland model with gradient winds (left side) and the one using Myers model with super gradient winds, Mitsuta • Fujii model (right side) (Moemi, et al., 2006)

From these past studies, it can be known that even if one can represent wind speed well, the results of surge simulations do not always have high precision in Suo-nada Sea. Thus it is quite difficult to realize numerical simulations on storm surge with high accuracy in the sea area. 


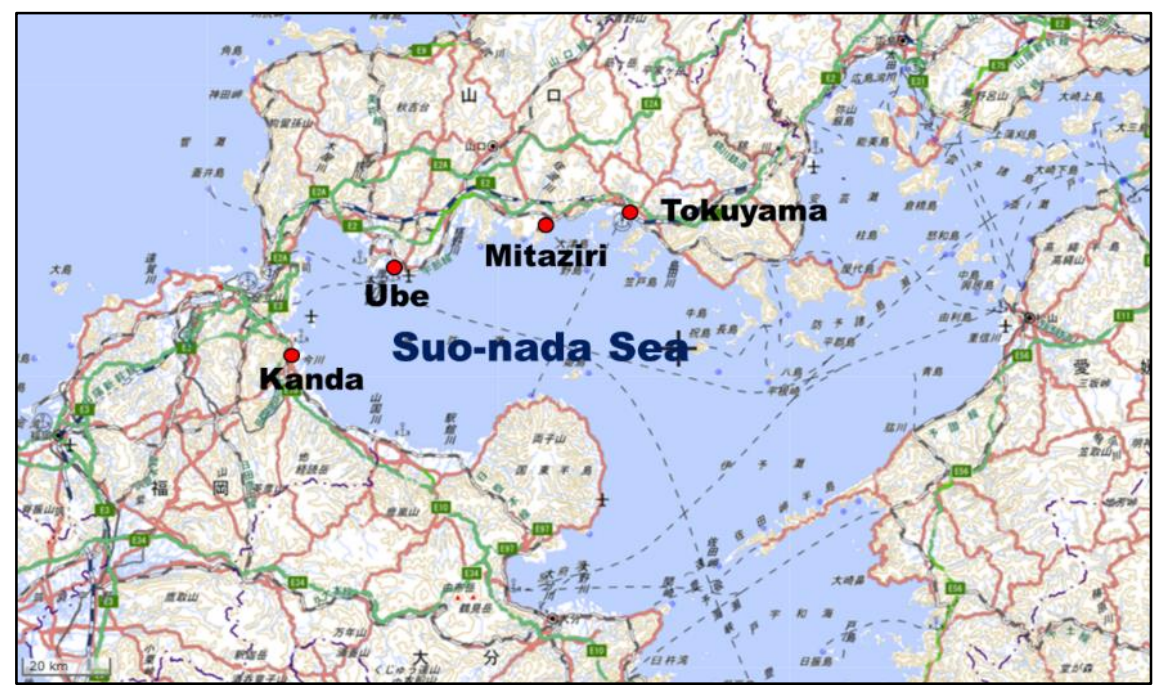

Figure 1.4.4 Location of the stations (Geospatial Information Authority of Japan, 2018)

\subsection{Objective}

The main objective of this study is to investigate the future storm surge in Suo-nada Sea by using Finite Volume Coastal Ocean Model (FVCOM). Due to topographical reasons, simulations about storm surge with high accuracy is quite difficult in this sea area so that as a first step, the most suitable conditions of numerical simulations such as domain size, computational time step and duration of computation etc. were investigated intended for optimizing the computational model. And also the characteristics of storm surge simulations in this sea area was revealed. As a second step future typhoons track which are possibly danger for the region were extracted from Database for Policy making for Future climate change (d4PDF) and the change of the typhoon trend around the region was examined. Moreover, several future typhoons were selected and for the typhoons, future storm surge simulations were performed with an experimental typhoon model using Myers equation. Also some hypothetical tracks were made by having selected original typhoon track parallel shifted for studying the future storm surge around the region more in detail. Moreover, typhoons become somewhat weak by going through land though a typhoon model by Myers equation has fixed intensity i.e. both wind and air pressure distribution are constant throughout a simulation. Therefore, the typhoon's fading by passing through land was considered for realizing more realistic simulation on storm surge. And on the basis of the results, the future storm surge in Suo-nada Sea were discussed for being of use for a coastal disaster prevention in the sea area. 


\section{Methodology \& Data \\ 2.1 FVCOM}

\subsubsection{Characteristic of FVCOM}

In this study in order to simulate storm surge, the numerical simulations were performed by using a coastal circulation model FVCOM (Finite Volume Coastal Ocean Model). FVCOM is an ocean circulation model, which is a prognostic, unstructured-grid, Finite-Volume, free surface, three-dimensional primitive equations Community Ocean Model developed by C. Chen et al., (2013) belong to the Marine Ecosystem Dynamics Modelling (MEDM) Laboratory at Massachusetts Dartmouth University. FVCOM has several representative characteristics which cannot be seen in other model and they are the reasons of using FVCOM in this study.

\section{1) 3-dimensional finite volume method}

FVCOM is a combination on advantages of both finite-element methods (FEM) and finite-difference methods (FDM) for the geometric flexibility, the computational accuracy and efficiency. From FEM, the characteristic that triangular grid meshes which can be easily change its size depending on an applied region type (e.g. for ocean, large mesh can be applied while for the area with complicated shape such as inner bays, it can be made small) are adopted to FVCOM, and this made it possible to obtain geometric flexibility in the simulations. And from FDM, since it is the most basic discrete scheme method, the feature was applied in FVCOM for computational efficiency. Moreover, as an improved point it can be mentioned that the integral form of the governing equations is discretized in FVCOM, while not in FDM and FEM. In the model, flux calculations are used to deal with the integral equations like FDM and they are performed over an arbitrarily sized triangular mesh like FEM, hence one can obtain suitable results on mass conservation in terms of both the individual control element and the entire computational domain. This combination is also contributing for a much better representation of mass, momentum, salt, and heat conservation even at a region with complicated geometry. Also FVCOM adopts "mode-splitting" method and the currents are divided into 2-D (external mode) and 3-D (internal mode) that can be computed using different time steps. Main governing equations dominating FVCOM; momentum, continuity, temperature, salinity and density without snow and ice were as follows. They are solved on Cartesian or spherical coordinate when calculating fluxes between arbitrarily sized triangle mesh adjoin each other.

Momentum equations:

$\frac{\partial u}{\partial t}+u \frac{\partial u}{\partial x}+v \frac{\partial u}{\partial y}+w \frac{\partial u}{\partial z}-f v=-\frac{1}{\rho_{0}} \frac{\partial\left(p_{H}+p_{a}\right)}{\partial x}+\frac{\partial}{\partial z}\left(K_{m} \frac{\partial u}{\partial z}\right)+F_{u} \quad x-$

direction

$\frac{\partial v}{\partial t}+u \frac{\partial v}{\partial x}+v \frac{\partial v}{\partial y}+w \frac{\partial v}{\partial z}+f u=-\frac{1}{\rho_{0}} \frac{\partial\left(p_{H}+p_{a}\right)}{\partial y}+\frac{\partial}{\partial z}\left(K_{m} \frac{\partial v}{\partial z}\right)+F_{v} \quad y-$

direction

$\frac{\partial w}{\partial t}+u \frac{\partial w}{\partial x}+v \frac{\partial w}{\partial y}+w \frac{\partial w}{\partial z}=\frac{\partial}{\partial z}\left(K_{m} \frac{\partial w}{\partial z}\right)+F_{w} \quad z$-direction 
Continuity equation:

$\frac{\partial u}{\partial x}+\frac{\partial v}{\partial y}+\frac{\partial w}{\partial z}=0$

Temperature equation:

$\frac{\partial T}{\partial t}+u \frac{\partial T}{\partial x}+v \frac{\partial T}{\partial y}+w \frac{\partial T}{\partial z}=\frac{\partial}{\partial z}\left(K_{h} \frac{\partial T}{\partial z}\right)+F_{T}$

Salinity equation:

$\frac{\partial S}{\partial t}+u \frac{\partial S}{\partial x}+v \frac{\partial S}{\partial y}+w \frac{\partial S}{\partial z}=\frac{\partial}{\partial z}\left(K_{h} \frac{\partial S}{\partial z}\right)+F_{s}$

Density equation:

$\rho=\rho(T, S)$

Table 2.1.1 Meaning of parameters

\begin{tabular}{|l|l|}
\hline Parameters & Meaning of the parameters \\
\hline$x, y, z$ & east, north, and vertical axes in the Cartesian coordinate system \\
\hline$u, v, w$ & x, y, z velocity components \\
\hline$T$ & temperature \\
\hline$S$ & Salinity \\
\hline$g$ & gravitational acceleration \\
\hline$\rho$ & Density \\
\hline$p_{a}$ & air pressure at sea surface \\
\hline$p_{H}$ & hydrostatic pressure \\
\hline$K_{m}$ & vertical eddy viscosity coefficient \\
\hline$f$ & Coriolis parameter \\
\hline$K_{h}$ & thermal vertical eddy diffusion coefficient \\
\hline$F_{u}, F_{v}, F_{w}, F_{T}, F_{s}$ & horizontal momentum, thermal, and salt diffusion terms \\
\hline$D=H+\zeta$ & $\begin{array}{l}\text { total water column depth } \\
\text { H: bottom depth (relative to z }=0) \\
\zeta: \text { height of the free surface (relative to } \mathrm{z}=0)\end{array}$ \\
\hline
\end{tabular}



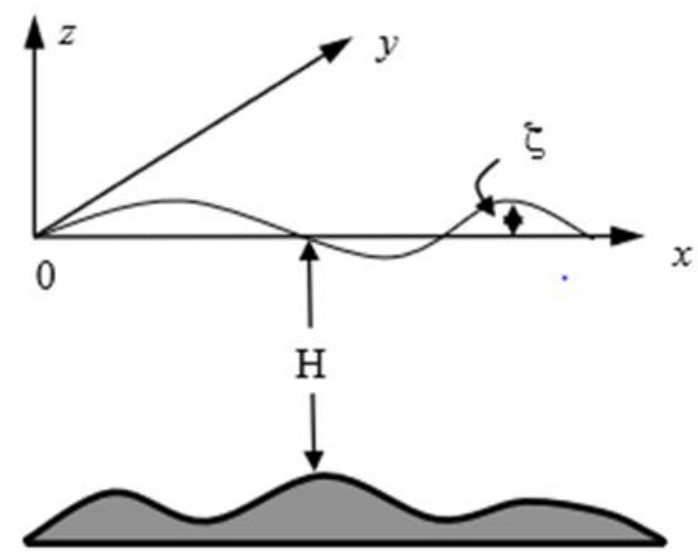

Figure 2.1.1 Cartesian coordinate system used in the model (x: eastward, $y$ : northward, z: upward) (Chen, et al., 2013)

\section{2) Unstructured- grid system}

Normally, coastal line and ocean-land margin is complicated and it is a big challenge to represent it correctly when one configuring the computational domain. And for this kind of simulations, structured grids were used generally e.g. in POM, ECOM-si and ROMS, which has features of Cartesian and all mesh is same size of rectangular thus error between real coastal line and the one of the model can be easily generated. On the other hands FVCOM applies unstructured grids which has non-overlapping triangular cells, can be resized flexibly hence one can realize the accurate fitting even with the complex geometry compared to the case applying structured grids (See Figure 2.1.2). Besides due to the feature of easy resizing, large mesh can be adopted to the open boundary while small one can be used around the region of the study area with irregular geometry so that simulations can be performed efficiently i.e. time cost can be saved a lot.

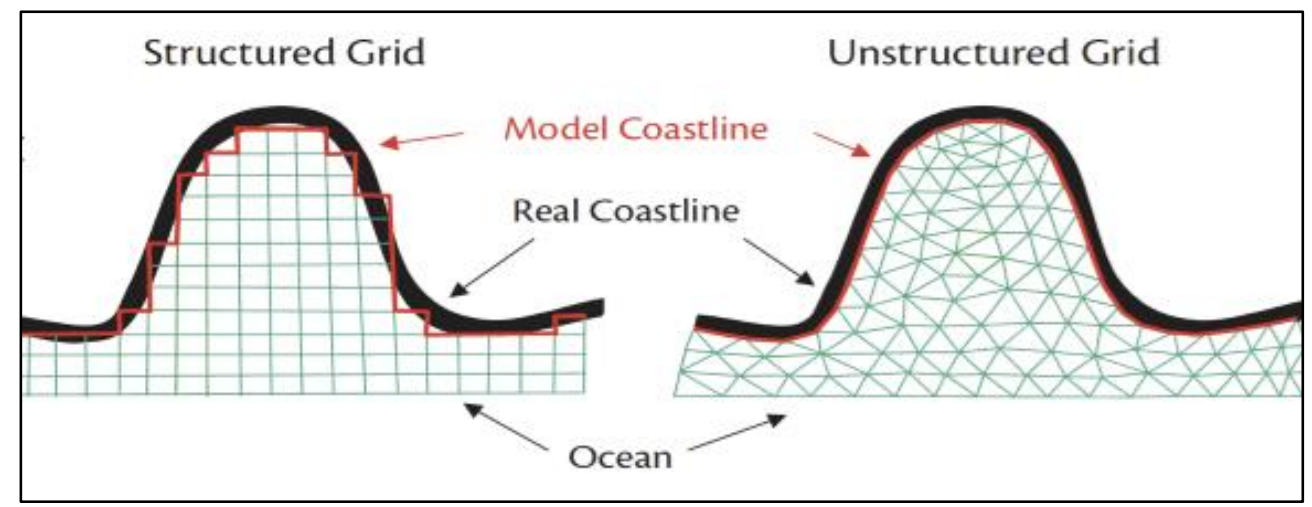

Figure 2.1.2 Comparison of structured grids and unstructured grids (Chen, et al., 2013) 


\section{3) Location of the model variables}

The computational domain is subdivided by triangular unstructured grids horizontally. An unstructured grid is composed of three nodes and a centroid. The variables expressed by fluxes $\mathrm{u}$ and $\mathrm{v}$ e.g. currents, salt and temperature are located on the centroids while all scalar variables e.g. water depth, density, salinity etc. are on the nodes in order to estimate the sea-surface elevation with better accuracy. In this study, scalar variables mainly used in the simulation is air pressure and flux variables is wind velocity or flow current. Scalar variables are derived by the net flux passing through the enclosed sections by lines connecting centroids with the mid-point of adjacent sides in the surrounding triangles of the node. Besides for determining flux variables, $\mathrm{u}$ and $\mathrm{v}$ at the centroids, the net flux on the three nodes which consists the triangular grid are used (See Figure 2.1.3).

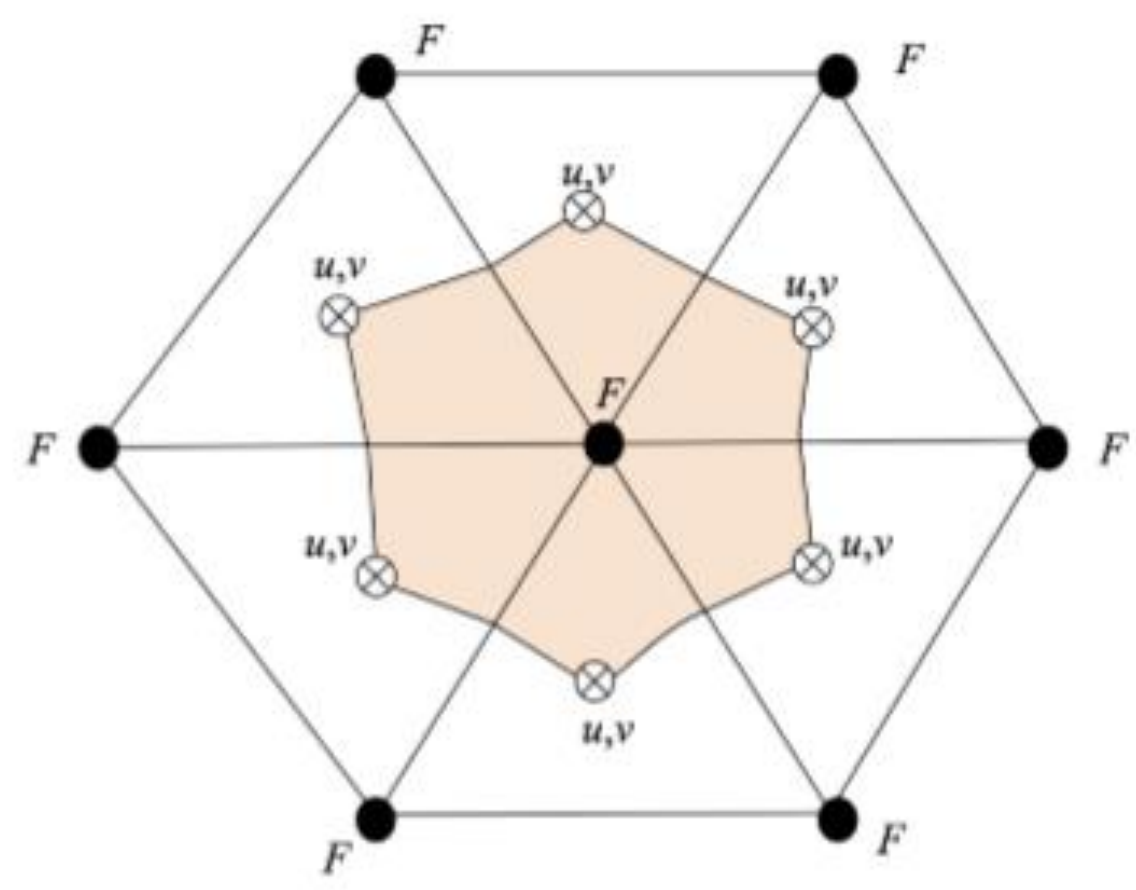

Figure 2.1.3 Illustration of the FVCOM unstructured grid. (Chen, et al., 2013) (Scalar variables which are determined by the flux passing through the colored region are located on the nodes, and flux variables derived by the flux through three nodes of the grid are on the centroids.)

Also though the water depth is divided into several layers to the vertical direction, all the model variables are placed at the middle level of each layer except for vertical velocity on the $\sigma$ layer surface and turbulence variables (See Figure 2.1.4). Moreover, the thickness of $\sigma$ layers do not need to be uniform. 


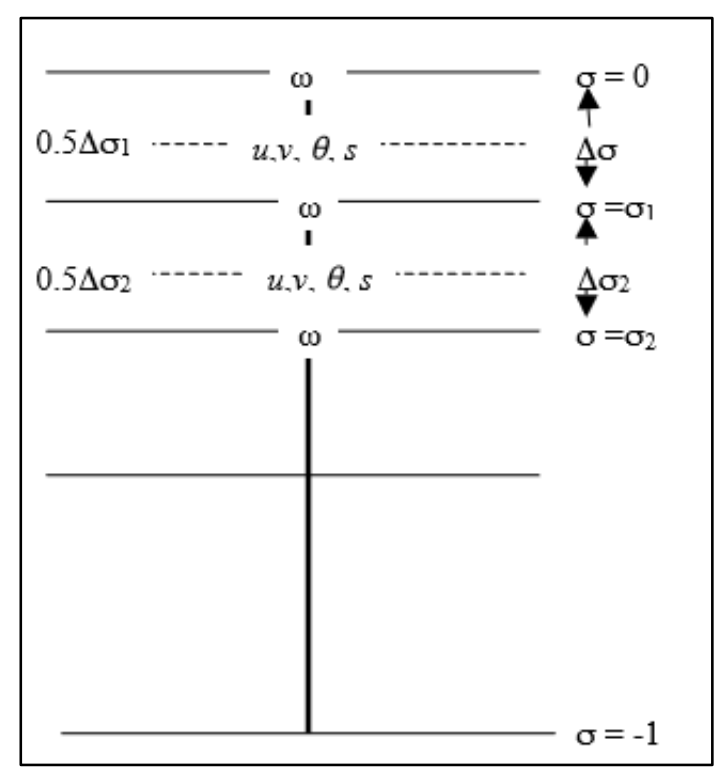

Figure 2.1.4 Location of the model variables in the vertical sigma coordinate (Chen, et al., 2013)

\section{4) $\sigma$ coordinates}

FVCOM uses $\sigma$ coordinates as vertical coordinates. Figure 2.1.5 shows a comparison between $\sigma$ coordinates system and Cartesian coordinate system. As shown in Figure 2.1.5 when using Cartesian coordinate system, the red line is the model ocean bottom topography though there is a big error between the real one and this error will be noticeable at the continental shelf edge where the water depth changed abruptly. On the other hands, $\sigma$ coordinates used in FVCOM divide the water depth into the same number of layers at the any points along the bottom topography (See Figure 2.1.5) hence it is possible to express the actual ocean bottom topography almost exactly even at a point where the water depth rapidly changes, which is difficult for Cartesian coordinate.

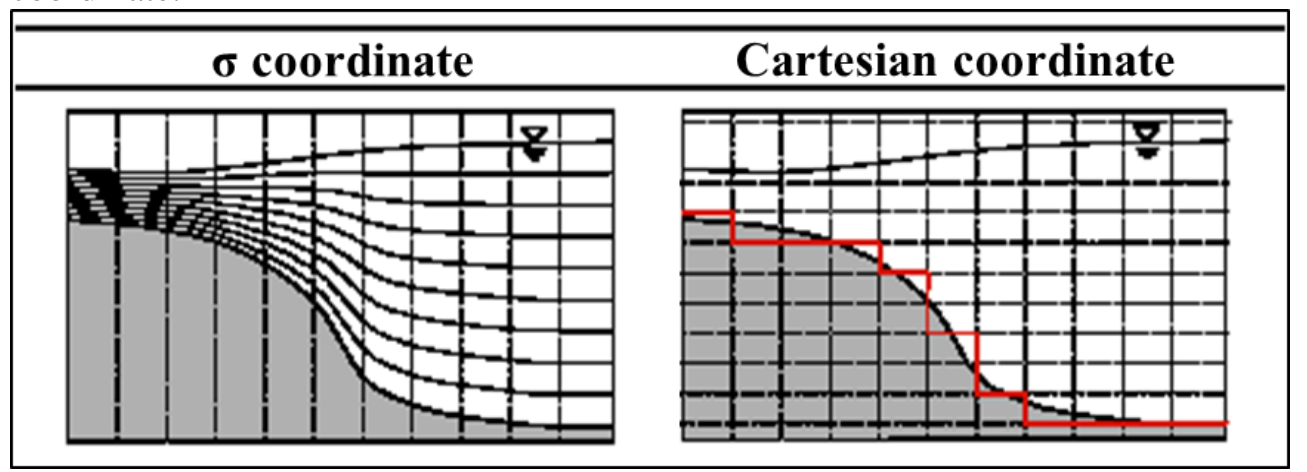

Figure 2.1.5 Comparison between $\sigma$ coordinate and Cartesian coordinate 


\subsubsection{Example of use of FVCOM in other studies}

Originally FVCOM was developed for estuarine flooding/drying process in estuaries and also the tidal-, buoyancy-, and wind-driven circulation in the coastal region featured with complex irregular geometry and steep bottom topography. FVCOM has many modules as shown in Figure 2.1.6 and Table 2.1.2 therefore one can choose suitable ones depending on a situation.

And also since FVCOM allows to represent coastal, estuaries and even global ocean easily with unstructured grids, it has been used for various purposes such as building biological model and sediment transport model e.g. for cohesive sediment erosion (Chen and Hooper, 2013).

\section{Modules of FVCOM}

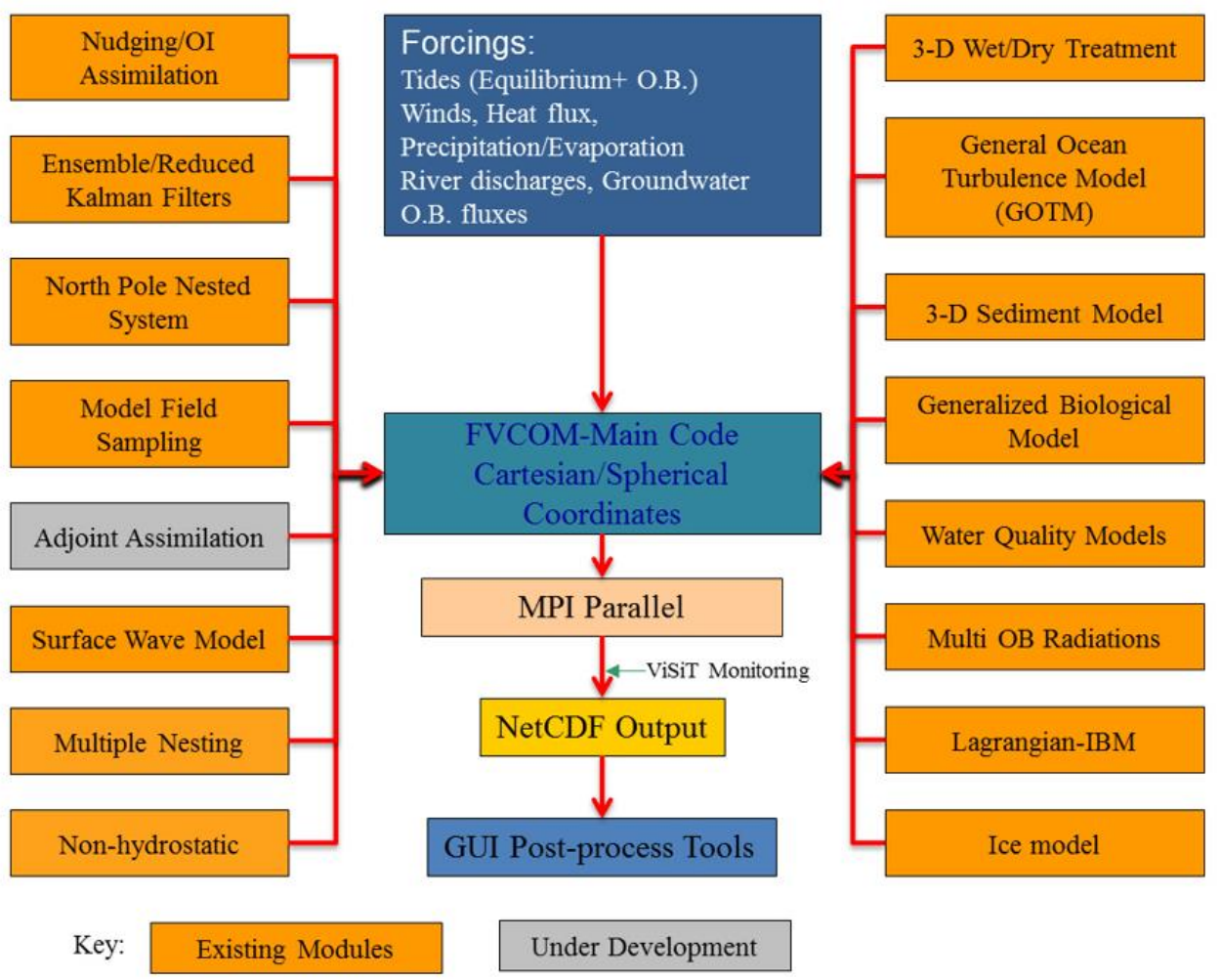

Figure 2.1.6 Modules of FVCOM (Chen and Hooper, 2013) 
Table 2.1.2 Detail of Modules (Chen and Hooper, 2013)

\begin{tabular}{|l|l|}
\hline 1 & Choice of Cartesian or spherical coordinate system \\
\hline 2 & $\begin{array}{l}\text { A mass-conservative wet/dry point treatment for the flooding/drying process } \\
\text { simulation }\end{array}$ \\
\hline 3 & $\begin{array}{l}\text { The General Ocean Turbulent Model modules for optional vertical turbulent } \\
\text { mixing schemes }\end{array}$ \\
\hline 4 & $\begin{array}{l}\text { A water quality module to simulate dissolved oxygen and other environmental } \\
\text { assimilation }\end{array}$ \\
\hline 5 & 4-D nudging and Reduced/Ensemble Kalman Filters for data assimilation \\
\hline 6 & Fully-nonlinear ice modules \\
\hline 7 & A 3-D sediment transport module for estuarine and near-shore applications \\
\hline 8 & A flexible biological module for food web dynamics study \\
\hline
\end{tabular}

By using modules explained above and unstructured grids, many studies have been performed for various kinds of fields such as bay, sea, shelf, inlet, lake, river and estuary. Some example of studies using FVCOM are introduced in below.

\section{Ogeechee River}

The use of FVCOM to this river is a good example of applying to multiple river intersection. Ogeechee River is located on Georgia in USA characterized by a series of barrier island complexes, tidal creeks and extensive salt marshes. Fresh water to the system is provided from mainly two major tributaries originating upstream in the piedmont while the estuary has a typical tidal- dominated dynamic system, which is even strongly effected to the upstream fresh water discharge. Moreover, due to the strong tidal flow, the two tributaries have a good vertical mixing throughout the year. However recently because of both natural environmental perturbations and human development activities, the system of the estuary has been remarkably changing. Hence in order to make strategies of maintain, rebuilding and the long-term management the estuarine system, it is essential to understand the natural variations, underlying mechanisms controlling complex estuarine ecosystem. Since the system is originally dominated by the complex mechanisms; nonlinear intersection of physical, biological, chemical, sedimentation processes and also the situation keeps changing with time and space therefore the data provided from several monitoring stations are not sufficient for studying characterize and model the system enough. FVCOM was used as a hydrodynamic model covering the estuary and made it possible to track point or non-point source pollutants and a real-time tidal forecasting so that contributed to coastal management and environmental assessment, which are important for sounddecision-making.

\section{Lake Michigan}

In Lake Michigan located in USA, in order to study the effect of sediment suspension to the ecosystem in the lake, hydrodynamic and biological model were combined and used. By using the coupled model, it became possible to study the influences of surface wind stress, heat flux and sediment suspension on the suspended plumerelated local ecosystem. There were multi-scale process interactions in the ecosystem 
in Lake Michigan hence the corporation of oceanographers and biologists was important for the project to be succeeded. The lower trophic level food web model was created as a phosphorous-controlled model including some biological variables such as phosphorous, phytoplankton, zooplankton, bacteria, detritus etc. By the model including the microbial loop which is strongly effected to the sediment suspended plume, the difference on phytoplankton by two seasons can be studied.

\section{Cook Inlet}

Cook Inlet is located in south Alaska. It is a large estuary characterized by a huge tidal range and strong tidal current. Moreover, the place is also known well due to tidal bores and a large amount of oil and gas deposits under the ground. For this region, tidal simulations were performed under the conditions with tidal, wind forcing, surface heat flux and river discharges to represent realistic flow field.

\section{Nested Global-Coast FVCOM system}

FVCOM-global is configured with unstructured grids and the spherical version of FVCOM. This system was used for the study about tsunami in Japan which happened in Tohoku region on $11^{\text {th }}$ March in 2011. The resulting tsunami-induced inundation killed many people, destroyed many buildings moreover as it struck the nuclear plant, the amount of radiation was released and became a big nuclear accident, of which impacts on the Pacific Ocean has been concerned by even neighbor countries. Hence with the aim of studying the mechanism of tsunami, simulating the inundation, and assessing the impact of radionuclides on the surrounding countries around the Pacific, the international team started studying with the FVCOM system. Figure 2.1.7 shows the nested and inundation domain from the global domain which is an ice-ocean coupled model with meteorological forcing, river discharges and tidal forcing consisting of eight major tidal constituents.

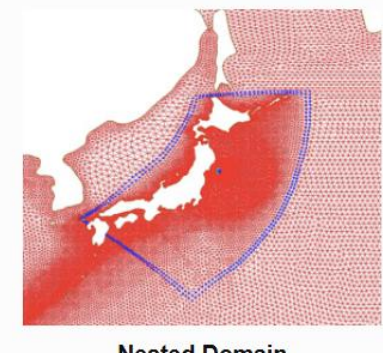

Nested Domain

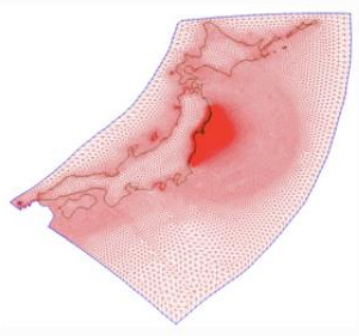

Inundation Domain

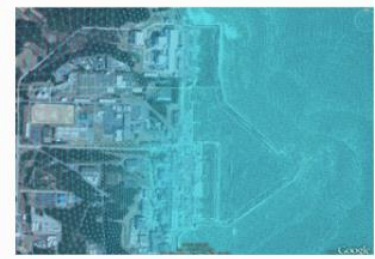

Nuclear Plant Inundation Domain

Figure 2.1.7 Nested domain and inundation domain used for the study on Japan's tsunami (Chen and Hooper, 2013) 


\subsection{Procedure of estimation on storm surge height}

Originally FVCOM is not the model intended for simulating surge height thus the simulation can be performed only with constant atmospheric pressure i.e. $1013 \mathrm{hPa}$ in normal. However, the atmospheric pressure is one of the most important external force factors for storm surge simulations so that the external forces; both atmospheric pressure and wind velocity distribution need to be estimated as a first step of the simulations with some way. In this study, the external forces were estimated by using several ways with various data; GPV, typhoon model and WRF which are mentioned below.

In addition, the topographical input data on computational domains were created by SMS (Surface-water Modelling System). This program allows to build and simulate surface water models. In this study, SMS was used to create computational domains with triangular mesh in mesh module and also visualize and analyze the outputs from FVCOM with various visualization tool such as contours and vectors. Simplified flow chart on procedure of estimation is as shown in Figure 2.2.1.

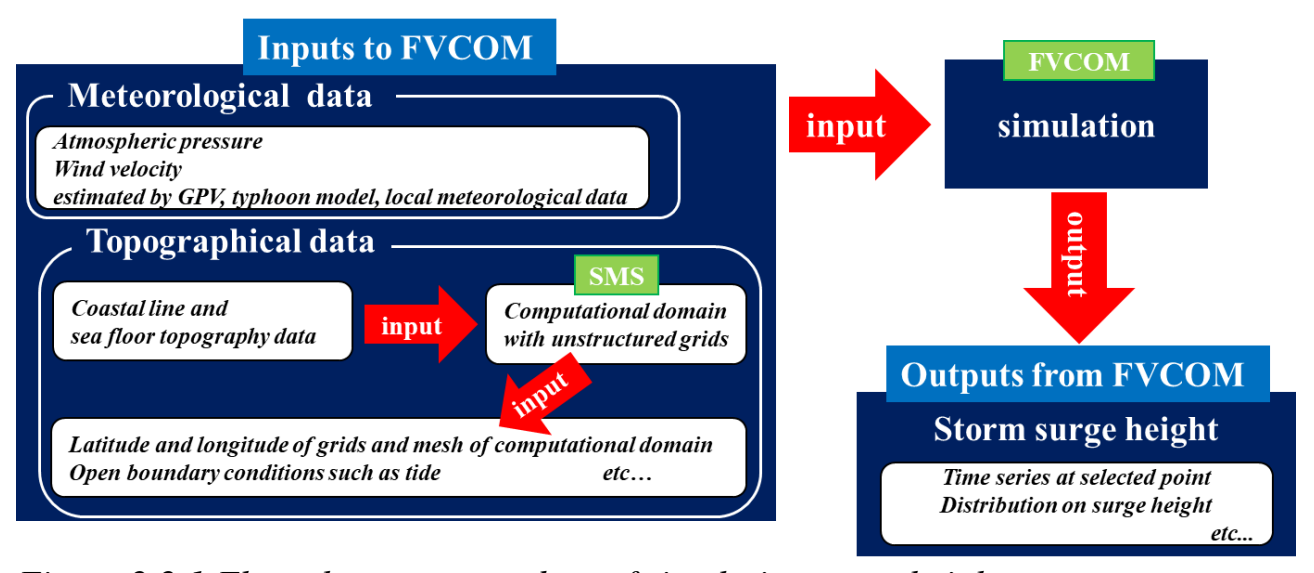

Figure 2.2.1 Flow chart on procedure of simulating surge height 


\subsection{Estimation of central atmospheric pressure and wind speed of typhoon}

Storm surge simulations were carried out for mainly four typhoons; Typhoon 19 in 1991 (T9119), Typhoon 18 in 1999 (T9918), Typhoon 16 in 2004 (T0416) and Typhoon 18 in 2004 (T0418). They gave severe damages to the region along not only Suo-nada Sea but also many places in Seto-Inland Sea. And the external forces of the typhoons for the simulations were estimated by the three kinds of data mentioned below.

\section{1) Grid Point Value}

Some simulations were performed by using GPV (Grid Point Value) data provided by Japan Meteorological Agency. GPV is re-analysis data on the basis of the observed data at several stations and there are several types of GPV which is available from Japan Meteorological Agency. In this study, MSM-S was selected since the resolution is the highest among them. The data of MSM exists from 2002/05/15 besides the data on atmospheric pressure and wind velocity is situated on every 0.125 degree of longitude and 0.1 degree of latitude, which is approximately $11 \mathrm{~km}$ around the region which Japan is located. Also the data is available range of $120 \sim 149.875$ of east longitude and $22.5 \sim 47.6$ of north latitude, which covers whole Japan. (See Figure2.3.1) The hourly data on atmospheric pressure and wind velocity distribution is available and by interpolating the data into the created computational domain, the external forces of the typhoons were given to the simulations.

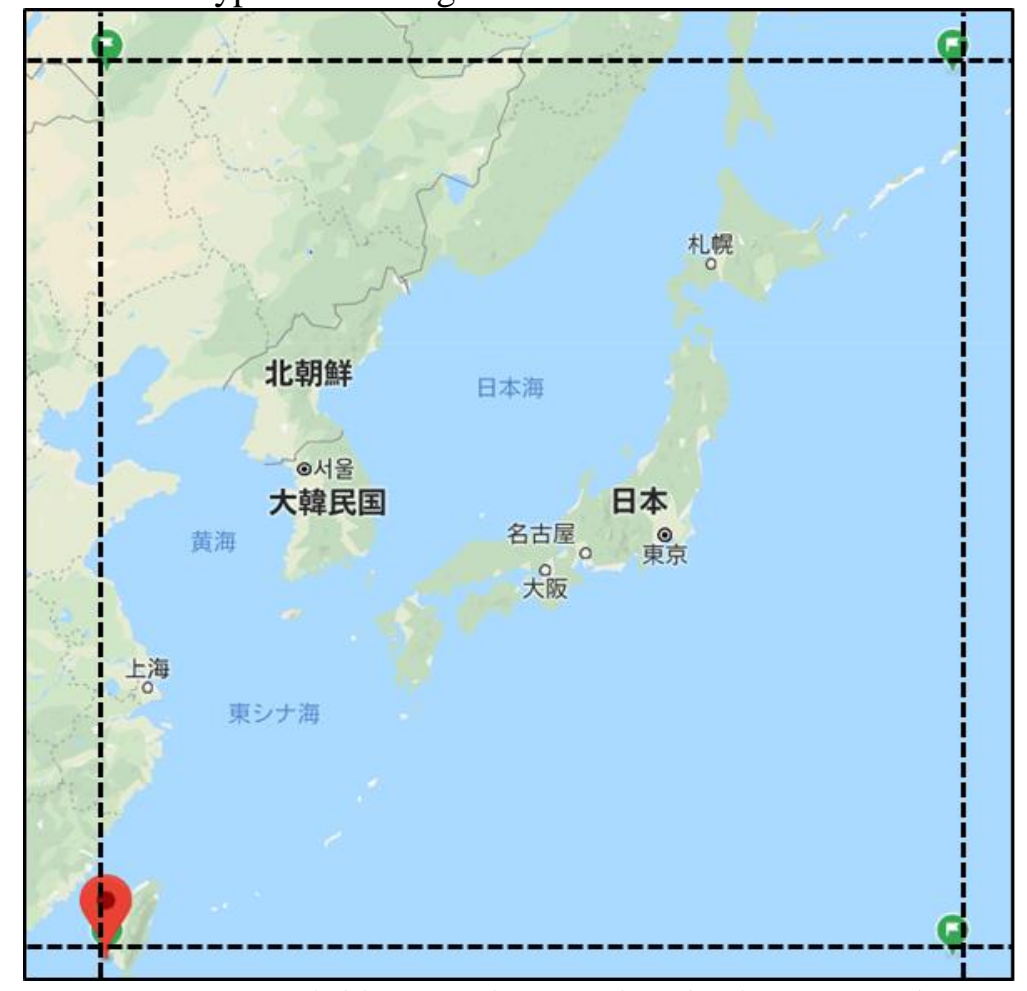

Figure 2.3.1 Domain of available GPV data (within dot-line) (Google map, 2018) 


\section{2) Typhoon model}

The empirical typhoon model derives both the sea level pressure of typhoon and the distribution of the offshore wind only by using basic typhoon parameters such as central atmospheric pressure, maximum wind velocity radius and typhoon's moving speed.

\section{i) Atmospheric pressure distribution}

In order to derive atmospheric pressure distribution, Myer's model and Fujita's model were the most commonly used. In these models, the atmospheric pressure distribution is concentric circle with isobaric lines and it is determined by two parameters; typhoon's central pressure and maximum wind speed radius. In this study, Myer's model was used for the simulation of storm surge. In this model, the air pressure distribution is expressed as a function on the distance from the center of typhoon as follow.

$p=p_{c}+\Delta p \exp \left(-\frac{r_{0}}{r}\right)$

$p:$ atmospheric pressure at the point which is located distance $r$ from the center of typhoon

$p_{c}$ : central pressure of the typhoon

$\Delta p:$ pressure depth $\left(=p_{\infty}-p_{c}\right)$

$p_{\infty}$ : the air pressure at the point which is located far from the typhoon i.e. normal air pressure, $1013 \mathrm{hPa}$

$r_{0}$ : radius of the maximum winds; the distance from the center of the typhoon to the point with maximum wind velocity

\section{ii) Wind velocity distribution}

In the empirical typhoon model, as a first step the wind in the free atmosphere; the wind velocity enough up above not to be effected by the friction of sea surface is calculated and multiplied with an empirical reduction coefficient so as to change the wind direction from tangential of an isobaric line to the direction of the central typhoon. The wind in the free atmosphere is derived by vector composition of two components; the gradient wind component and the wind component.

The gradient wind component can be found by solving the balance equation of atmospheric pressure gradient force, Coriolis force and centrifugal force as expressed by the follow.

$\frac{1}{\rho_{a}} \frac{\partial p}{\partial r}=\frac{U_{g r}^{2}}{r}+f_{1} U_{g r}$

$U_{g r}$ : gradient wind

Solving the above equation for $U_{g r}$, one can get the following equation.

$U_{g r}=-\frac{r f}{2}+\sqrt{\left(\frac{r f}{2}\right)^{2}+\frac{\Delta p}{\rho_{a}} \frac{r_{0}}{r} \exp \left(-\frac{r_{0}}{r}\right)}$ 
$\rho_{a}$ : Density of the atmosphere $\left(=1.22 \mathrm{~kg} / \mathrm{m}^{3}\right)$

$f$ : Coriolis coefficient $\left(=2 \omega \sin \varphi, \omega\right.$ : Angular velocity of Earth rotation $=7.29 \times 10^{-5} \mathrm{rad} / \mathrm{s}$, $\varphi$ : latitude)

And corresponding $U_{l}$ (Wind velocity blowing $10 \mathrm{~m}$ above the sea surface) to the obtained $U_{g r}$ is given by

$$
U_{1}=C_{1} U_{g r}
$$

$C_{l}$ is an empirical coefficient and in general a value between 0.6 and 0.7 is used. The wind direction at sea is considered to be deflected by 30 degrees towards the center of the typhoon comparing with the tangential direction of isobaric line i.e. the wind direction in the free atmosphere.

Also the wind component can be calculated by an empirical function on the typhoon traveling speed and the distance from the center of the typhoon, as shown by the follows.

$U_{2}=C_{2} \frac{U_{1}(r)}{U_{1}\left(r_{0}\right)} V_{T}$

$U_{2}$ : Wind component of the field at sea

$V_{T}$ : Typhoon's traveling speed

$C_{2}$ is also an empirical coefficient and generally the same value as $C_{l}$ is used for it.

Synthetic wind ( $U_{3}$ in Figure 2.3.2) is calculated as the vector sum of $U_{1}$ and $U_{2}$ (See Figure 2.3.2) and one can obtain the wind velocity as well as the wind direction in free atmosphere.

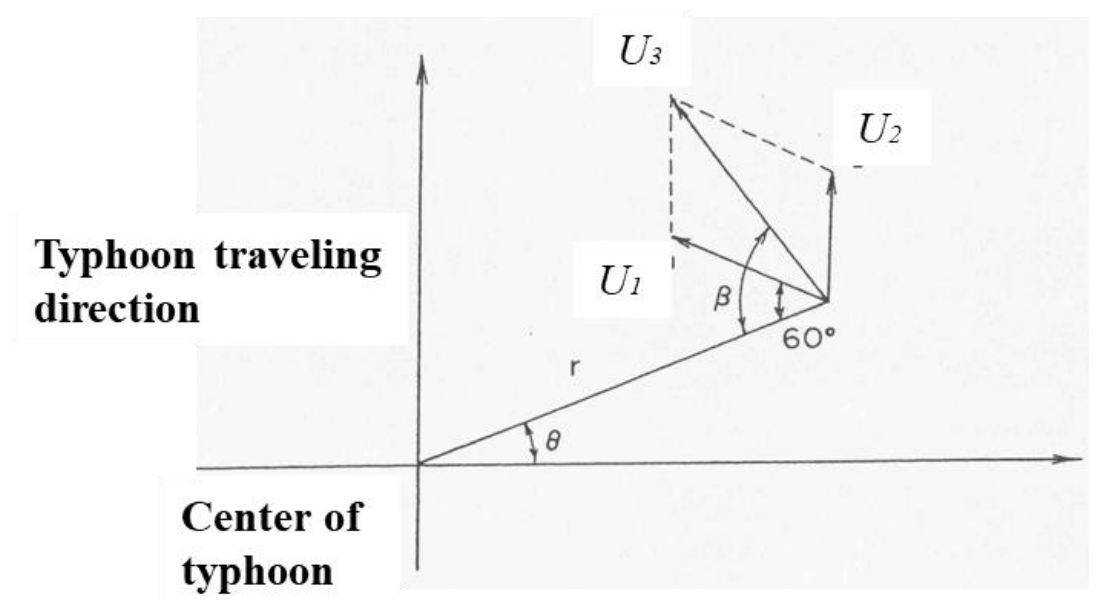

Figure 2.3.2 Schematic diagram on the gradient wind component, the wind component and synthetic wind derived by the vector sum of them, all which are calculated by the typhoon model

Moreover, in general a model proposed by Mitsuda and Fujii (1986) also has been used, which makes it possible to derive a wind distribution at once by taking the effect 
of typhoon movement into the equilibrium for finding the gradient wind component. Also there is another model by Mitsuda and Fujii (1986) which consider the super gradient wind occurring near the eyes of the typhoon by giving the wind speed reduction coefficient as a function of the distance from the center of the typhoon. Though they were not used in this study.

\section{3) The Weather Research \& Forecasting Model, WRF}

Simulations using the data simulated by WRF were also performed. WRF is developed by National Center for Atmospheric Research (NCAR) and the model makes it possible to compute with considering various natural phenomenon such as a flow of atmospheric and ground heating or cooling by the sun. Figure 2.3.3 shows the domain size and resolution of the data which was estimated for using in this study. And also the duration of computation for each typhoon is as shown in Table 2.1.3. For whole region shown in Figure 2.3.3, there are data with $5 \mathrm{~km}$ resolution and downscaling data with $2.0 \mathrm{~km}$ resolution is available only a part of it, around west side of Japan. Duration of computation was determined depending on the location of the typhoon at that time and made it the shortest as much as possible due to the computational efficiency. The data of atmospheric pressure and wind velocity in the domain are available every twenty minutes.

Table 2.1.3 Duration of computation

\begin{tabular}{|l|l|}
\hline Typhoon & Duration of computation (UTC) \\
\hline T9119 & $1991 / 09 / 2415: 00 \sim 1991 / 09 / 286: 00$ \\
\hline T9918 & $1999 / 09 / 2015: 00 \sim 1999 / 09 / 2418: 00$ \\
\hline T0416 & $2004 / 08 / 2515: 00 \sim 2004 / 08 / 3112: 00$ \\
\hline T0418 & $2004 / 09 / 0415: 00 \sim 2004 / 09 / 086: 00$ \\
\hline
\end{tabular}

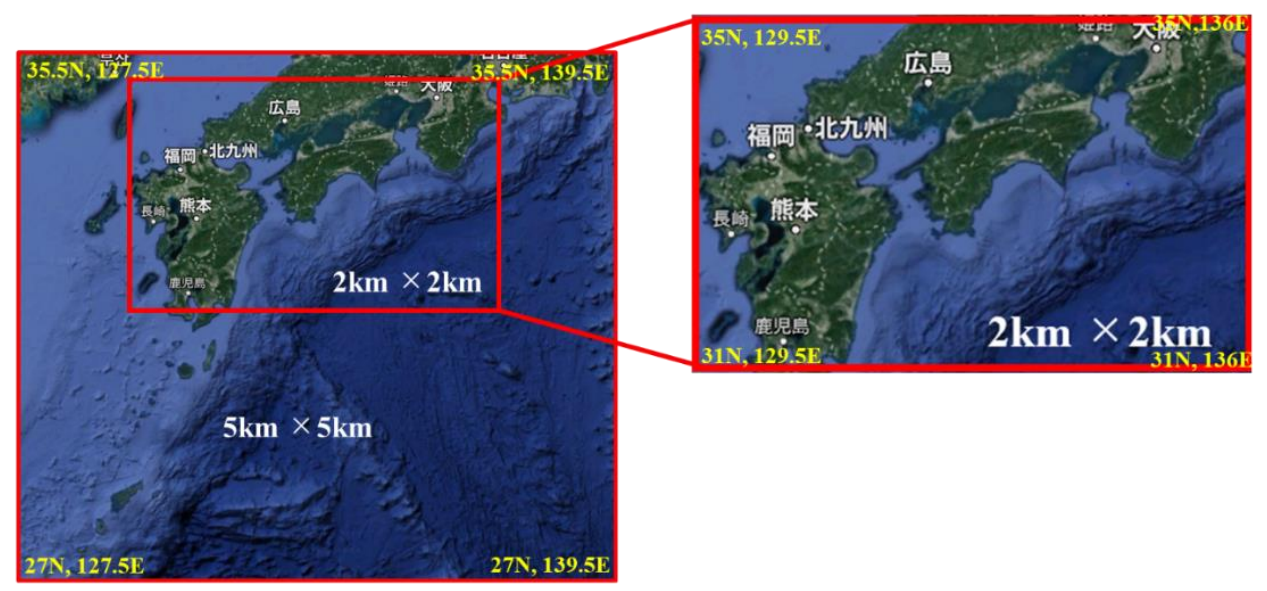

Figure 2.3.3 Computational domain and resolution of WRF (Google map, 2018) 


\subsection{Database for Policy Decision making for Future climate change (d4PDF)}

Nowadays the global warming has become a big issue and unusual climate events originated from global warming has been observed all over the world. Besides it is considered that the unusual unpredictable natural disaster will increase in the future. Hence some kinds of adaptation strategies with evaluating the effects of global warming are necessary and in order to realize that, an estimation of climate change with quantitative assessment on uncertainty of future climate is essential. The program for Risk Information on Climate Change, Japan provided with the database for Policy Decision making for Future Climate Change (d4PDF), which is a mega-ensemble climate projection database about both present and future. By using this database, it is expected that it becomes possible to analyze a factor of extreme climate events in the past as well as understand and study the uncertainty about natural change in the future prediction, and project low- frequently local-scale events.

In d4PDF, there are two kinds of datasets; an unprecedentedly large ensemble of climate simulations with a $60-\mathrm{km}$ atmospheric general circulation model (AGCM) and dynamical downscaling with a $20-\mathrm{km}$ regional climate model which covers Japan area (RCM). (See Figure 2.4.1) (Ministry of Education, Culture, Sports, Science and Technology, et al., 2015)

\section{AGCM}

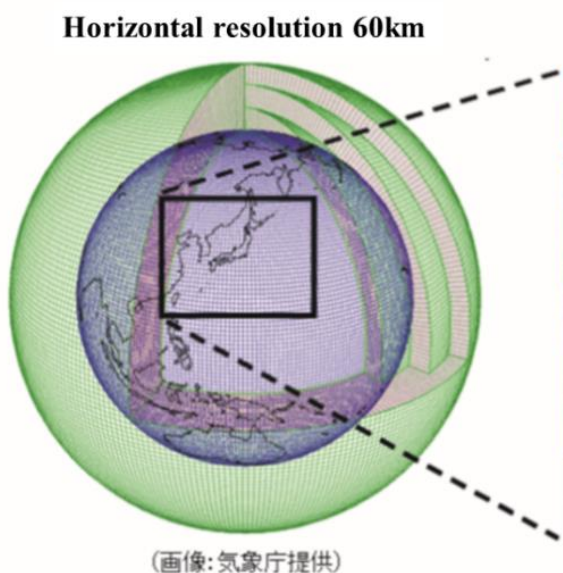

NHRCM

Horizontal resolution $20 \mathrm{~km}$

Figure 2.4.1 Computational area and resolution of AGCM and NHRCM (Ministry of Education, Culture, Sports, Science and Technology, et al., 2015)

There are several sets of experiments in each model and the simulated periods area and the number of ensemble members are as shown in Table 2.4.1. This kinds of large ensemble simulations makes it possible to analyze the probabilistic future changes and extreme climatic events such as heavy precipitation and tropical cyclones. For historical climate simulation, observed data such as sea-surface temperature, sea-ice concentration and sea-ice thickness were given to the model as the boundary conditions besides global-mean concentrations of greenhouse gases, threedimensional distributions of ozone and aerosols are as the external forcing. 100 
members of the simulation has the different initial values moreover the small perturbations on sea-ice and sea-surface temperature were given. The same boundary conditions were used for non-warming simulation also though it does not contain the long-term trend; the pre-industrial conditions were adopted as the external forcing since the simulation was performed to study attribution of past climate change by comparing the results with the one of historical climate simulation. The $+4 \mathrm{~K}$ simulation represented the future climate with 4 degrees warmer than the preindustrial level on global mean surface air temperature. Besides the experiments were conducted for 6 different SST (Sea Surface Temperature) warming patterns with 15 different perturbations for each i.e. 90 members in total. By using 6 different SST patterns, one can evaluate the probabilistic change of localized severe events depending on internal variability. Figure 2.4.2 shows the future variation of annual mean SST and the institutes which provided the data in each model were as shown in Table 2.4.2. With regards to the region around Japan, it can be seen that the future variations in GF and MI are especially large while they are small in $\mathrm{CC}$ or $\mathrm{HA} .+2 \mathrm{~K}$ future simulation were performed similarly with $+4 \mathrm{~K}$ simulation i.e. using the same 6 SST patterns with 9 different perturbations for each; 54 members. The dynamical downscaling with a $20-\mathrm{km}$ regional climate model were carried out with the results of AGCM about historical simulation, $+4 \mathrm{~K}$ simulation and $+2 \mathrm{~K}$ simulation. In this study, the results of historical climate simulation and $+4 \mathrm{~K}$ future climate simulations were used and based on these data the future risk of storm surge around Suo-nada Sea was investigated. (Ministry of Education, Culture, Sports, Science and Technology, et al., 2015)
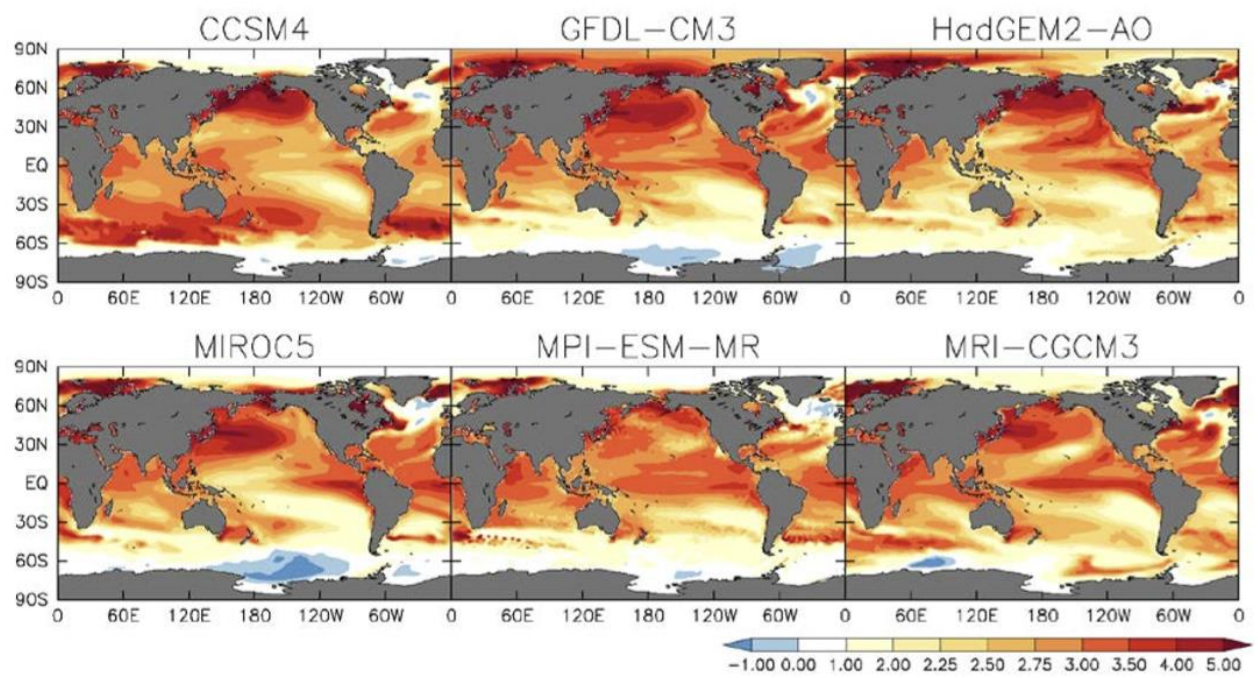

Figure 2.4.2 Future variation of annual mean SST (Ministry of Education, Culture, Sports, Science and Technology, et al., 2015) 
Table 2.4.1 Simulated periods and the number of ensemble members of each model

\begin{tabular}{|l|l|l|}
\hline $\begin{array}{l}\text { Historical } \\
\text { simulation }\end{array} \quad$ climate & $\begin{array}{l}\text { AGCM } \\
\text { 1001-2010, }\end{array}$ & $\begin{array}{l}\text { SHRCM } \\
\text { 50members }\end{array}$ \\
\hline $\begin{array}{l}+4 \mathrm{~K} \text { future climate } \\
\text { simulation }\end{array}$ & 2031-2090, 90members & $\begin{array}{l}\text { Sep2050-Aug2111, } \\
\text { 90members }\end{array}$ \\
\hline $\begin{array}{l}+2 \mathrm{~K} \text { future climate } \\
\text { simulation }\end{array}$ & 2031-2090, 54members & $\begin{array}{l}\text { Sep2030-Aug2091, } \\
\text { 54members }\end{array}$ \\
\hline Non-warming simulation & $\begin{array}{l}1951-2010, \\
100 m e m b e r s\end{array}$ & \\
\hline
\end{tabular}

Table2.4.2 Institution which provided the data of each model

\begin{tabular}{|l|l|}
\hline MODEL NAME & INSTITUTION \\
\hline CCSM4(CC) & National Center for Atmospheric Research (USA) \\
\hline GFDL-CM3(GF) & $\begin{array}{l}\text { Geophysical Fluid Dynamics Laboratory } \\
\text { (USA) }\end{array}$ \\
\hline HadGEM2-AO(HA) & Met Office Hadley Centre (UK) \\
\hline MIROC5(MI) & JAMSTEC(Japan) \\
\hline MPI-ESM-MR(MP) & $\begin{array}{l}\text { Max Planck Institute for Meteorology } \\
\text { (Germany) }\end{array}$ \\
\hline MRI-CGCM3(MR) & $\begin{array}{l}\text { Meteorological Research Institute } \\
\text { (Japan) }\end{array}$ \\
\hline
\end{tabular}

\subsection{Other data used in the study}

In order to create the computational domains, national land numerical information provided by Ministry of Land, Infrastructure, Transport and Tourism was used. Besides, the data on water depth provided by Japan Hydrographic Association was interpolated to the created computational domains. The observed data of astronomical tide used in the study was estimated by Japan Coast Guard. In terms of tidal level, there are some kinds of data sources depending on the site; Japan Meteorological Agency, Yamaguchi Prefecture Seaports Affairs Division, Japan Oceanographic Data Center and Kanmon waterway Office.

Furthermore, information on past tropical cyclones in the western North pacific and the South China is provided by the Regional Specialized Meteorological Center (RSMC) Tokyo - Typhoon Center in Japan Meteorological Agency. The data is available from 1951 to 2018 and includes the information on latitude and longitude of the center, central pressure and maximum sustained wind speed etc. of typhoons. The data is called "Best Track Data (BT)" and it is mainly used for estimating external forces by an empirical typhoon model. Astronomical tide which was one of the open boundary conditions was estimated by using NAO.99jb (Tsumoto, et al., 2000). 


\section{Numerical simulations on storm surge in Suo-nada Sea 3.1 Investigation on the computational domain size}

\section{1) Past study}

As a first step, the most suitable numerical domain size was investigated. For the simulation on storm surge, not only storm but also tide was given as one of the external forces hence the domain needs to be validated for both tide and storm surge. For examining it, past study performed by Yoshiaki and Hidenori (2010) was referred. In the study, the sensitivity of tidal simulation to the several model size (See Figure 3.1.1) was investigated.

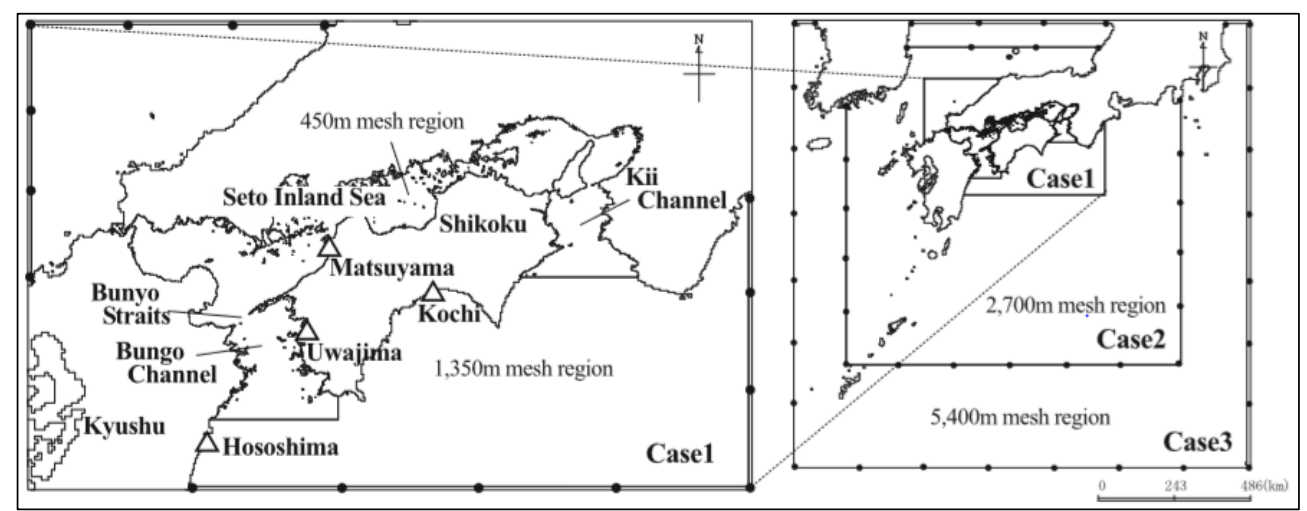

Figure 3.1.1 Several pattern of model size for the tidal simulation (Yoshiaki and Hidenori, 2010)

In the study, a Global Ocean Tide Model (NAO. 99jb model) was used for the tidal simulation. There are three cases in the investigation; Case1 is the smallest including Shikoku Island with Bungo and Kii Channels, Case 2 is the middle size with west-side of Japan and Case 3 is the largest with Okinawa. In the simulation, tidal movement became constant and stable in two days. The results were as shown in Figure 3.1.2. From the results, it was known that error of Case 1 and 2 are less than 10\% comparing estimated values at any points; Kochi, Uwajima, Hososhima and Matsuyama while the error of Case 3 exceeded $10 \%$ at Uwajima and Hososhima. The results of Case 1 showed the highest accuracy everywhere; Seto-Inland Sea, south coast of Shikoku Island and east coast of Kyushu island. Case2 had less precision compared to Case1 though it was still within allowable range. About Case3, the results also had accuracy to some extent in southern coast of Shikoku Island and Seto-Inland Sea, however, the precision clearly declined at east side of Kyushu island and Bungo-Channel. From the results, it was known that as expanding the domain size, the tidal movement became a bit smaller. This is because that the open boundary at which the tidal values were given was located far in Case 3 comparing other cases thus this domain size seems not to be suitable for the storm surge simulation with tide. 


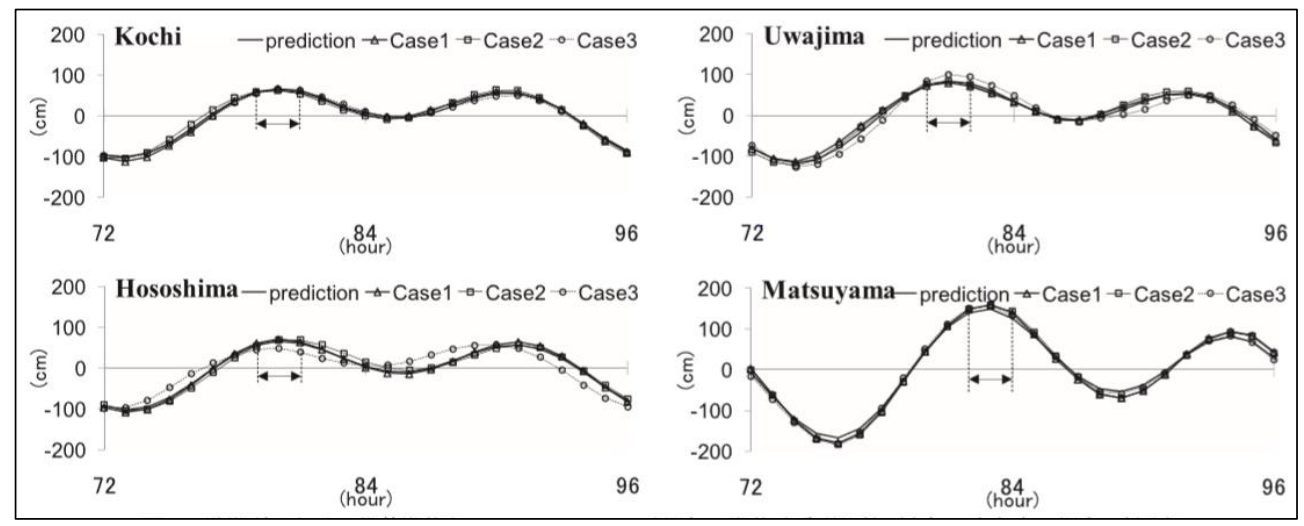

Figure 3.1.2 Comparison of three cases (Yoshiaki and Hidenori, 2010)

\section{2) Examination of computational domain for FVCOM}

Based on the past study (Yoshiaki and Hidenori, 2010), two kinds of computational domains were created for a numerical simulation (See Figure 3.1.3). Case name of created domains are corresponding to the one in the past study. Other simulation conditions are as shown in Table3.1.1.

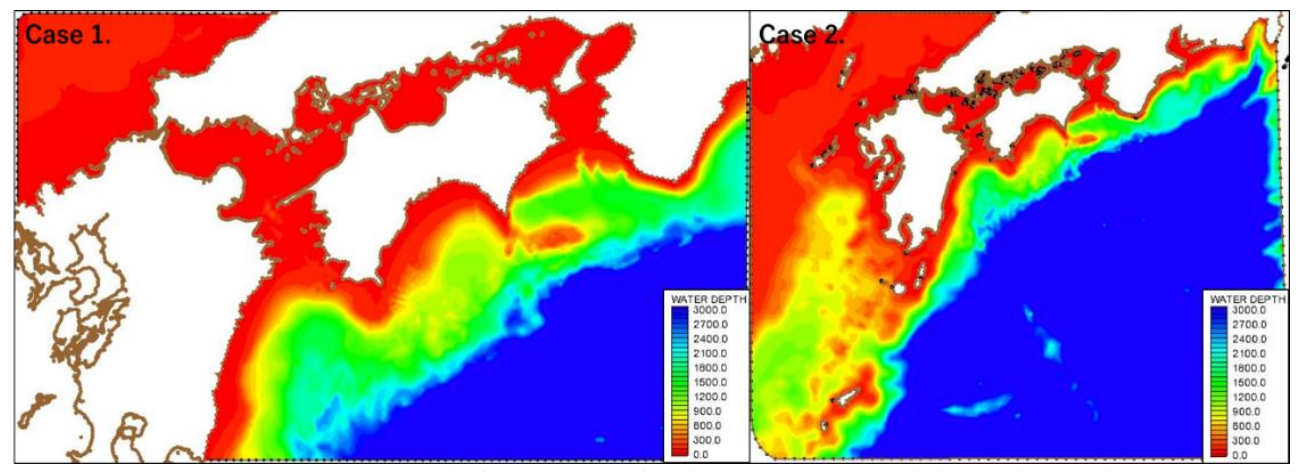

Figure 3.1.3 Computational domains which were created based on the past study (Yoshiaki and Hidenori, 2010)

Table 3.1.1 Simulation conditions

\begin{tabular}{|l|l|l|l|l|}
\hline Case name & $\begin{array}{l}\text { Horizontal } \\
\text { mesh size }\end{array}$ & $\begin{array}{l}\text { Vertical } \\
\text { layers }\end{array}$ & $\begin{array}{l}\text { Computational } \\
\text { time step }\end{array}$ & Duration of computation \\
\hline Case1 & $200 \sim 7000 \mathrm{~m}$ & 3 & $0.08 \mathrm{sec}$ & $2004 / 08 / 28 \sim 2004 / 08 / 31$ \\
\hline Case2 & $300 \sim 20000 \mathrm{~m}$ & 3 & $0.08 \mathrm{sec}$ & $2004 / 08 / 27 \sim 2004 / 08 / 31$ \\
\hline
\end{tabular}

With those domains, tidal simulations were performed by giving estimated astronomical tide from NAO.99jb (Tsumoto, et al., 2000) to an open boundary condition and Figure 3.1.4 shows the results with predicted value at Tokuyama, Ube and Kanda. 


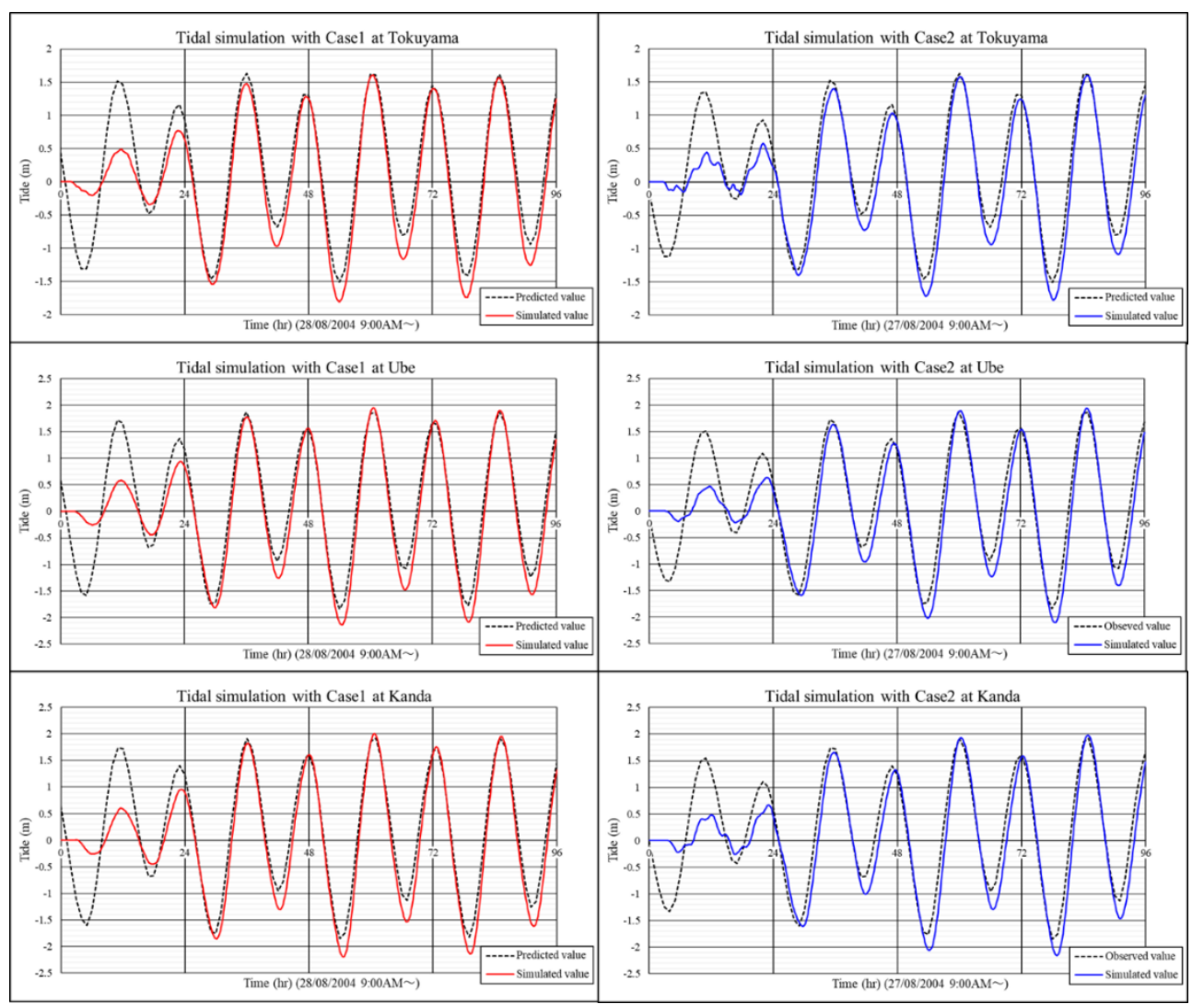

Figure 3.1.4 Results of tidal simulation with Case1 and 2 at Tokuyama, Ube and Kanda

Seeing the results, simulated value in Case1 could mostly reproduce predicted value though there are still some errors when it becomes the minimum, approximately $0.3 \mathrm{~m}$. On the other hands, simulated value in Case 2 slightly had a phase shifted compared to the predicted one besides some errors can be seen similarly in Case1. Therefore, the simulation of tide in Case 1 is more accurate than Case 2 and it might be able to say that a computational domain should not be larger than Case 2 for accurate simulation on storm surge in Suo-nada Sea. 


\section{3) Comparison of 5 kinds of computational domain with storm surge}

In order to determine the most suitable computational domain size for estimating storm surge height, 5 kinds of computational domain were created. (See Figure 3.1.5) Mainly the domains are focused on the coastal region along Suo-nada Sea. Case 1 is middle size including Shikoku Island with Bungo and Kii Channels. Case 2 is the largest including whole Kyushu island, whole Kii-peninsula and sea area on south of Japan. Case 3 is the second largest with reducing Sea area and absence of Ise-bay compared to Case 1. Case 4 is the second smallest with short length of Bungo-Channel and without Pacific Ocean compared to Case 1. Case 5 is the smallest without Kii Channel compared to Case 4. The largest mesh of each case is along the open boundary and gradually made them smaller as getting close to Suo-nada Sea. The details about conditions of the simulations are as shown in Table 3.1.2. As an external force, T0416 was selected which caused huge damages around the region. In order to reproduce the typhoon in the domains, GPV data was used for giving atmospheric pressure and wind velocity distribution. Duration of computation was determined depending on the size of computational domain and except for Case 4 and 5, in order to make a simulation stable, external forces i.e. wind velocity and atmospheric pressure were given as gradually approaching to the original values from around 0 $\mathrm{m} / \mathrm{s}$ and $1013 \mathrm{hPa}$ with taking 24 hours.

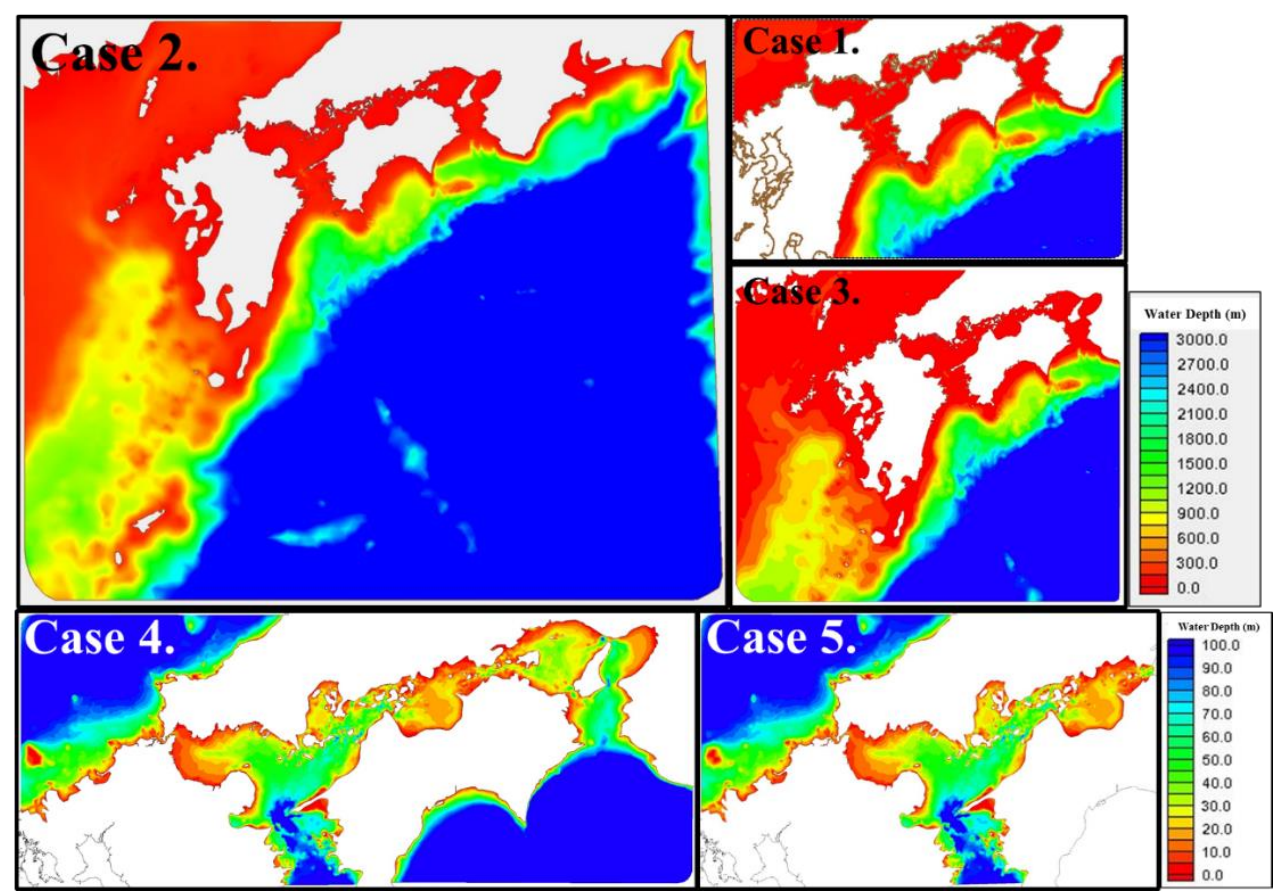

Figure 3.1.5 5 kinds of computational domain with water depth indicator 
Table 3.1.2 Simulation conditions

\begin{tabular}{|c|c|}
\hline Horizontal mesh size & $\begin{array}{c}\text { Case } 2.300 \sim 20000 \mathrm{~m} \\
\text { Case } 3.200 \sim 10000 \mathrm{~m} \\
\text { Case } 1,4,5.200 \sim 7000 \mathrm{~m}\end{array}$ \\
\hline The number of vertical layers & 0.08 seconds \\
\hline Open boundary condition & 0 \\
\hline Meteorological condition & Typhoon 16 in 2004 \\
\hline Computation time step & 0.08 seconds \\
\hline Duration of computation & Case 2. 2004/08/27 2004/08/31 \\
& Case 3. 2004/08/26 2004/08/31 \\
& Case 1, 4, 5. 2004/08/28 2004/08/31 \\
\hline
\end{tabular}

The results of simulation with 5 domains were compared at Tokuyama and Ube with observed data in Figure 3.1.6. The outputs in all cases were underestimated compared to observed data. Among 5 cases, especially the results of Case2, 4 and 5 are much smaller than observed one, around $0.7 \mathrm{~m}$ below at Tokuyama and $1.0 \mathrm{~m}$ at Ube. Besides, in the results of Case1, there are small fluctuations as a whole therefore the simulation in Case1 seems not to be stable. This might be caused by the size of computational domain; Case 2 is the largest among 5 cases and the time when a simulation started (2004/08/27 9:00, JST) a part of the typhoon had already been within the domain thus strong wind value were given from the start of the simulation even though wind velocity and air pressure were interpolated with taking 24 hours. On the other hands, the typhoon was gradually moving into the domain in other cases. Hence if the simulation time in Case2 was longer, the surge height might develop more in this case. Surge height in Case 4 and 5 was also largely underestimated due to the domain size. This two cases were much smaller than observed data because of less part of Pacific Ocean with short Bungo-Cannel. Thus compared to other cases, less sea water was provided from Pacific Ocean to Suo-nada Sea and this was lead to the lack of surge height development. The results of Case 1 and 3 are relatively high and they are matched with observed data just before and after the peak. In Case3, in order to get rid of small fluctuations caused by instability of calculations like Case2, the simulations were started on $26^{\text {th }}$ August in 2004 when the typhoon was located out of the domain. However, Figure 3.1.6 shows that the storm surge height in Case 1 and 3 is almost same, rather Case 3 is a bit smaller than Case 1 though the domain size of Case 3 is larger than Case 1 and it was expected that there was more water supply into Suo-nada Sea in Case 3. From this comparison, it can be known that the poor development of storm surge height in Case 1 is not due to the domain size. And also from the point of computational efficiency, Case1 was only 4-day simulation while two days longer in Case 3. Moreover, the domain size of Case 3 is much larger than Case1 so that the time which takes to finish the simulation in Case 1 is much shorter than Case 3. Hence it can be concluded that Case 1 is the most suitable among 5 cases about the accuracy of results and also computational efficiency. 

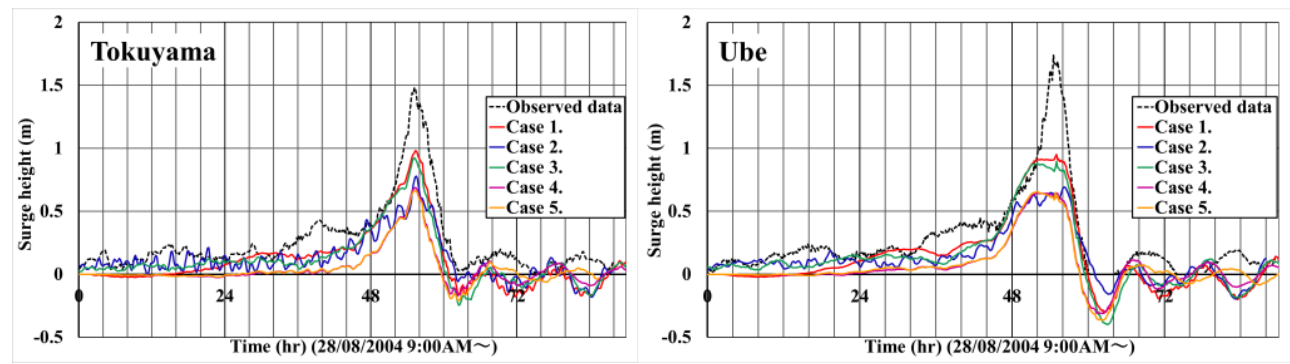

Figure 3.1.6 Comparison of surge height with different computational domain at Tokuyama and Ube 


\section{4) Investigation on Kii-Channel}

In order to study the influence which is given to the surge simulations by the existence of Kii Channel, the results obtained by the two computational domain (See Figure 3.1.7) were compared in Figure 3.1.8. From Figure 3.1.8, it is seen that there is little difference between them though it was expected that the surge height with computational domain including Kii Channel would be higher due to water flowing in Suo-nada Sea through Kii Channel.

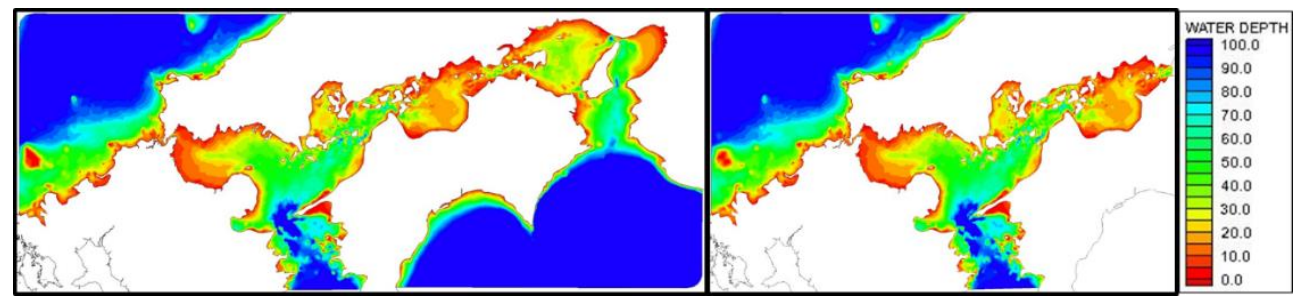

Figure 3.1.7 Computational domains with (left) and without (right) Kii Channel
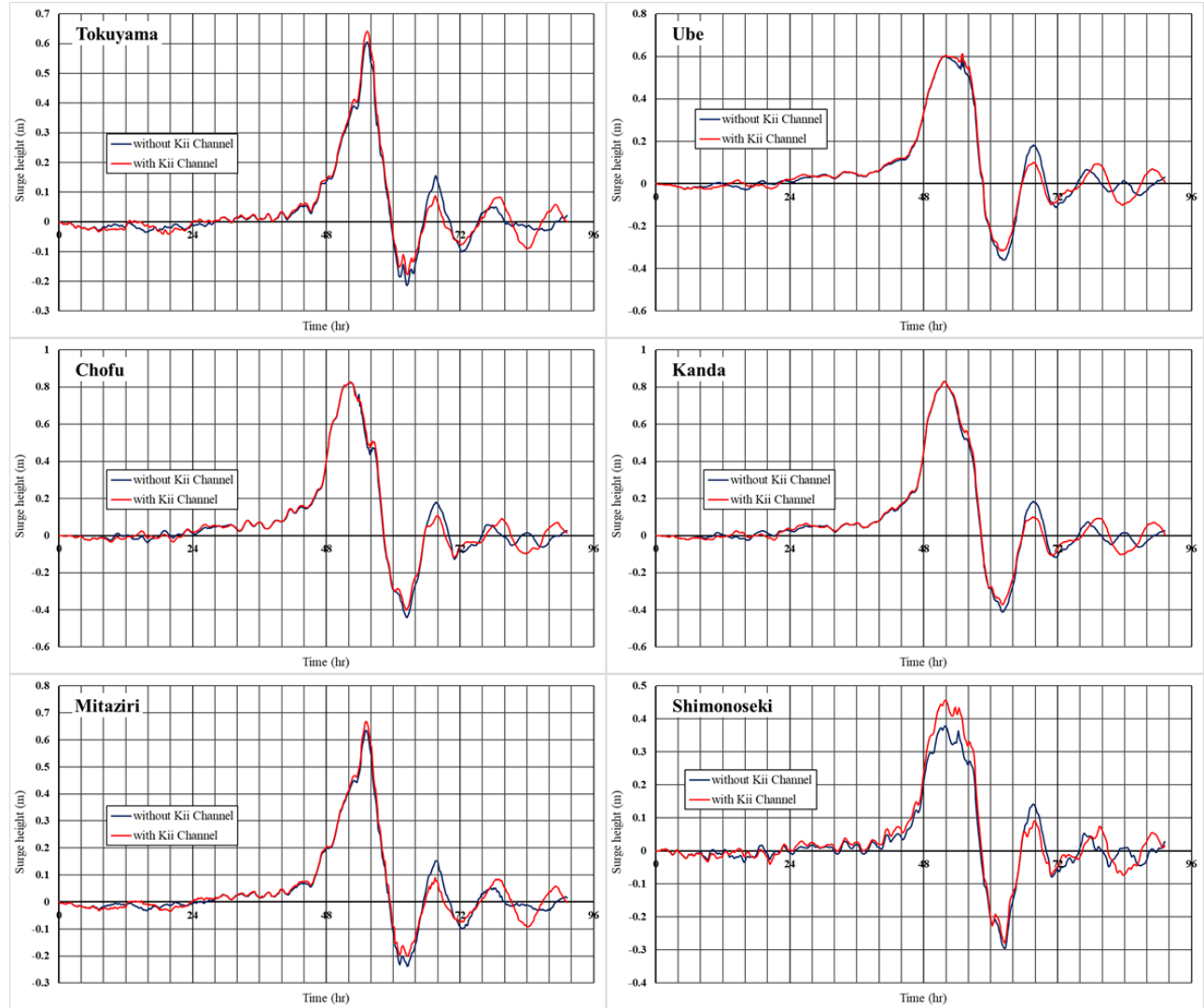

Figure 3.1.8 Comparison of the results with and without Kii Channel

Table 3.1.3 Time of storm surge becoming the highest

\begin{tabular}{|l|l|l|}
\hline Location & Tokuyama & Ube \\
\hline Highest time & $15: 302004 / 8 / 30$ & $16: 102004 / 8 / 30$ \\
\hline
\end{tabular}


Figure 3.1.9 shows the tidal currents in the simulations at the time before storm surge became the highest (See Table 3.1.3); 12:00, 13:00 and 14:00 on 30 ${ }^{\text {th }}$ August in 2004. From the figures, it can be seen that the tidal current was stopped at the area within red circles. It seems to be because that the amount of sea water flowing through Bungo Channel was quite large due to the strong winds blowing towards north hence it hit against the water flowing through Kii Channel and blocked it. Moreover, the islands in Seto-Inland Sea blocked the currents as well. Therefore, these factors made estimations on storm surge with the domain including Kii Channel almost equal to the one obtained by using the domain without the channel.

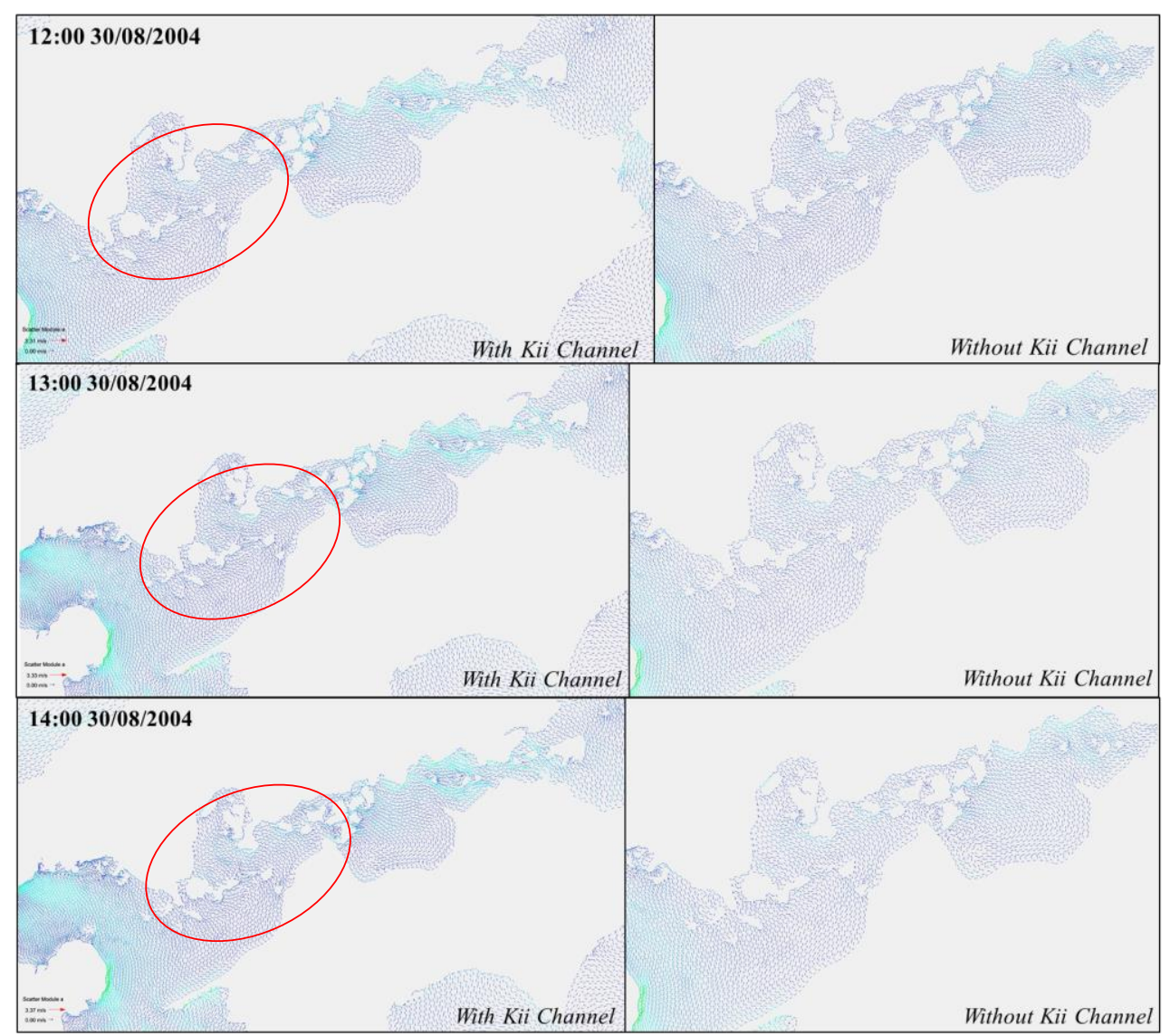

Figure 3.1.9 Simulated tidal currents on $30^{\text {th }}$ August in 2004 at 12:00 14:00 with two computational domains 


\subsection{Verification of numerical simulations on storm surge with several kinds of data}

\subsubsection{Numerical simulations of past storm surge}

In order to investigate the computational model in detail, several simulations with various kinds of data such as GPV, typhoon model and WRF were performed for four typhoons; T9119, T9918, T0416, T0418. The data was used for estimating the external forces such as atmospheric pressure and wind speed distribution of typhoons. And the influence which is given to the accuracy of the storm surge simulations in Suo-nada Sea by using different kinds of data was examined. Table 3.2.1 shows the presence and absence of the data for each typhoons. Data of typhoons in 1990's (T9119 and T9918) were available about only WRF.

Also the present and absence of the time series observed data on storm surge height caused by the typhoons were as shown in Table 3.2.2. The observed data on the storm surge caused by the typhoons in 1990's is also limited compared with the ones in 2000's. The location of the stations is shown in Figure 3.2.1.

The observed data at several points does not disclose the location information where the data was measured thus it cannot be said that they were absolutely correct i.e. they are just kind of criterion since the extracted points on simulated storm surge might be different from the site of stations. Besides, time series of observed data at several points was derived by subtracting an observed astronomical tide from an observed tidal level. And they are expressed as above T.P. (Tokyo Peil) though the mean sea level is different depending on the sea area therefore some amount needs to be deducted from both observed tidal level and astronomical tide in order to adjust the mean sea level zero for comparing with simulated results. However, the amount to be subtracted is changing depending on the time whereas the only one data was available within long time range in the same source. Hence in this study, as much as possible the detailed data was used although it was from other sources hence it also can be said that the time series of observed data might have some errors.

Moreover, in terms of wind speed, several observed data were available provided by other organization about the same point and there are some gaps between them. It might be because that the measured points had different environment, for instance the one was measured on land and surrounded by hills while another one was measured on an open space near a coastal area. And in this study, one of them was selected which more was corresponding with winds estimated by GPV since GPV is reanalysis data created on the basis of observed data and has high accuracy near land area where the station is located.

Among the stations, it can be said that the storm surge estimation at Shimonoseki might be much more difficult comparing with the others since Shimonoseki is located inside the Kanmon Strait and affected two sea areas; Suo-nada Sea and Hibiki-nada Sea. Thus the estimated values tend to have some oscillations which cannot be seen in the results of other places. 
Table 3.2.1 Presence and absence on each data for four typhoons

\begin{tabular}{|l|c|c|c|}
\hline Typhoon name & GPV & Typhoon model & WRF \\
\hline T9119 & $\times$ & $\times$ & $\bigcirc$ \\
\hline T9918 & $\times$ & $\times$ & $\bigcirc$ \\
\hline T0416 & $\bigcirc$ & $\bigcirc$ & $\bigcirc$ \\
\hline T0418 & $\bigcirc$ & $\bigcirc$ & $\bigcirc$ \\
\hline
\end{tabular}

Table 3.2.2 Presence of absence about time series observed data on surge height for four typhoons

\begin{tabular}{|l|l|l|l|l|l|}
\hline Typhoon & Tokuyama & Ube & Chofu & Shimonoseki & Oita \\
\hline T9119 & $\bigcirc$ & $\times$ & $\times$ & $\bigcirc$ & $\bigcirc$ \\
\hline T9918 & $\times$ & $\times$ & $\times$ & $\bigcirc$ & $\bigcirc$ \\
\hline T0416 & $\bigcirc$ & $\bigcirc$ & $\bigcirc$ & $\bigcirc$ & $\bigcirc$ \\
\hline T0418 & $\bigcirc$ & $\bigcirc$ & $\bigcirc$ & $\bigcirc$ & $\bigcirc$ \\
\hline
\end{tabular}

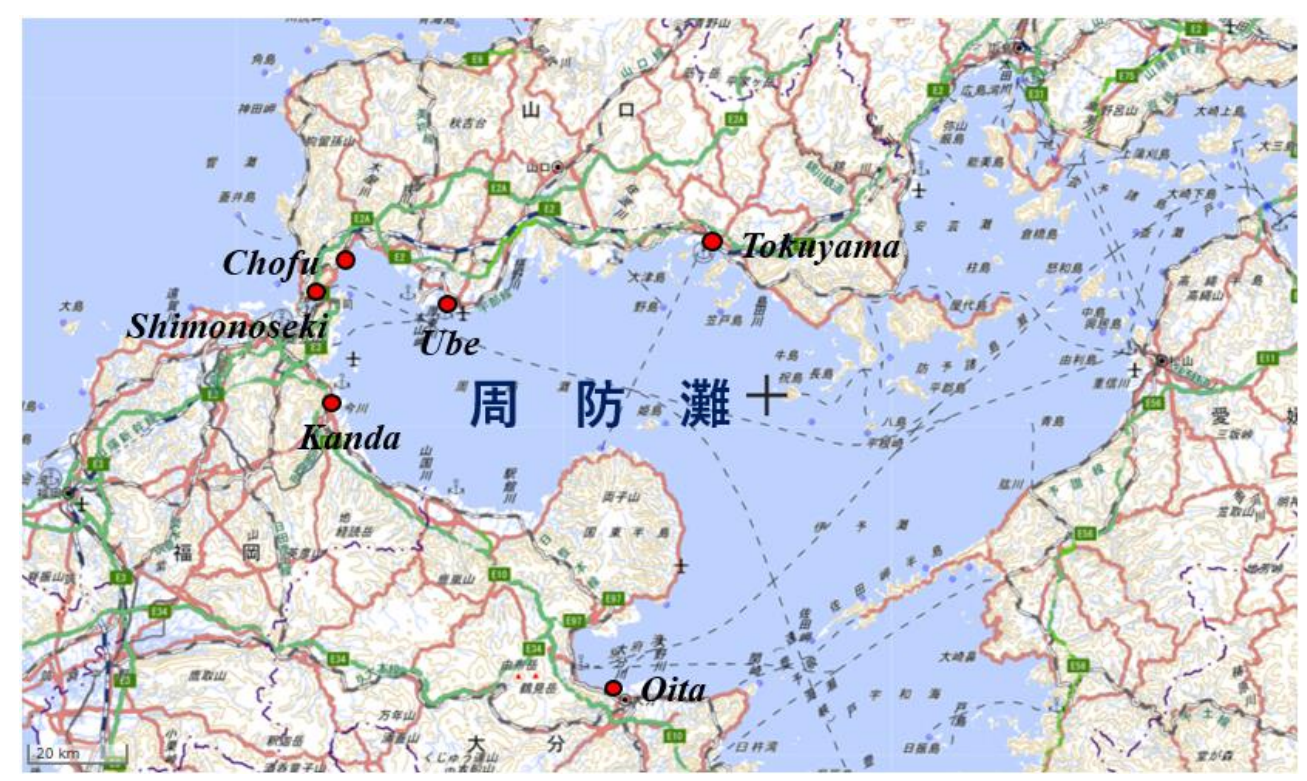

Figure 3.2.1 Location of observing stations (Geospatial Information Authority of Japan, 2018) 


\section{1) Typhoon 19 in 1991 (T9119)}

Figure 3.2.2 shows the results of simulations with WRF on T9119. At Tokuyama and Shimonoseki, the simulated values were smaller than observed data around $0.4 \mathrm{~m}$ and $0.09 \mathrm{~m}$ respectively. On the other hands the results at Oita was overestimated around $0.17 \mathrm{~m}$. In addition, the observed data at Oita is around $0.1 \mathrm{~m}$ minus when the simulation started and the difference at the start point might affect the subsequent simulation more or less. If the minus start of observed data was led by natural conditions, like the sea level at that time was lower than usual at Oita, it was unable for simulation to consider it. Thus the gap of the peak between observed data and simulation at Oita might be much smaller than $0.17 \mathrm{~m}$. Also according to Masamori (2003), the highest surge height at Kanda, Tokuyama and Oita was as shown in Table 3.2.3. There are some differences between time series observed data and the data in the table, and no one knows which is the correct. However, the data shown in Table 3.2.3 match with estimated value better at Kanda and Tokuyama, the gap is within only $0.1 \mathrm{~m}$ thus the simulated value can be much more correct than expected. Hence from all the results although the periods and height of rebound after peak of surge were not matched with the observed one, however, still the simulation using the typhoon seems to be able to reproduce surge height approximately.

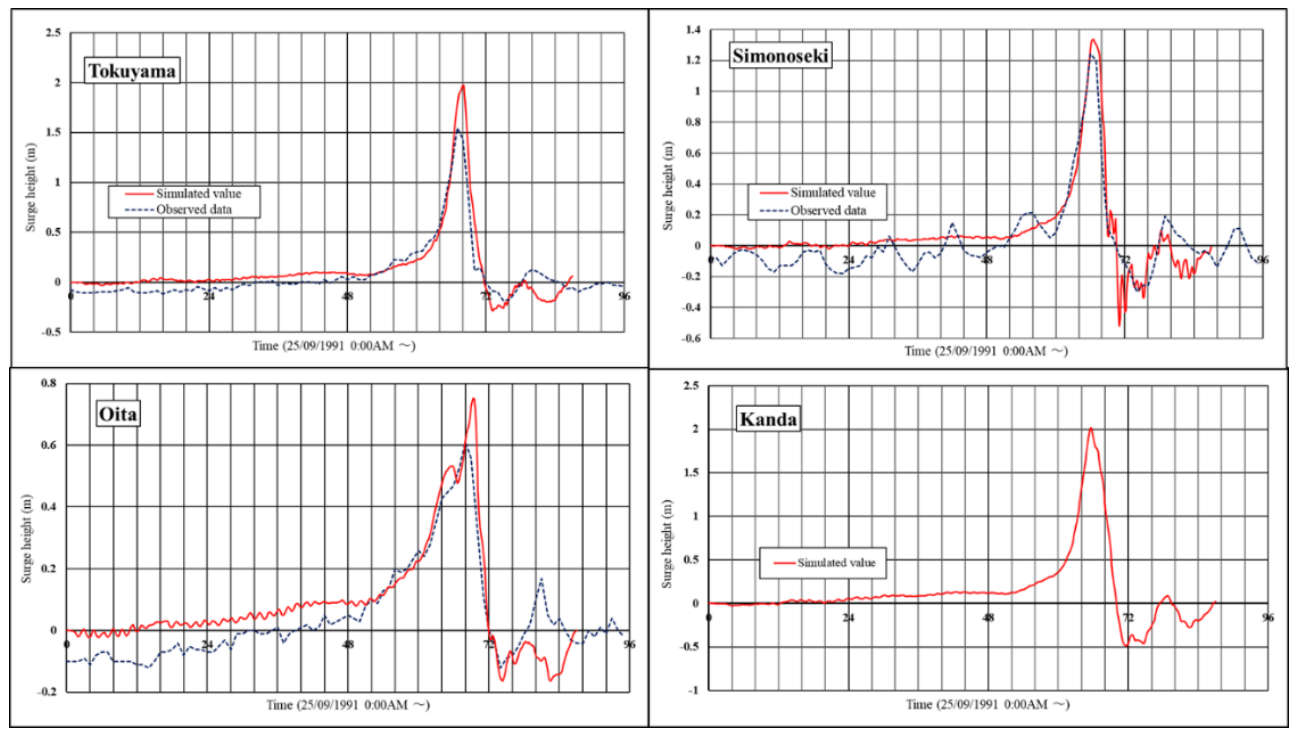

Figure 3.2.2 Results of simulation on T9119 with WRF

Table 3.2.3 Highest surge height caused by T9119 (Masamori, 2003)

\begin{tabular}{|l|l|}
\hline Location & Height of storm surge \\
\hline Kanda & $1.8 \mathrm{~m}$ \\
\hline Tokuyama & $1.9 \mathrm{~m}$ \\
\hline Oita & $1.0 \mathrm{~m}$ \\
\hline
\end{tabular}




\section{2) Typhoon 18 in 1999 (T9918)}

Figure 3.2.3 shows the results of simulation on T9918 with WRF at the same four points as T9119. Observed data at Tokuyama was missing around the peak so that the results can be compared with observed data at only Shimonoseki and Oita. From Figure 3.2.3, it is known that the simulation is overestimated at both points, around $0.5 \mathrm{~m}$ at Shimonoseki and $0.6 \mathrm{~m}$ at Oita. Furthermore, the results at the points have a large drop while surge developing which cannot be seen in observed data. And also the vibrations after the peak is intense therefore the simulation seems not to be stable. Although there is no available time series observed data, according to Hiroyasu (2000) the peak value at Kanda was around $2.1 \mathrm{~m}$ and the one at Tokuyama was around 2.0 $\mathrm{m}$. Thus the estimation at Kanda seems to be good; only around $0.1 \mathrm{~m}$ overestimated, while the one at Tokuyama was almost $0.6 \mathrm{~m}$ overestimated. Also the way of surge developing just before peak at Tokuyama and Shimonoseki were similar with observed one, however, overall it seems that the simulations could not reproduce the surge enough about the typhoon.

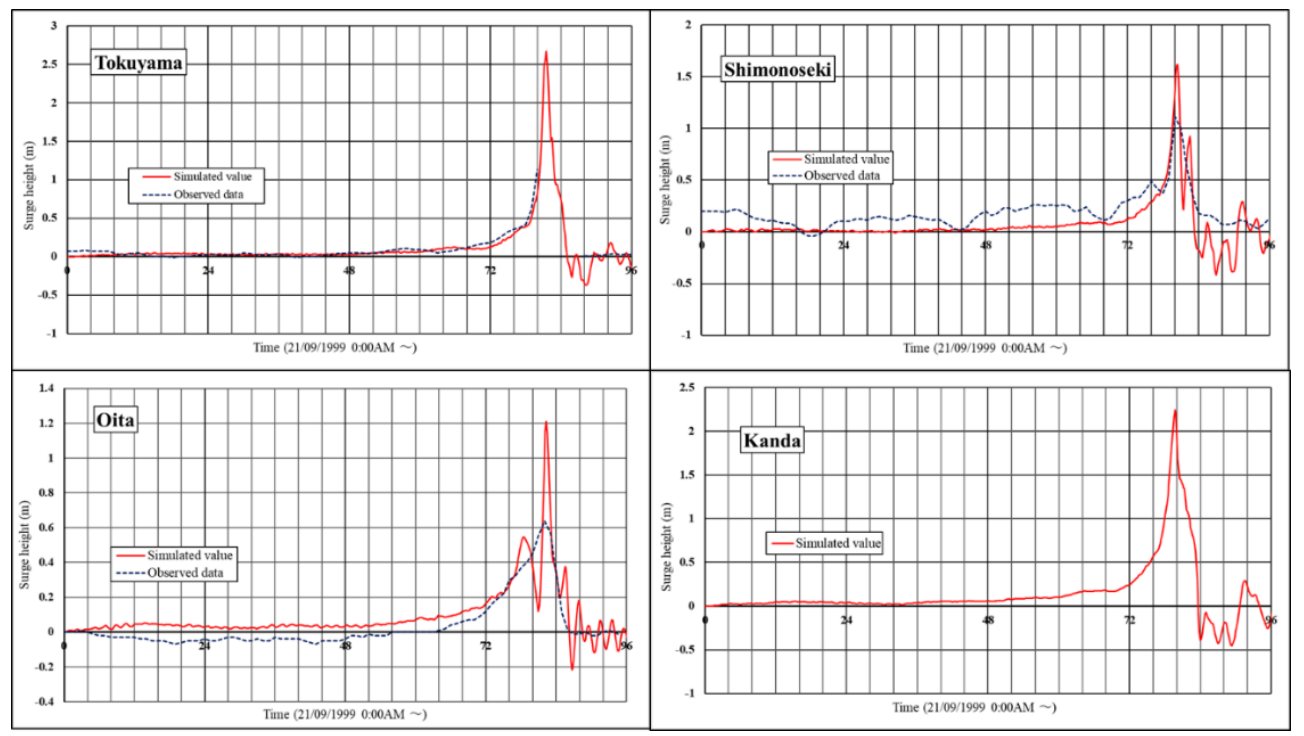

Figure 3.2.3 Results of simulation on T9918 with WRF 


\section{3) Typhoon 16 in 2004 (T0416)}

Figure 3.2.4 shows the comparison the results of T0416 simulated by WRF, GPV and typhoon model with observed data at 5 points, apart from Kanda. It can be seen that the results are not matched with observed one as a whole, except for the one by WRF at Tokuyama though there is 1.5 hour- gap with observed data about the time of the peak. Comparing the observed data, all results by simulations were underestimated, especially at Ube the difference is around $0.8 \mathrm{~m}$ about all data. However, the way of surge developing at Tokuyama and Ube is similar with observed one and also the time of the peak seems to be almost same. On the other hands, at Chofu and Shimonoseki the difference on the peak time looks comparatively large, the time of the results is earlier than observed ones, around 2 hours or more at both points. However, it can be said that the way of surge dropping is similar with observed one at any points. Besides the results by typhoon model is the largest among three data at Chofu, Kanda and Shimonoseki thus about this typhoon, it seems that the result by typhoon model tends to be the largest at the inner part of Suo-nada Sea.

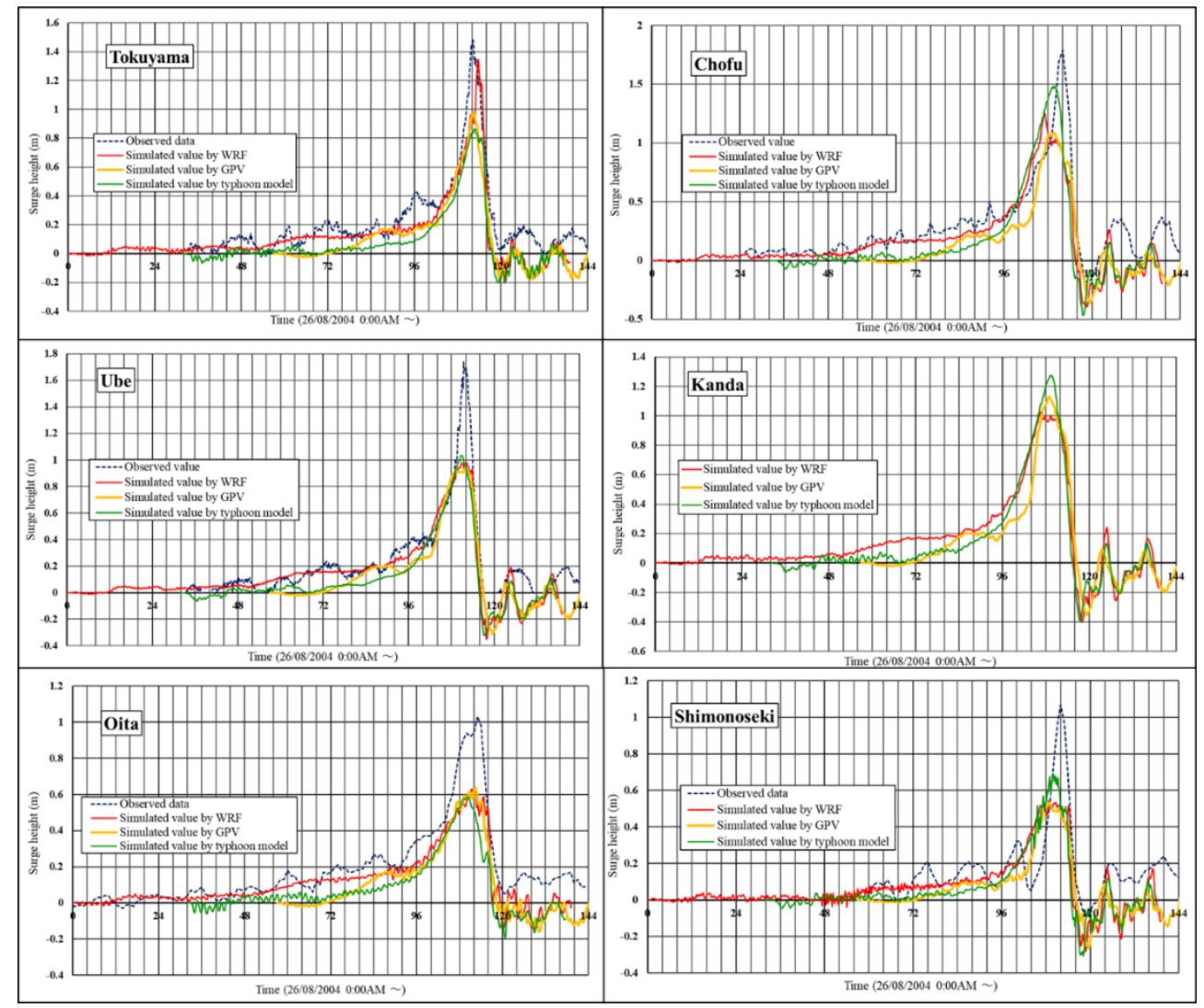

Figure 3.2.4 Results of simulation on T0416 with WRF, GPV and typhoon model 


\section{4) Typhoon 18 in 2004 (T0418)}

Figure 3.2.5 shows the results of T0418 simulated by WRF, GPV and typhoon model comparing with observed data at 5 points, except for Kanda. At Shimonoseki, the result obtained by WRF is overestimated, around $1.0 \mathrm{~m}$ and also after the peak, the result has lot of large oscillations though the other data, GPV and typhoon model were able to represent almost same surge height. On the other hands, the results at Oita were underestimated by all data, the difference of typhoon model is the largest, around 0.4 $\mathrm{m}$. Moreover, the three kinds of results at Oita have obvious two peaks although the observed data also has quite small one before the second peak. About this difference, the simulation results might be correct since the simulation results are exist every 10 minutes while the observed data is just every 1.0 hour so that the drop between two peaks might not be represented on the graph. However, as a whole the results were almost similar with the observed data at every points and it can be said that the simulations were able to reproduce the surge height enough on this typhoon.
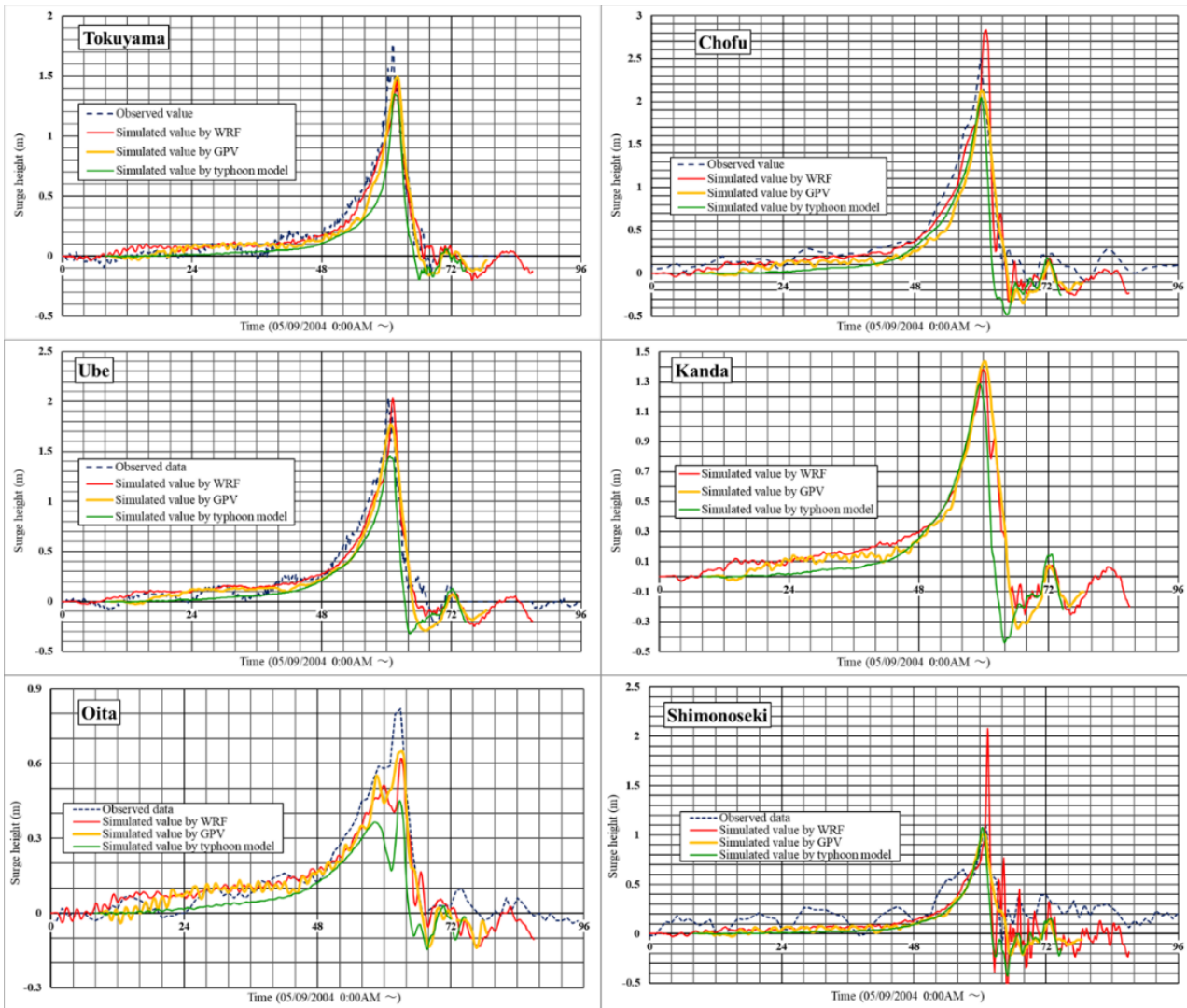

Figure 3.2.5 Results of simulation on T0418 with WRF, GPV and typhoon model 


\subsubsection{Discussion}

\section{1) Comparison of the results obtained by three different kinds of data}

The estimated storm surge by numerical simulations became lower than observed data overall though not all and this tendency was as reported by Hiroyasu, et al., (2000); the storm surge estimations were underestimated at the areas located west of Ube whereas the estimations accorded with observed data at the areas east of Ube. From the results of T0416 and T0418 (Figure 3.2.4 and Figure 3.2.5), it is able to discuss the influence which is given to the accuracy of the simulations by using different kinds of data on external forces. From the figures, it seems that the results by WRF and GPV have the almost same extent of precision on storm surge simulations. On the other hands, the results by typhoon model were underestimated at almost every points comparing with observed data even about the simulation on T0418. Hiroyasu, et al., (2000) reported that when estimating wind speed of typhoon model, 0.7 is applied as reduction coefficients of wind speed in general however the derived wind by the coefficient tended to be smaller than observed data. Suo-nada Sea is surrounded by high mountains and width of the bay is getting smaller as going to the inner part. As the scale of the sea area is much smaller than wind area of typhoons thus they pointed out that the influence from the land area to the ocean wind needed to be considered when simulating storm surge accurately in Suo-nada Sea by typhoon model. Indeed, they improved the estimation of peak value at Kanda by changing the reduction coefficient sequentially. It also can be considered that not only wind velocity but also wind direction affect to the estimation of storm surge, which might also strongly depend on the topography of the objective sea area.

In this connection, the influence of the land was included in the external forces by WRF and GPV when they were estimated and could obtain better results than typhoon model.

Therefore, for simulating storm surge in Suo-nada Sea with high accuracy, wind speed and direction of typhoon is one of the key factors and the influence of the topography needs to be contained when they are estimated. 


\section{2) Investigation on relationship between the results of storm surge and typhoon track}

From Figure 3.2.2 3.2.5, typhoons can be divided two types; the typhoons which can be simulated with high accuracy (in this case, T9119 and T0418) and the ones which cannot (T9918 and T0416). Typhoon tracks of each typhoon were as shown in Figure 3.2.6. From the figure, this two groups seem to be categorized depending on the type of typhoon tracks. T9119 and T0418 which can represent surge enough went through the west side of Suo-nada Sea while the other two typhoons i.e. T9918 and T0416 were passing through just above Suo-nada Sea. Generally speaking, atmospheric pressure is getting lower as approaching to the center of typhoon and becomes the lowest at the center. Also about wind velocity, it is getting weaker as approaching to the center. Therefore, it can be said that the external forces such as pressure and wind speed change significantly around the center of typhoon, which have a large influence to the currents surrounding environment. Hence when the center of typhoon passing across Suo-nada Sea, the small difference of typhoon path from BT can have led to the big difference on the results of storm surge simulations especially about T9918 and T0416 as they were traveling above Suo-nada Sea.

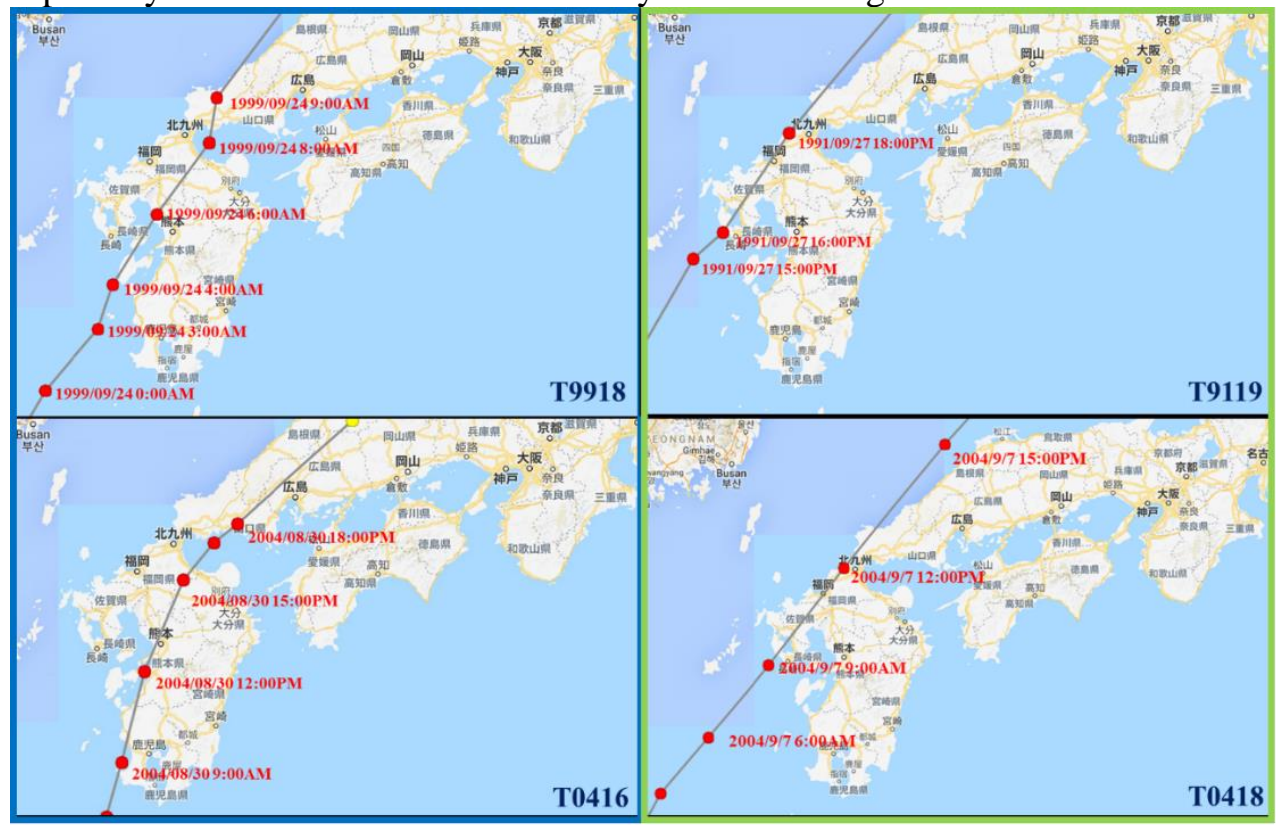

Figure 3.2.6 Track and time of four typhoons (Asanobu, 2014)

Typhoon track and central pressure by WRF are compared with BT around Suo-nada Sea in Figure 3.2.7. From the figure, one can know that the central pressure of WRF is around $10 \mathrm{hPa}$ lower than $\mathrm{BT}$ and also typhoon tracks have some gaps between them about all four typhoons respectively. Especially in terms of T9918 and T0416, the path seems to have large gaps around Suo-nada Sea. In addition, time series of estimated wind speed by three data were compared with observed one at Tokuyama and Ube about T0416 and T0418 in Figure 3.2.8. From Figure 3.2.8, wind speed estimated by GPV is fitting with observed data the best at each stations for both 
typhoons though the results of surge simulation of T0416 by GPV were not good. Especially at Ube the growth of the surge was stopped on the way to the peak and the difference was the largest comparing with other stations. Moreover, about T0416 wind speed estimated by WRF was greatly overestimated though the result of storm surge by the estimated wind was the best fitting with observed data. On the other hands the estimated wind speed about T0418 seems to have better fit with observed one on the whole; there is less variation among three data comparing to T0416 and also the storm surge simulation could obtain almost same value as observed ones. Thus it can be said that the estimation of wind speed on typhoon which went through west side of the sea area seems to be easier. Moreover, about typhoon passing above Suo-nada Sea like T0416, it was known that even one could estimate the wind velocity well at the specific point, it does not always lead to the good results of simulations on storm surge height. In fact, in the past study Veltcheva and Hiroyasu (2002) who made estimation about storm surge by T9918 said that the storm surge simulations with target for the bays which stretches from north to south such as Ariake-Sea almost can reproduce real phenomenon well in the case of typhoon going through west side of the bay and strong south wind generates surge. And also about Suo-nada Sea, they pointed out that since Suo-nada Sea is long from east to west and T9918 went through just above Suonada Sea, storm surge by the typhoon was generated by a drop of pressure and winds which blew easterly at forward. In addition, they mentioned the possibility that the pressure distribution might have changed while the typhoon going across the land area i.e. north part of Kyushu island. Thus they insisted the importance of taking into account the distortion of pressure distribution and characteristics of wind blowing frontal part of typhoon for the simulations on storm surge in Suo-nada Sea. Besides Moemi et al., (2006) who performed storm surge simulations with T9918 and T0416 also indicated that when one wanted to study the surge occurred in the south part of the sea area, the whole winds in Suo-nada Sea needed to be considered as Suo-nada Sea have a long fetch from east to west. Hence it can be said that the estimation of external forces such as pressure distribution and wind velocity is quite difficult for the typhoons which comes to above the objective area after passing through the land. Therefore, it is concluded that due to the low accuracy of estimating external forces it is quite difficult for storm surge caused by typhoon whose center went across Suonada Sea to simulate with high accuracy while it is comparatively easy for the one caused by typhoon which passed through west side of the sea area. 

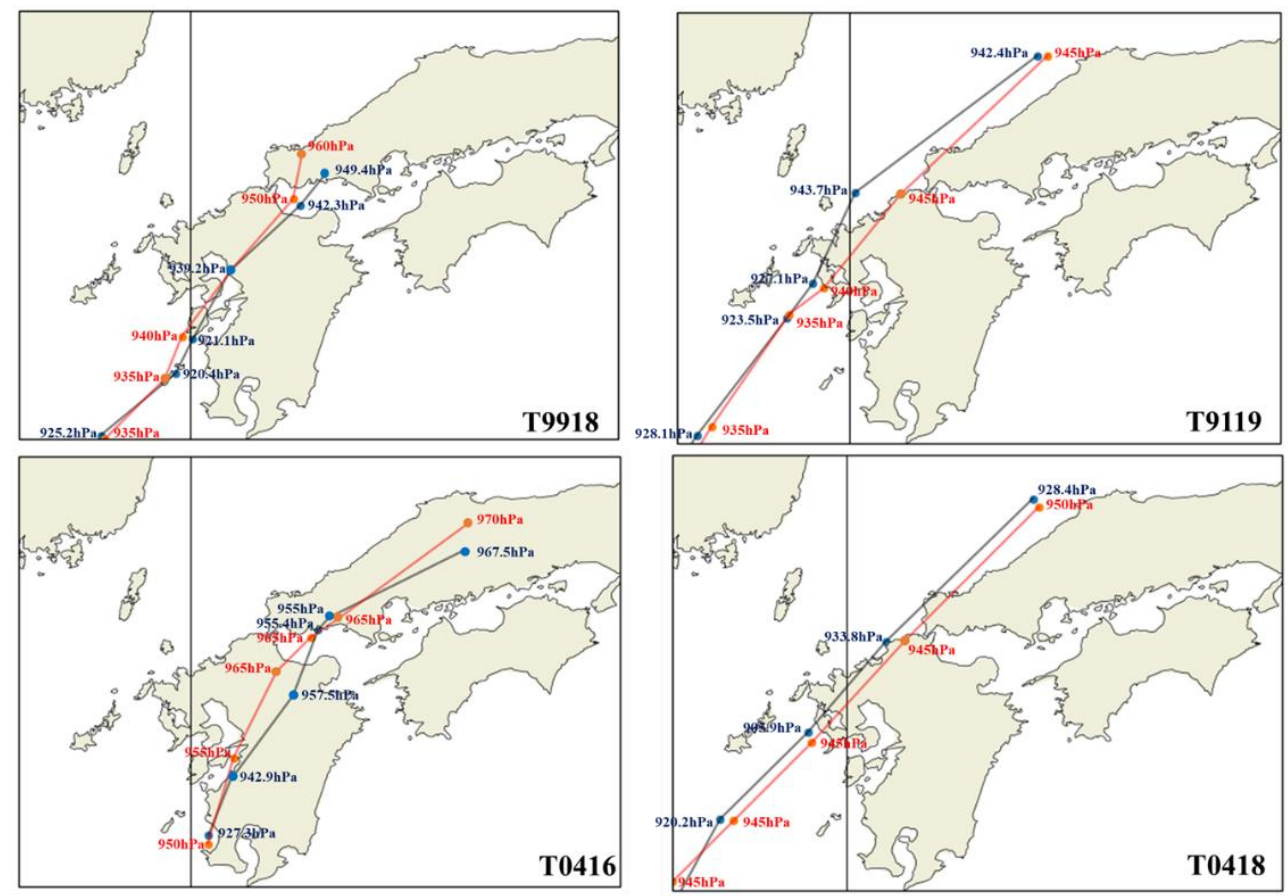

Figure 3.2.7 Comparison of typhoon course and central pressure by WRF with BT
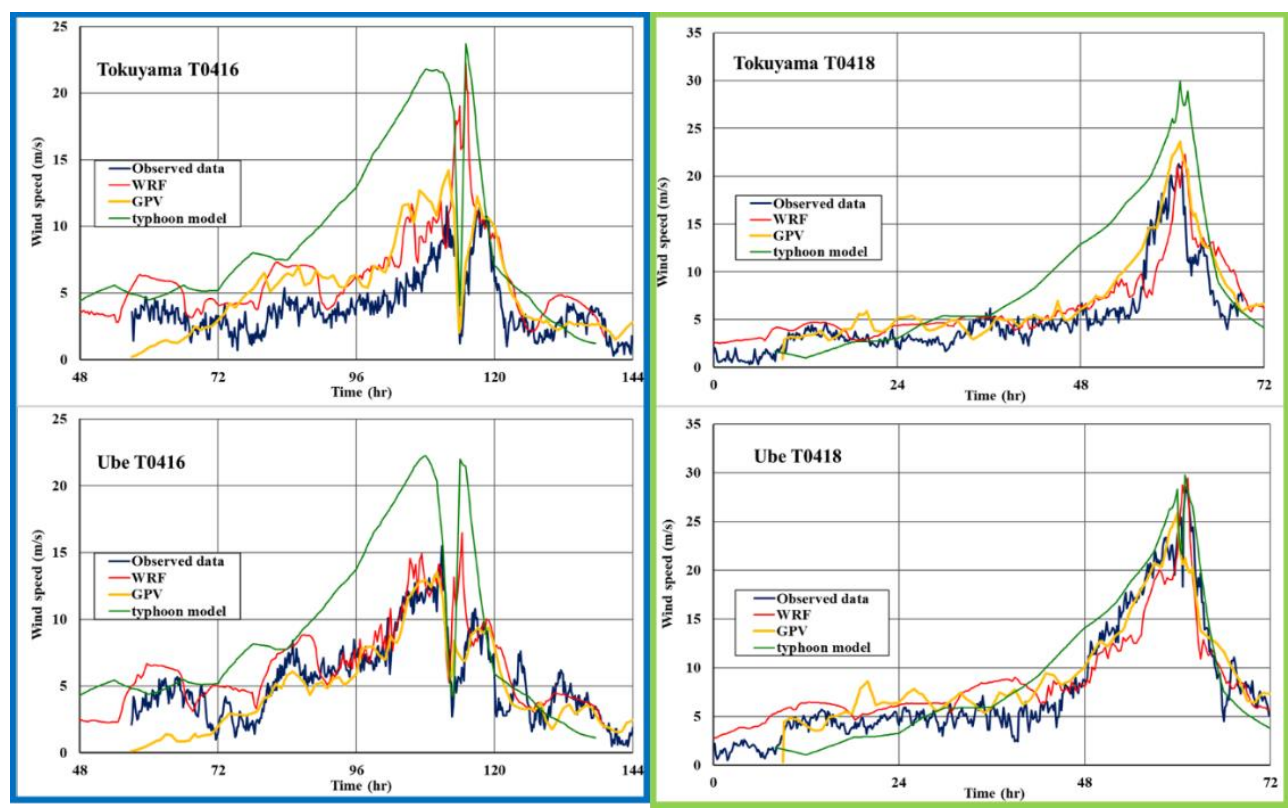

Figure 3.2.8 Time series of wind speed estimated by three kinds of data; WRF, GPV and typhoon model comparing with the observed one 


\section{3) Comparison of the results between only surge and tide}

The results shown so far were simulated by using only external forces such as pressure distribution and winds, which means a tide level was fixed as average water level i.e. $0 \mathrm{~m}$, there was no consideration on astronomical tide. However, it can be expected that tide have some effects to the surge height. And also it was aimed to have the simulations approached to the real situations more, tidal value was given to the model as an open boundary condition and the results were compared with the one simulated without tide. However, one cannot compare the two results directly. To derive surge height from the results by simulations with tide, two simulations needed to be performed. The one is tidal level simulation which means including tide and external forces of typhoon, and the other one is simulated for astronomical tide which means only astronomical tide was given to the simulation as external force. The way of computing surge can be explained by using Figure 3.2.9. The difference between dark blue line and red dotted line in the above graph of Figure 3.2.9 will be deviation called storm surge which is shown in the below graph by black line. By using the way, surge height about the simulation with tide was derived at several points.

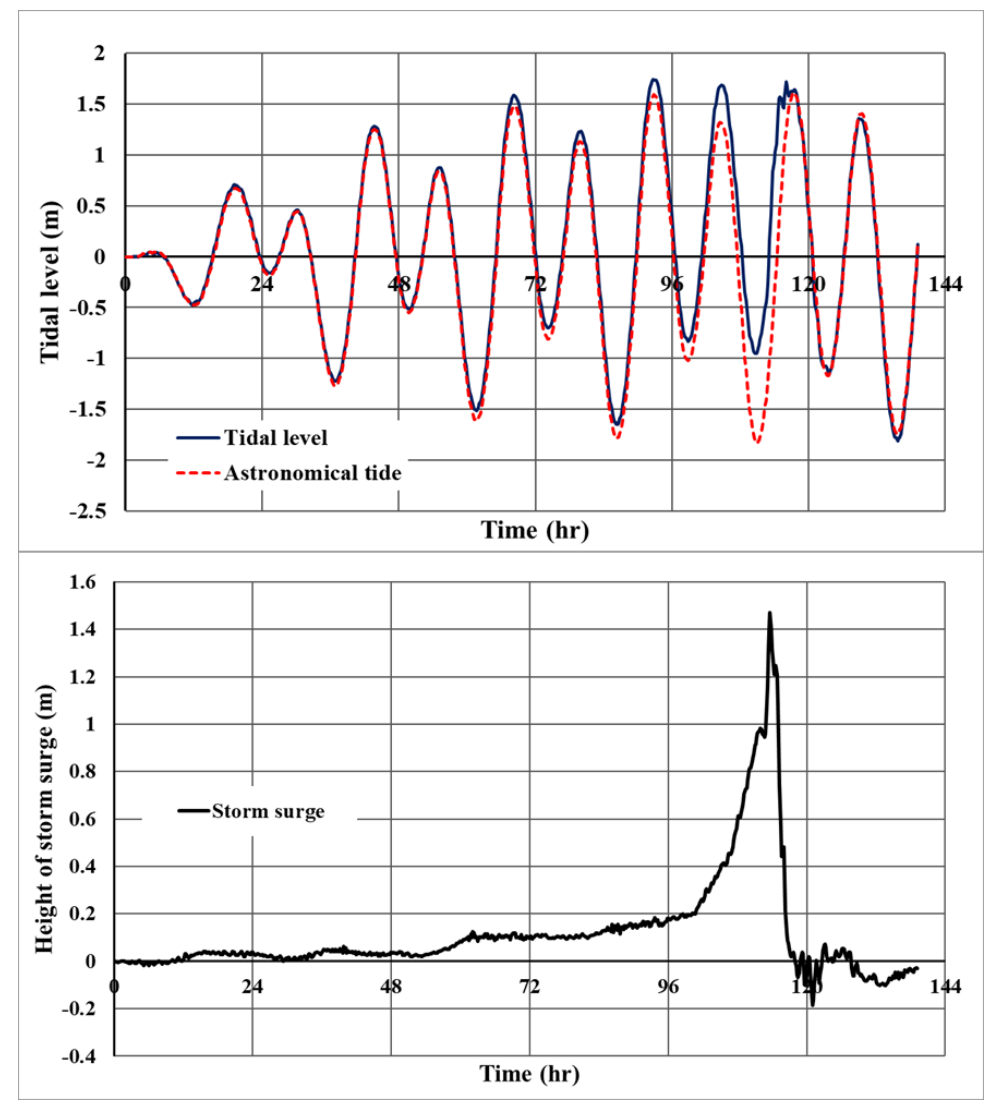

Figure 3.2.9 Explanation of the way to derive surge height from the results by simulations with tide (Above graph is comparing the results of tidal level with the one of astronomical tide and below graph is showing the difference of them called surge deviation.) 
Figure 3.2.10 and Figure 3.2.11 shows the comparison of the results about T0416 and T0418 at four points, Tokuyama, Ube, Chofu and Kanda. About T0418, it is seen that the results by the simulations with tide and without tide are almost same whereas about the results of T0416 there are some differences between them. At Tokuyama, the peak of surge by the simulation with tide developed a bit more than the one by simulation without tide and the results with tide became almost same as the observed one. Moreover, at Ube there was no clear peak in the results by the simulation without tide while the other one have clear peak though the peak value was still underestimated comparing with observed one.
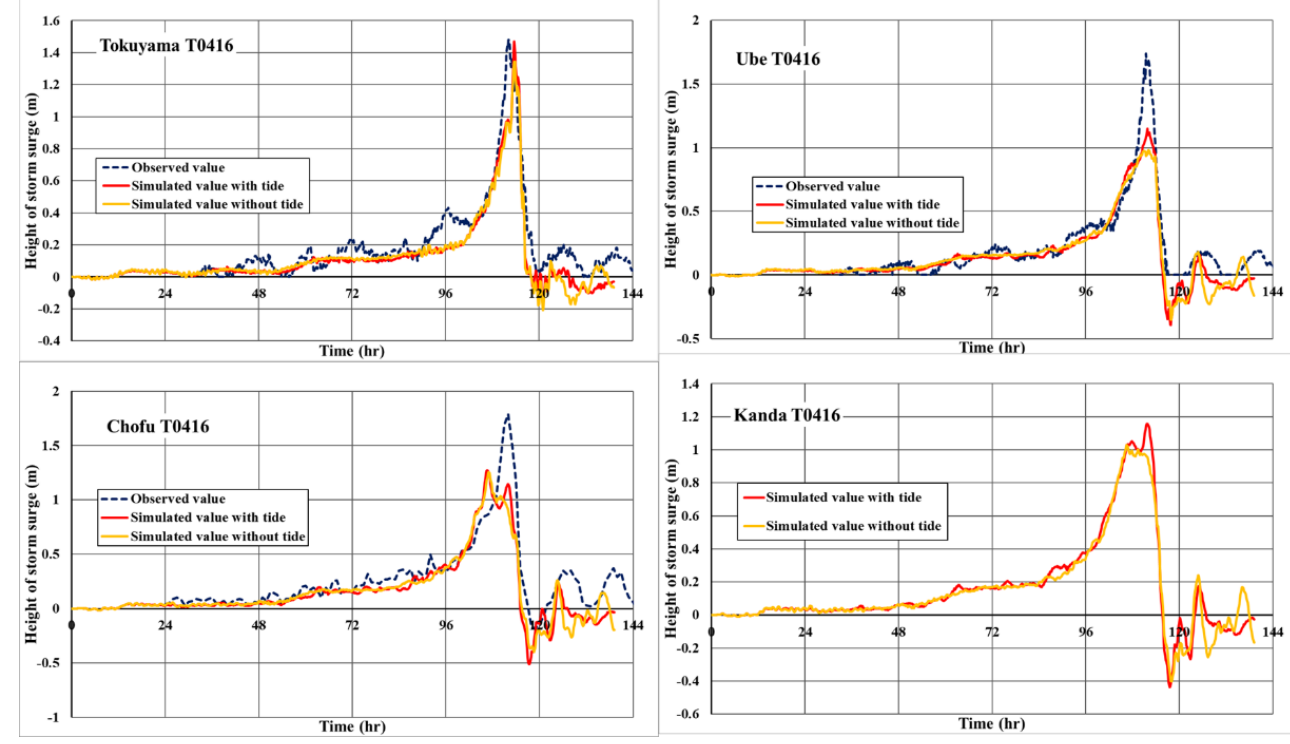

Figure 3.2.10 Comparison of the results about T0416
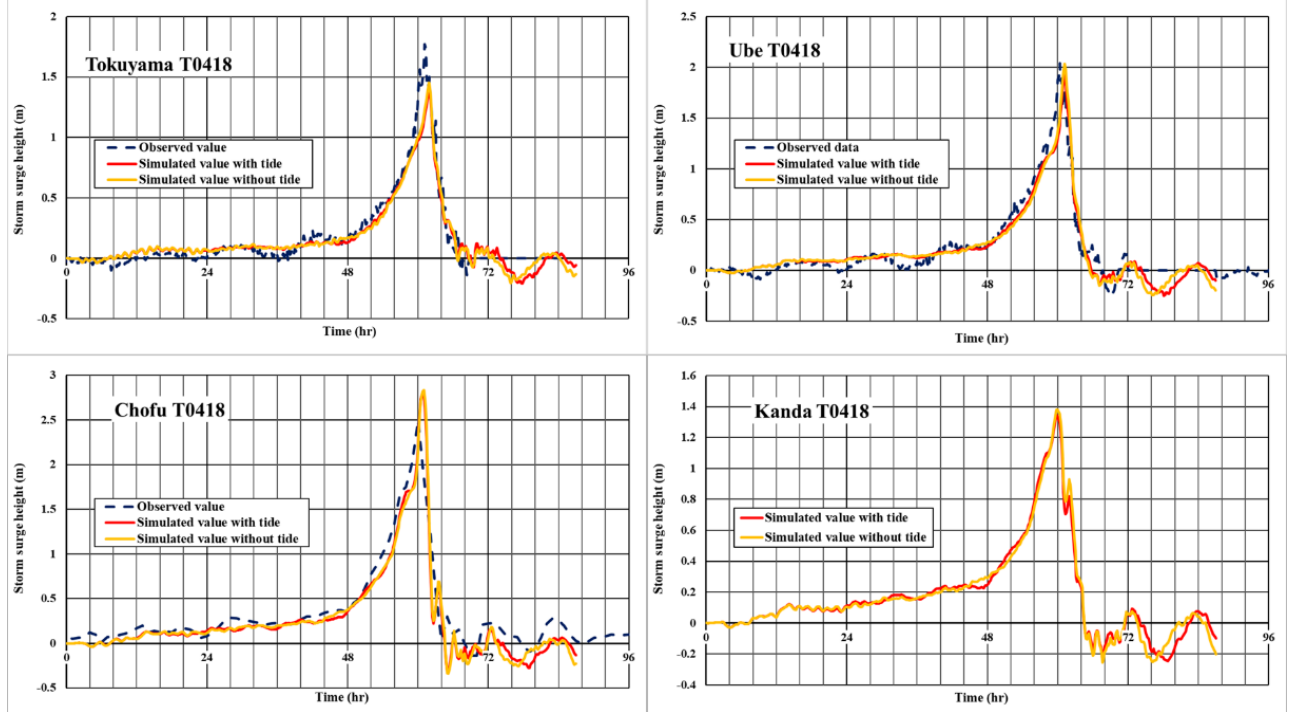

Figure 3.2.11 Comparison of the results about T0418 
In addition, focusing on the oscillation after the surge, it is seen that the results by simulation with tide have better fitting with observed one (See Figure 3.2.12). The period of the results by simulation without tide is a bit shorter while the other one has almost same period with observed data. Thus in order to have better results about both the peak of surge and the period of backlash, tidal value should be given to the model as an open boundary condition.
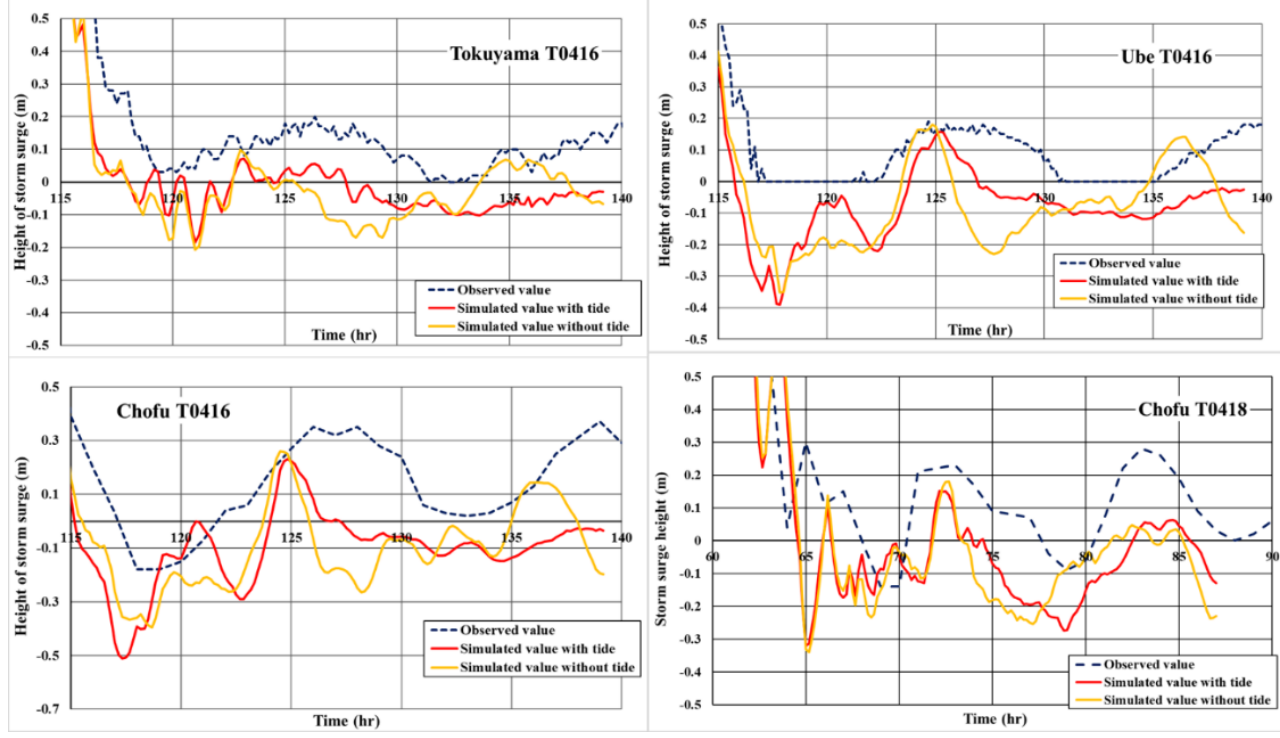

Figure 3.2.12 Comparison simulated values with and without tide about the period of backlash

Also apart from the investigations about the suitable computational conditions, an interesting phenomenon can be seen in the results of T0416 at Chofu and Kanda (See Figure 3.2.13). The two points are located on the innermost part of Suo-nada Sea and the results by simulations with tide at the points have two peaks while the simulated value without tide have only the first one. Hence it can be considered that the second peak was generated by tidal effect. Besides seeing the results at Chofu, it can be known that the time of the second peak is almost same as the observed peak. Thus the first peak was caused by a drop of air pressure and strong wind however as the accuracy of estimation on them is quite low, the first peak occurred earlier, though it should have generated at the same time as second peak. And also about the second peak, it was produced due to the low tide. Table 3.2.4 shows the time and tidal level when high and low tide, in addition Figure 3.2.14 shows the time series of the astronomical tide on August $30^{\text {th }}$. From these materials, it can be seen that the second peak was around the low tide i.e. 14:00 16:00 while the lowest point cause by backlash was located around the time of high tide i.e. 21:00 22:00. Normally storm surge height is calculated by following equation.

$\eta_{\omega}=k \frac{F}{h} U^{2}$

$\eta_{\omega}$ : Amount of sea level rising

$U$ : Wind velocity

$h$ : Water depth 


\section{$k: 4.8^{*} 10^{-2}$ \\ $F$ : Length of fetch}

From the above equation, it is known that the amount of sea level rising is depending on not only wind velocity but also length of the fetch and water depth. Moreover, as water depth is getting shallower, sea level will be rising more. Therefore, it can be considered that the second peak was generated as water depth became shallower than usual due to the low tide, and in addition similarly the lowest tide led by backlash of the results with tide became a bit lower than the one without tide due to deep water depth caused by high tide.
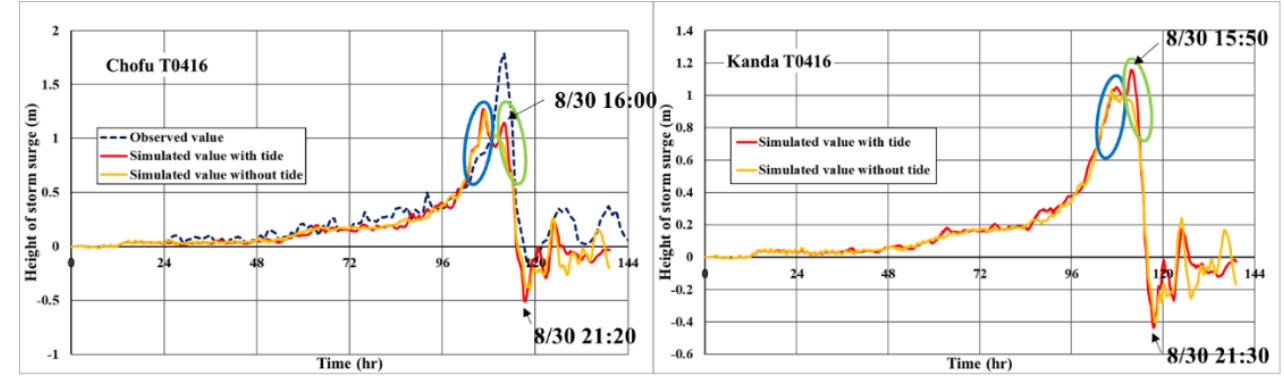

Figure 3.2.13 Results of T0416 at Chofu and Kanda which have two peaks (The first peak in the blue circle seems to be generated by the external forces such as air pressure and wind velocity with low accuracy while the second peak in the green circle might be produced by the tidal effect.)

Table 3.2.4 Time and tidal level of high and low tide at both Chofu and Kanda

\begin{tabular}{|l|ll|lc|}
\hline Name of the point & \multicolumn{2}{|l|}{$\begin{array}{l}\text { Time and tidal level of high } \\
\text { tide }\end{array}$} & $\begin{array}{l}\text { Time and tidal level of low } \\
\text { tide }\end{array}$ \\
\hline Chofu & $8: 53$ & $380 \mathrm{~cm}$ & $3: 06$ & $113 \mathrm{~cm}$ \\
& $21: 40$ & $410 \mathrm{~cm}$ & $15: 18$ & $23 \mathrm{~cm}$ \\
\hline Kanda & $8: 53$ & $371 \mathrm{~cm}$ & $3: 06$ & $97 \mathrm{~cm}$ \\
& $21: 41$ & $404 \mathrm{~cm}$ & $15: 17$ & $12 \mathrm{~cm}$ \\
\hline
\end{tabular}




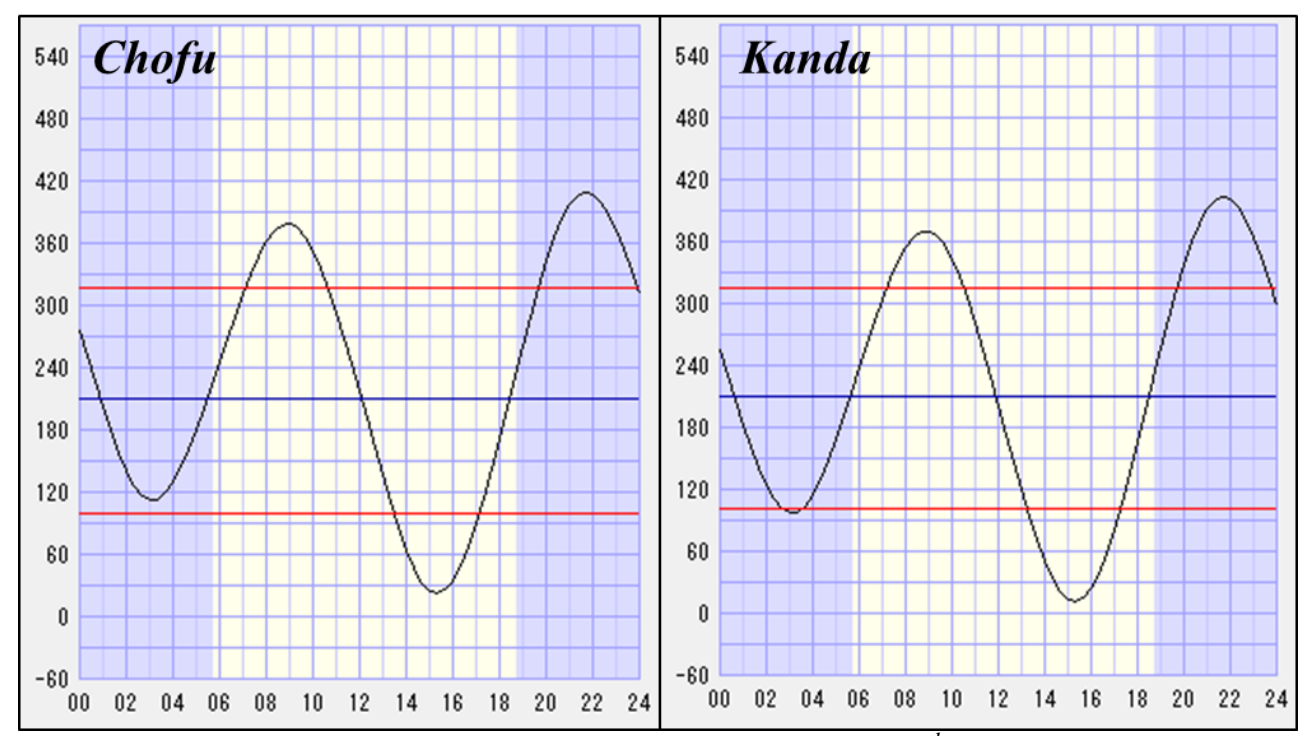

Figure 3.2.14 Time series of astronomical tide on August $30^{\text {th }}$ at Chofu and Kanda (TIDEforWIN, version.3.03)

\section{4) Computational conditions for the simulations}

Since the simulation results on T0416 had large gaps comparing to the observed data, several simulations were attempted with changing drag coefficient. Because in general wind effect is strong factor more than pressure to make storm surge higher and especially in Suo-nada Sea, since water depth is not so deep, the wind strongly effects on development of storm surge hence it seems to become more important for Suonada Sea to determine a suitable drag coefficient versus wind speed compared to other sea areas. In FVCOM the equation proposed by Large and Pond (W.G.Large and S.Pond, 1980) is used for deriving drag coefficient as a default setting.

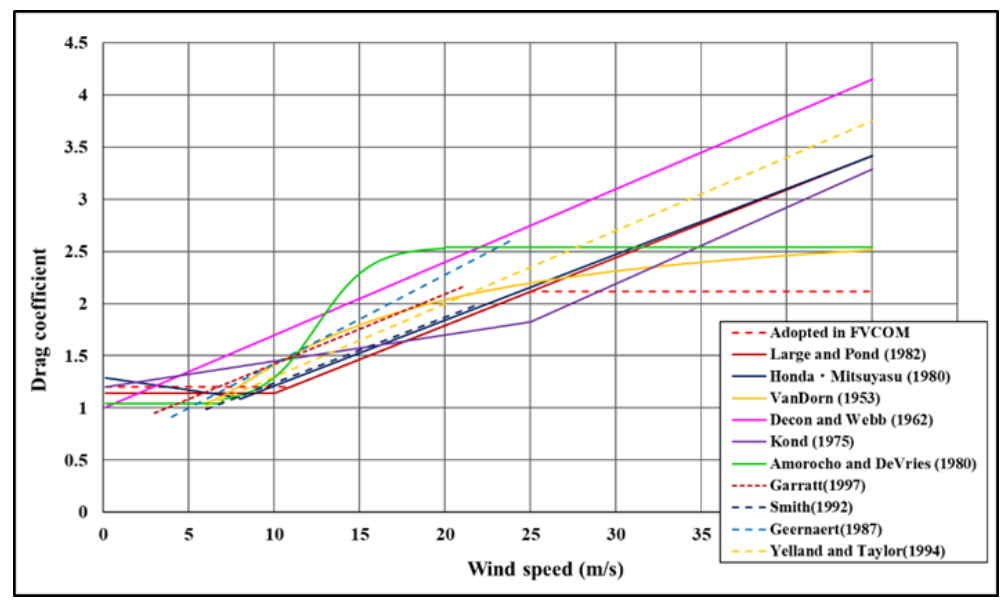

Figure 3.2.15 Drag coefficient versus wind speed 
However, as shown in Figure 3.2.15, there are various ways to derive the drag coefficient and several equations were selected among them by referencing wind speed of T0416 at Tokuyama and Ube in Figure 3.2.8. The drop of the wind speed shown in Figure 3.2.8 was caused by the center of typhoon going through the points and just before and after the time, the strongest wind blew. In the case of T0416, the strongest wind was in range of $10 \sim 15 \mathrm{~m} / \mathrm{s}$. Thus with setting the wind velocity of 10 $\sim 15 \mathrm{~m} / \mathrm{s}$ as the target, two equations which have much larger drag coefficient than Large and Pond within the wind speed range were selected; Decon and Webb (1962) and Amorocho and DeVries (1980). Storm surge simulations with them were carried out by using only GPV. The results were in Figure 3.2.16.
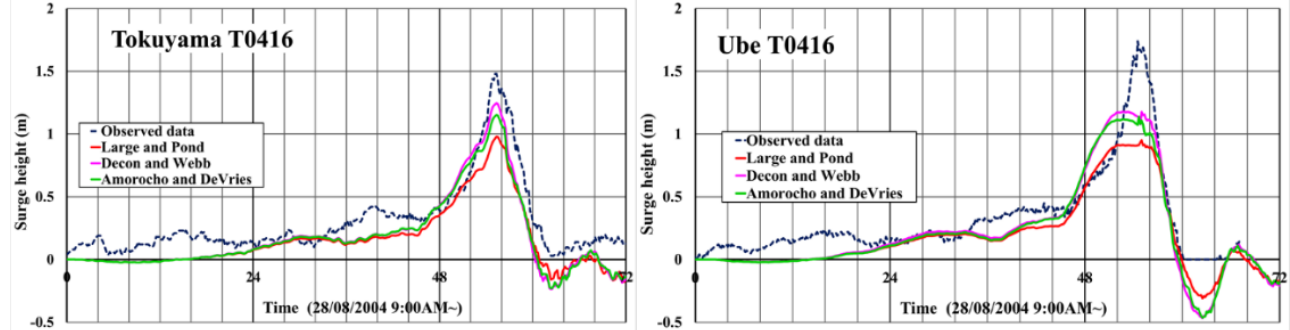

Figure 3.2.16 Results of simulations on T0416 with changing drag coefficient at Tokuyama and Ube

From Figure 3.2.16, it is seen that the results by alternative two equations made storm surge higher and peak value got close to the observed one. Moreover, the results using Decon and Webb developed the most at both points, and especially at Tokuyama the gap with the observed one became much smaller comparing with the result by Large and Pond.

In addition to the investigation about drag coefficient, a study on an open boundary condition except for astronomical tide was conducted. In order to make the simulations more realistic, the sea level rising by the degradation of pressure along open boundary was given as another boundary condition. The results with considering sea level rising on the boundary were as shown in Figure 3.2.17. Large and Pond was used as a drag coefficient for the simulations.
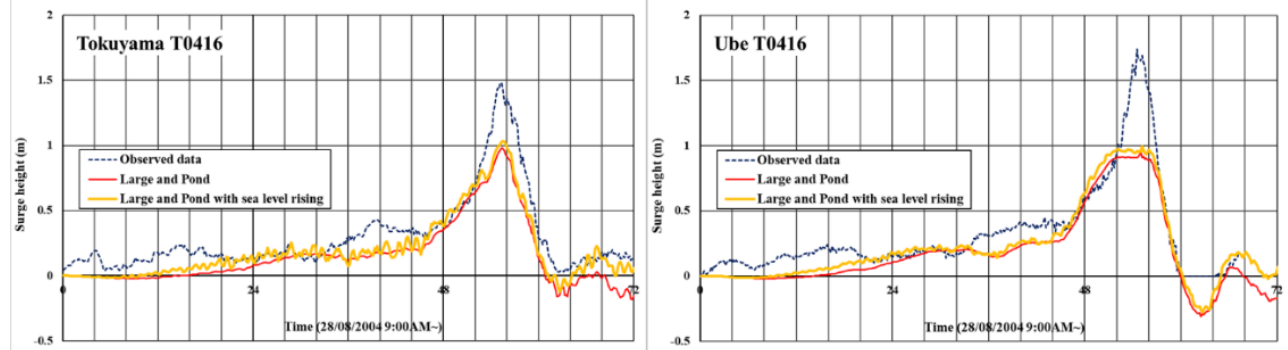

Figure 3.2.17 Comparison the results of simulations with and without considering sea level rising on open boundary at Tokuyama and Ube

From Figure 3.2.17, the results of simulations with considering sea level rising became a bit higher than the one without it. Also the height of backlash and its period 
of the results obtained better fitting with observed data.

Combining two investigations, i.e. in the case that one used Decon and Webb as a drag coefficient with taking into account sea level rising, and furthermore add astronomical tide to the simulation, the results became the best about T0416 (See Figure 3.2.18).
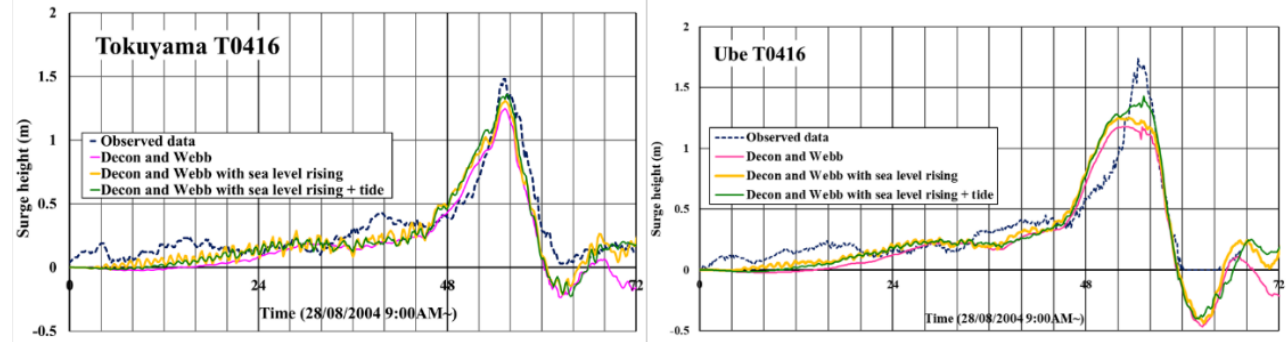

Figure 3.2.18 Results of simulation combined two investigations using T0416

Seeing the results of the simulations on T0416, the combinations of Decon and Webb as drag coefficient with sea level rising plus tide seems to be the best answer as conditions of computational model. However, the computational conditions should be suitable for simulations on any kinds of typhoons. Thus since the simulated value on T0418 already had some accuracy, in order to make clear whether the conditions are applicable to any typhoons or not, several simulations were performed for T0418 as well with these conditions. The results at Tokuyama and Ube is as shown in Figure 3.2.19.
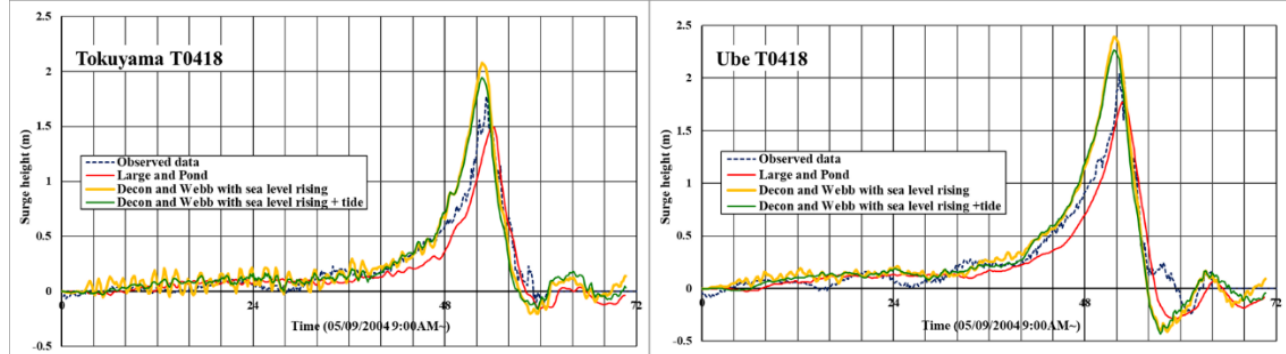

Figure 3.2.19 Results of simulation combined two investigations using T0418

Seeing Figure 3.2.19, it is seen that the results using the conditions became overestimated and there is little difference about the accuracy comparing with the results obtained by Large and Pond. Moreover, the simulated value with WRF had already some accuracy hence by applying the computational conditions, the results might become even worse if this verification was carried out by using the data of WRF. According to the above results, it was confirmed that if one can give the estimation of external forces with high accuracy, it is possible to simulate storm surge accurately without changing the conditions i.e. the gap between observed data and simulated value depends on not the computational model and conditions but the accuracy of estimation on external forces. And in the case of Suo-nada Sea, one can simulate the storm surge with high accuracy for the typhoon passing through west side of the sea area by using the computational model with default settings; Large and Pond as a drag coefficient. 


\section{5) Accuracy of Best track (BT)}

In order to verify the accuracy of BT, numerical experiments were performed with another typhoon model which was created based on the external forces estimated by WRF about both T0416 and T0418. Results at Tokuyama and Ube were as shown in Figure 3.2.20.
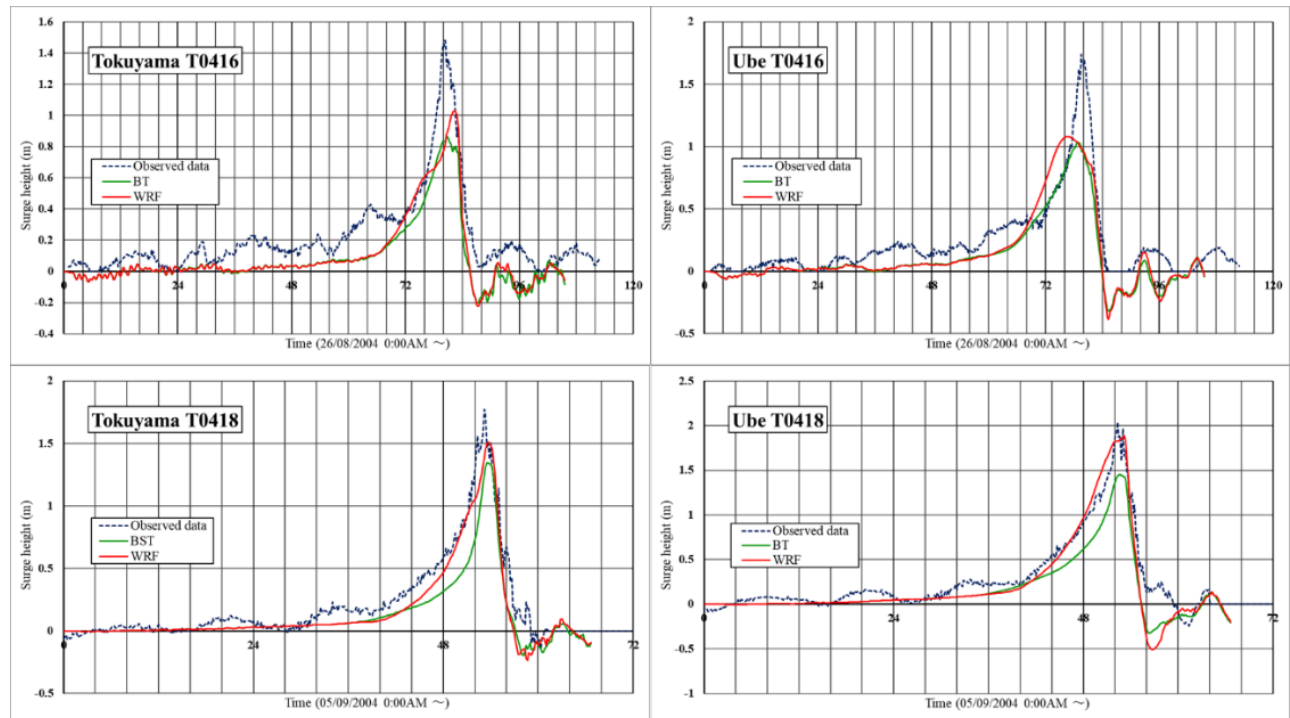

Figure 3.2.20 Results of simulations by typhoon model created on the basis of BT and WRF

From the figure, especially on T0418, the simulation based on WRF have better results. Besides even on T0416, the storm surge developed more than the one based on BT. Therefore, there might be possibility that WRF have more precision than BT though BT has been provided as an observed data. 


\section{Future risk of storm surge in Suo-nada Sea}

\subsection{Change of the trend on typhoon struck the region along Suo-nada Sea}

\section{1) Extraction of dangerous future typhoon}

In order to evaluate the risk of storm surge in the future around Suo-nada Sea, storm surge simulations with future typhoon were performed. Future typhoons used in the simulations were selected from d4PDF. When a typhoon gets closer to $300 \mathrm{~km}$ from the specific point, it is defined as a typhoon which is approaching to the area according to Japan Meteorological Agency. Thus based on this definition, one point on the middle of Suo-nada Sea (33.77N 131.28E) was set as a designated point (See Figure4.1.1) and the typhoons approaching to the point were extracted from d4PDF. For those extracted typhoons, the nearest point to the designated one on the track was specified and atmospheric pressure on that point were compared and ranked for all extracted typhoons. Therefore, the order on the intensity of typhoons were determined as a future dangerous typhoon for Suo-nada Sea. Also in order to compare and analysis the change of a characteristic on typhoon passing across the region around Suo-nada Sea, the same attempts were performed for past typhoons as well. For this process, a large ensemble of climate simulations with a $60-\mathrm{km}$ atmospheric general circulation model was used and also since the original data were available only every 6 hours, the data were interpolated to every one-hour for analyzing.

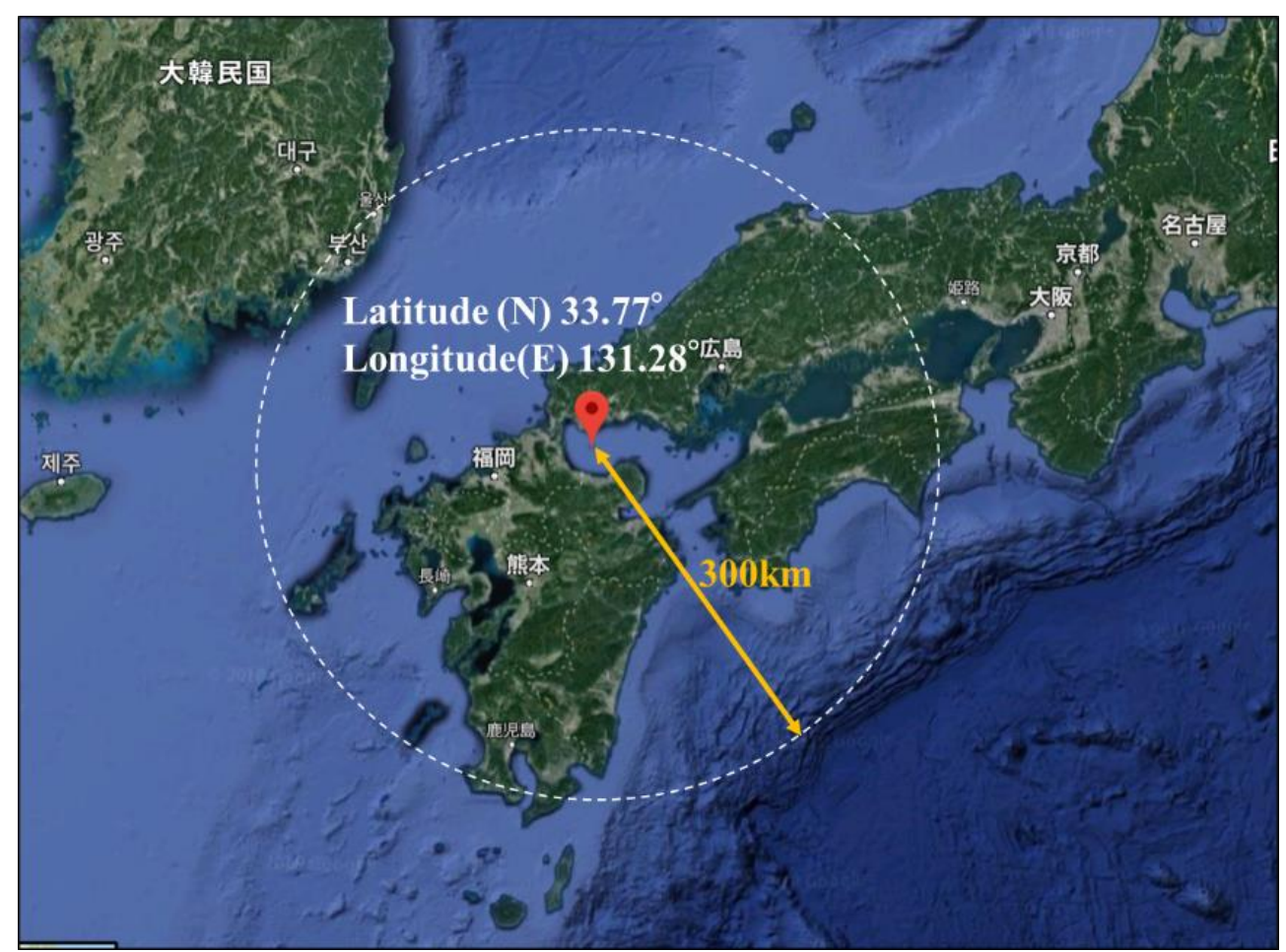

Figure4.1.1. Location of the designated point and the region which is $300 \mathrm{~km}$ from the point (Google map, 2018) 


\section{2) Change of the trend on typhoons going through around Suo-nada Sea}

In order to study the change of the typhoons trend going through around Suo-nada Sea, the strongest 30, 50 and 100 typhoons were extracted and plotted on the map for the past and future (Figure 4.1.2). From Figure 4.1.2, it can be known that typhoon which might be dangerous to the region tends to going toward north-east in the past while in the future the trend will change to going north. Moreover, though there are a few typhoons going towards north-west comparing to north-east in the past, in the future there are the almost same number of typhoons. Storm surge is strongly affected by typhoon track. In fact, in 2018 the course of Typhoon 12 was unusual (See Figure 4.1.3) and the advance warning against unexpected storm surge was given to the region where typhoon went across. Hence the usual trend on storm surge around Suonada Sea also might change accompanying the change of the trend on typhoon course in the future.
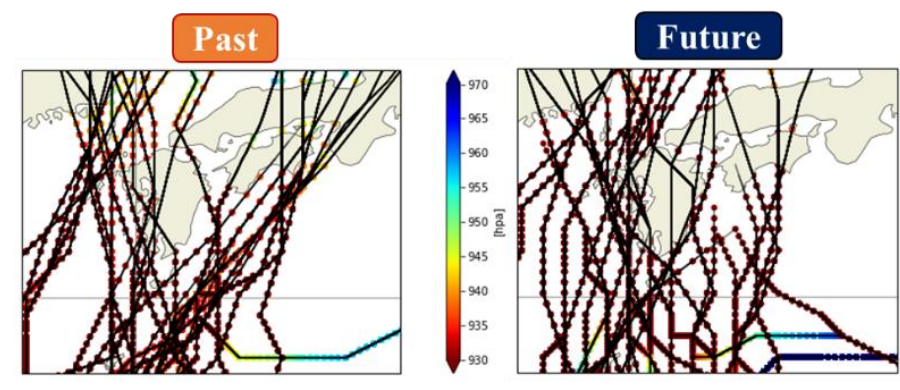

Strongest 30 typhoons
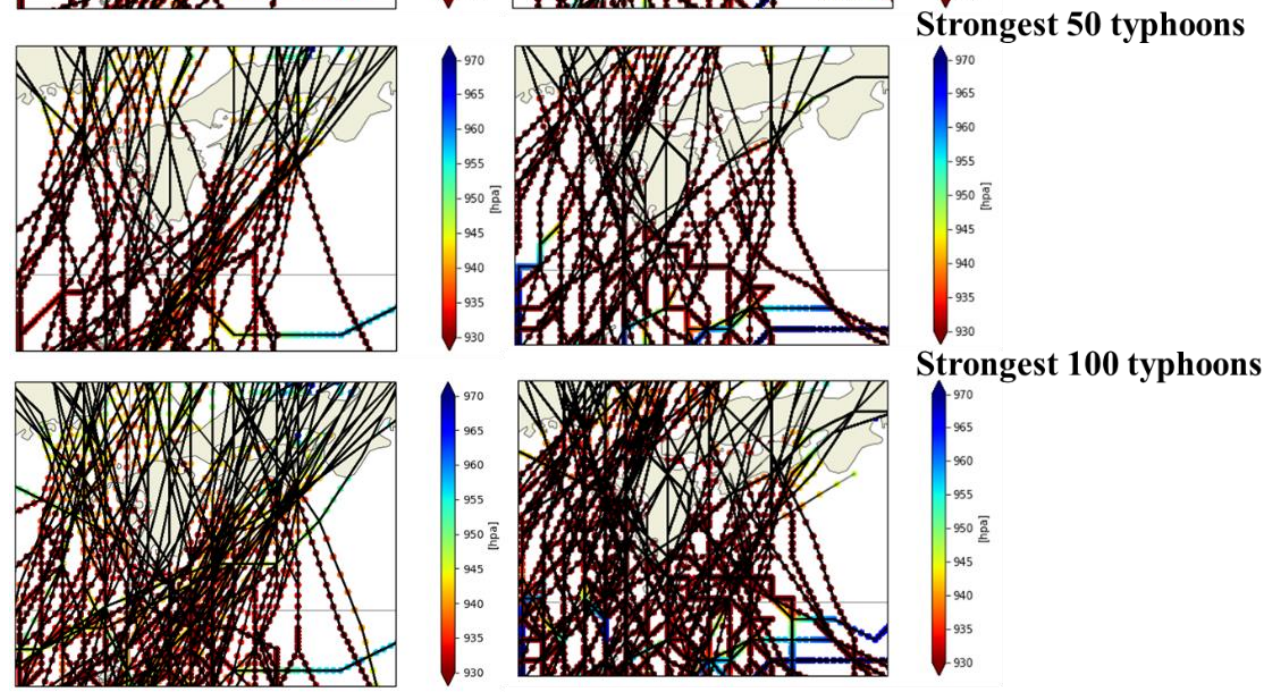

Figure 4.1.2 Comparison on typhoon tracks between past and future (There are several missing points on the tracks of the land area due to technical problems about python) 


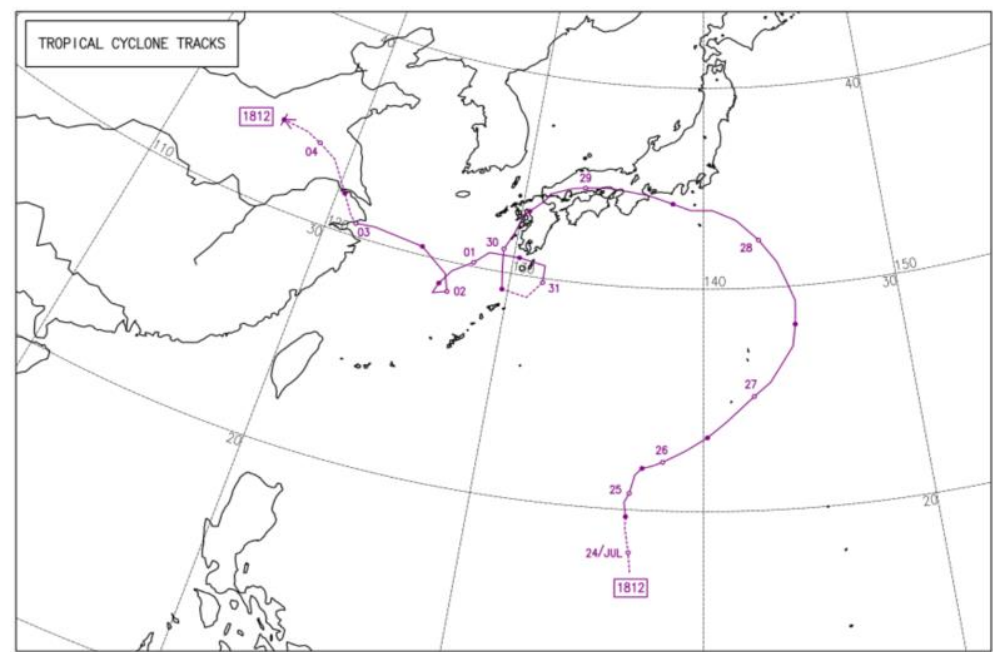

Figure 4.1.3 Typhoon track of Typhoon 12 in 2018(Japan Meteorological Agency, 2018)

Furthermore, the histogram on the relationship between the central atmospheric pressure and the number of the typhoons per 1000 years which approach the region is shown in Figure 4.1.4. From Figure 4.1.4, it turns out that comparing the past, the number of typhoons which might be dangerous to the region will be decreased in the future in general while the number of strong typhoons whose central atmospheric pressure is under $950 \mathrm{hPa}$ is increasing.

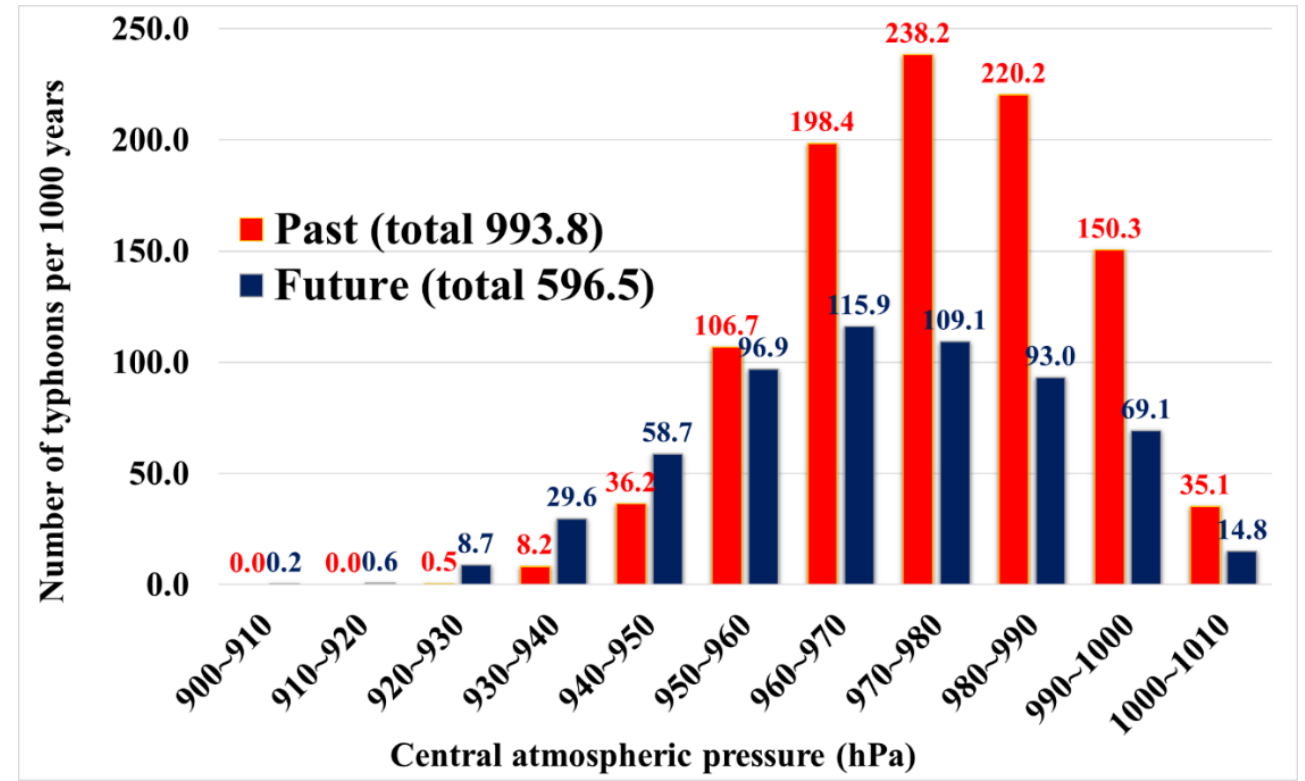

Figure 4.1.4 Histogram on the relationship between the number of typhoons which might be dangerous to Suo-nada Sea and its central atmospheric pressure comparing past with future 


\subsection{Storm surge simulation with future typhoons from d4PDF}

\section{1) Strongest 10 typhoons passing around Suo-nada Sea}

In order to investigate the future risk on storm surge around the region along Suonada Sea, several typhoons need to be determined for surge simulation. Figure 4.2.1 shows the strongest 10 typhoons in the future and from those, two typhoons were selected for the simulations.

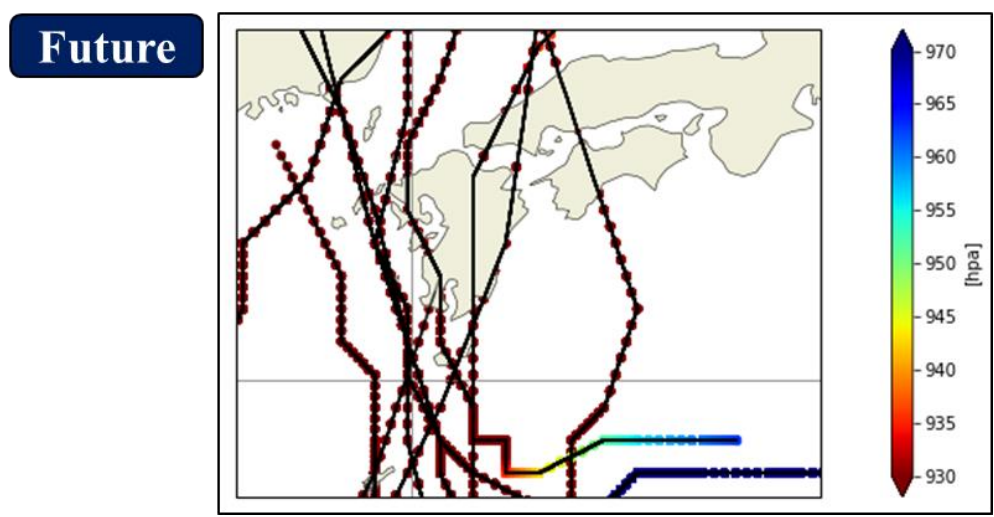

Figure 4.2.1 Typhoon track of the strongest 10 typhoons which is approaching to Suonada Sea (There are several missing points on the tracks of the land area due to technical problems)

The one of them is the strongest one, which means it has the lowest central air pressure at the nearest to the designated point on the typhoon track and it does not land on Kyushu island in the range of $31 \sim 34$ degrees of north latitude, only going through sea area. Another typhoon is the fifth-strongest typhoon and it was selected because of similar typhoon track with Suo-nada typhoon which caused severe damage around the region in 1942 and named the sea name. (See Figure 4.2.2)
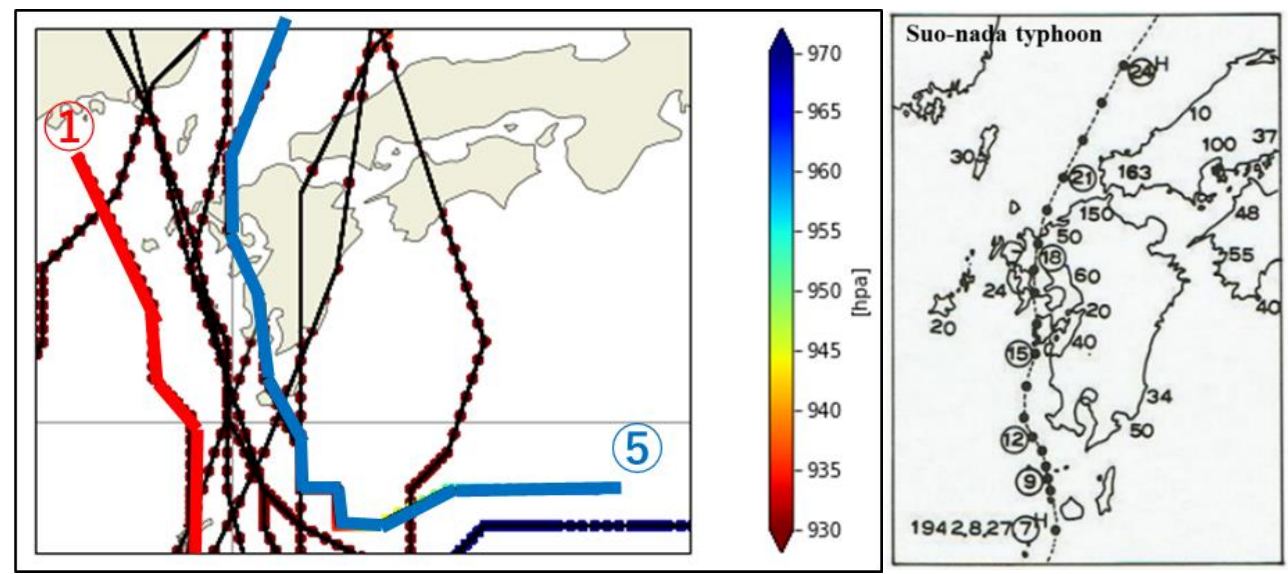

Figure 4.2.2 Typhoon tracks of the strongest and fifth strongest typhoon (left side) and Typhoon track of Suo-nada typhoon in 1942 (right side) (Yo, 1986) 


\section{2) Bias correction on central air pressure of future typhoons extracted from d4PDF}

About the model used in d4PDF, it was reported that the typhoons generated on the mid-latitude tend to be extremely strong more than expected. It is because that the model does not consider the interaction between sea water and air thus the degradation of sea temperature caused by water vertical mixing is not included and typhoons were supplied energy more than enough (Ogata, et al., 2015). Therefore, the central air pressure of the extracted typhoon from the model need some correction. Yoshihiko, et al. (2018) verified the precision of d4PDF by comparing typhoon central pressure extracted from present experiments of d4PDF with Best Track Data (BT) provided by Japan Meteorological Agency and proposed the way of bias correction depending on the latitude. The range of applying the correction is north latitude of $20 \sim 40$ degrees and it was divided into four regions, every 5-degree. (See Figure 4.2.3, left side) The equation of correction was created by harmonizing d4PDF with BT on both average and standard deviation of typhoon central pressure. Figure 4.2.3 (right side) shows the comparison before and after correction on $30 \sim 35$ degrees of north latitude where Kyushu island is located. The corrected typhoon central pressure is obtained by the following equation.

$x^{\prime}=\frac{\sigma_{B T}}{\sigma_{d 4 P D F}}\left(x-\bar{x}_{d 4 P D F}\right)+\bar{x}_{B T}$

$x$ : Typhoon central pressure of d4PDF (before correction)

$x^{\prime}$ : Corrected typhoon central pressure

$\sigma_{B T}, \sigma_{d 4 P D F}:$ standard deviation on typhoon central pressure of BT and d4PDF respectively

$\bar{x}_{B T}, \bar{x}_{d 4 P D F}$ : average on typhoon central pressure of BT and d4PDF respectively

From Figure 4.2.3 (right side), it can be known that the corrected typhoon central pressure is fitting with BT well. Hence in this study, this bias correction was applied when creating input data of simulating storm surge led by future typhoons.
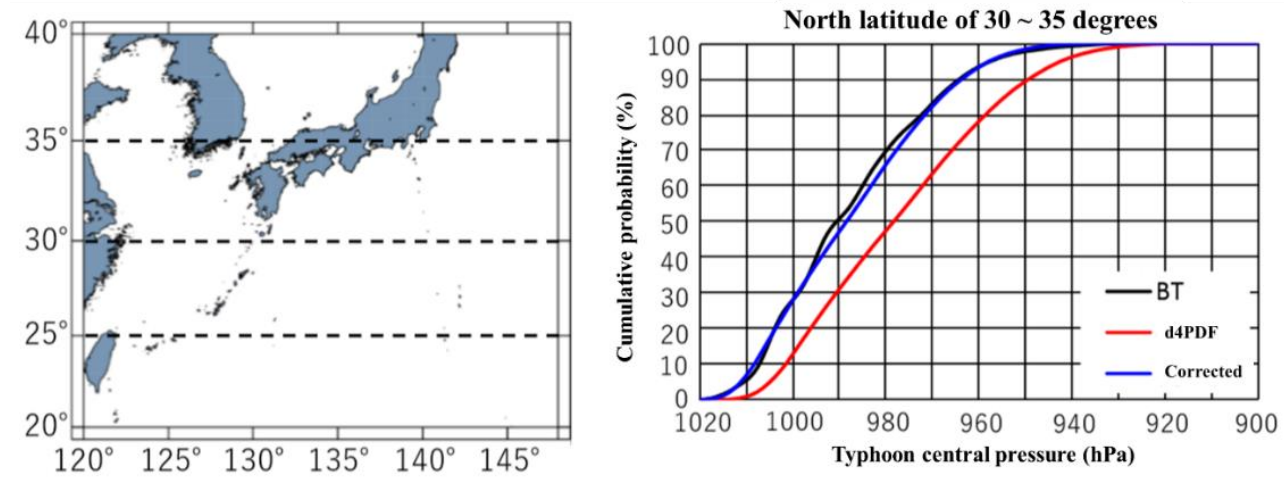

Figure 4.2.3 Range of latitude proposed bias correction (left side) and the comparison of corrected and uncorrected pressure with BT (right side) (Yoshihiko, et al., 2018) 


\section{3) Typhoon model for the future typhoons}

\section{i) Typhoon central pressure}

Bias correction was adopted to the selected two typhoons. Detail of the typhoons are as shown in Table 4.2.1. From Table 4.2.1, one can know the time when the typhoon is at the point nearest to the designated one in Suo-nada Sea and the typhoon central pressure at the time before and after applying the correction. Besides the time of typhoon going across around Kyushu Island (north latitude $31 \sim 34$ degrees) is also on the table. Figure 4.2.4 compares the central pressure of typhoons before and after applying the bias correction. From Figure 4.2.4, it can be known that the pressure of $\mathrm{d} 4 \mathrm{PDF}$ is corrected to be raised around $10 \mathrm{hPa}$ when typhoons are on mid-latitude including the region around Kyushu Island, which have important effects to the results of storm surge simulations while the corrected pressure on the low-latitude is almost same as original pressure. At the point nearest to the designated one, typhoon central pressure was raised more than $10 \mathrm{hPa}$ about both typhoons. In order to reflect the correction to the storm surge simulations, typhoon model was composed base on the corrected central typhoon pressure.

Table 4.2.1 Detail of the future typhoons

\begin{tabular}{|c|c|c|c|}
\hline Typhoon & Time (nearest point) & Pressure $(\mathrm{hPa})$ & $\begin{array}{l}\text { Time (north latitude } \\
\text { 31 34 degree) }\end{array}$ \\
\hline $\begin{array}{l}\text { Strongest } \\
\text { typhoon }\end{array}$ & $\begin{array}{l}\text { 2066/ 8/ } 16 \text { 17:00 } \\
\text { (209 hours later) }\end{array}$ & $\begin{array}{c}904.88 \text { (before) } \\
916.77 \text { (after) }\end{array}$ & $\begin{array}{l}\text { 8/16 8:00 AM } ~ \\
\text { 8/17 0:00 AM } \\
\text { (200 216 hours later) }\end{array}$ \\
\hline $\begin{array}{l}5^{\text {th }} \text { strongest } \\
\text { typhoon }\end{array}$ & $\begin{array}{l}\text { 2067/ 8/ } 617: 00 \\
\text { (71 hours later) }\end{array}$ & $\begin{array}{c}921.01 \text { (before) } \\
935.14 \text { (after) }\end{array}$ & $\begin{array}{l}8 / 62: 00 \mathrm{AM} \sim \\
8 / 618: 00 \\
(56 \sim 72 \text { hours later })\end{array}$ \\
\hline
\end{tabular}
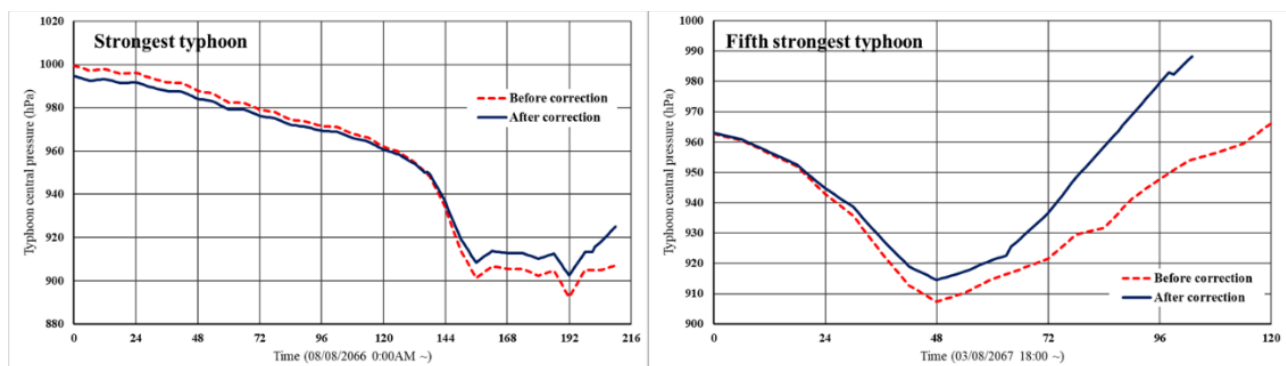

Figure 4.2.4 Comparison typhoon central pressure before and after the correction

\section{ii) Radius of maximum wind speed}

In preparing typhoon model, a radius of the maximum winds on every time step, which is the distance from the center of a typhoon to the point with maximum wind velocity, is one of the important factors. It can be determined by trial and error comparing theoretical pressure derived from Myer's equation with observed data at several stations. However, in this case the simulations intended to perform about future typhoons thus there is no available observed data. Therefore, radius of maximum wind speed was decided based on d4PDF by setting some sample points to do trial and error. 
Figure 4.2.5 (left side) shows the definition on the location of sample points. They were located every $5 \mathrm{~km}, 20$ or 50 spots for each four directions with center of typhoon as the starting-point i.e. in total 80 or 200 points, and pressure at the points were calculated by interpolating from the surrounding pressure distribution of d4PDF on each grid. And typhoon radius was determined as the sum of square errors being the smallest. Example of the results of trial and error on typhoon radius with four directions can be seen in Figure 4.2 .5 (right side).

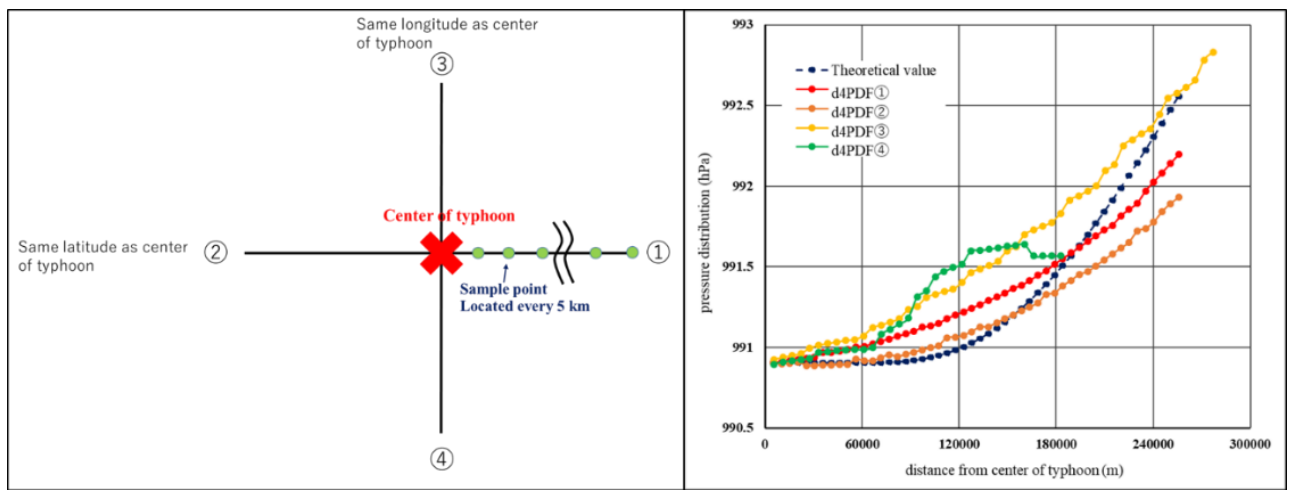

Figure 4.2.5 Definition on the location of sample points from d4PDF (left side) and Example of trial and error about typhoon radius with four directions (right side)

Radius of maximum wind speed was derived by using not only d4PDF with $60 \mathrm{~km}$ resolution but also d4PDF with $20 \mathrm{~km}$ resolution since the radius might be changed depending on the roughness of data's resolution. The derived radius on each time step is as shown in Figure 4.2.6. In general typhoon radius is mostly less than $200 \mathrm{~km}$ therefore it can be known that the radius of maximum wind speed in future typhoons is quite large. In addition, it is not caused by the roughness of data's resolution since the radius of maximum wind speed became large with both $60 \mathrm{~km}$ and $20 \mathrm{~km}$ resolution data. Moreover, the radius of $60 \mathrm{~km}$ resolution is larger than the one of $20 \mathrm{~km}$ in the early stage though the relationship turned over as time passing. It is because that the typhoon pressure of d4PDF with $20 \mathrm{~km}$ resolution is weaker than the one with $60 \mathrm{~km}$ resolution and usually radius of maximum wind speed becomes larger when the intensity of typhoon is lower. Hence future typhoons might have tendency to have larger typhoon radius comparing to the present. Also comparing the radius derived by 20 points with the one by 50 points, it can be seen that there is a little difference between them though radius obtained by 20 points are relatively smaller than the other. Also since sample points were located every $5 \mathrm{~km}$, radius obtained by 50 points was calculated with taking into account the effect of the spots which is $250 \mathrm{~km}$ far from the central typhoon while another one does for only $100 \mathrm{~km}$. Thus one can say that radius calculated by 20 points reflected the effect of surrounding area more compared to the other one hence radius of maximum wind speed derived by 20 sample points from d4PDF with $60 \mathrm{~km}$ resolution were selected to apply the simulations. 

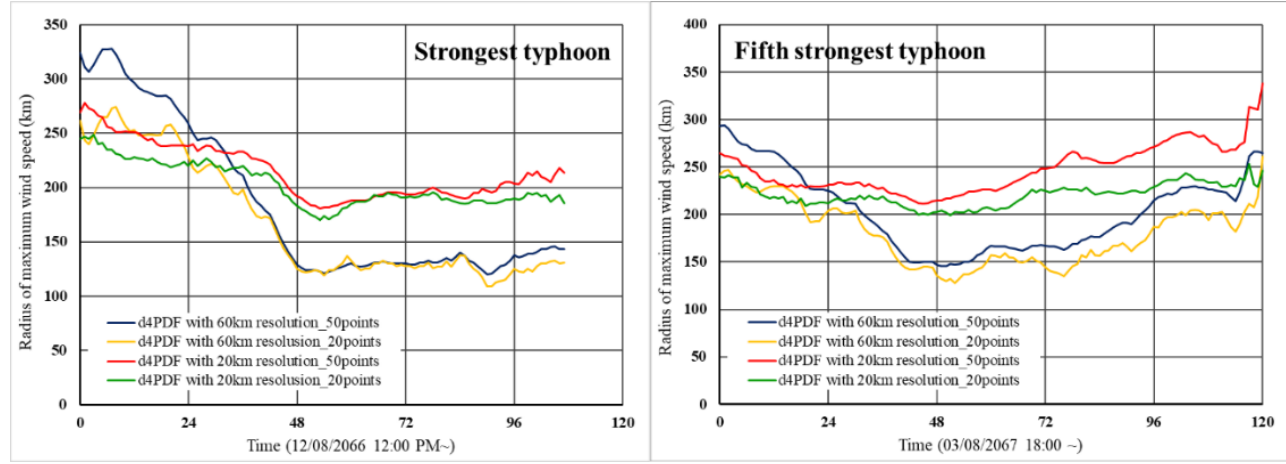

Figure 4.2.6 Time series on derived radius of maximum wind speed about selected two typhoons

Figure 4.2.7 compares the pressure distribution of d4PDF with theoretical one calculated by the derived radius at the specific time randomly chosen. From the figure, theoretical value is fitting with the pressure distribution of d4PDF enough. This verification was carried out about not only one but also several time and similar precision was observed though the accuracy was not good when typhoon is at lowlatitude, which does not effect to the surge simulation of Suo-nada Sea. Hence it can be concluded that the typhoon radius in Figure 4.2.6 should be appropriate enough and based on this radius, future typhoon was created with typhoon model and future storm surge simulations were performed.

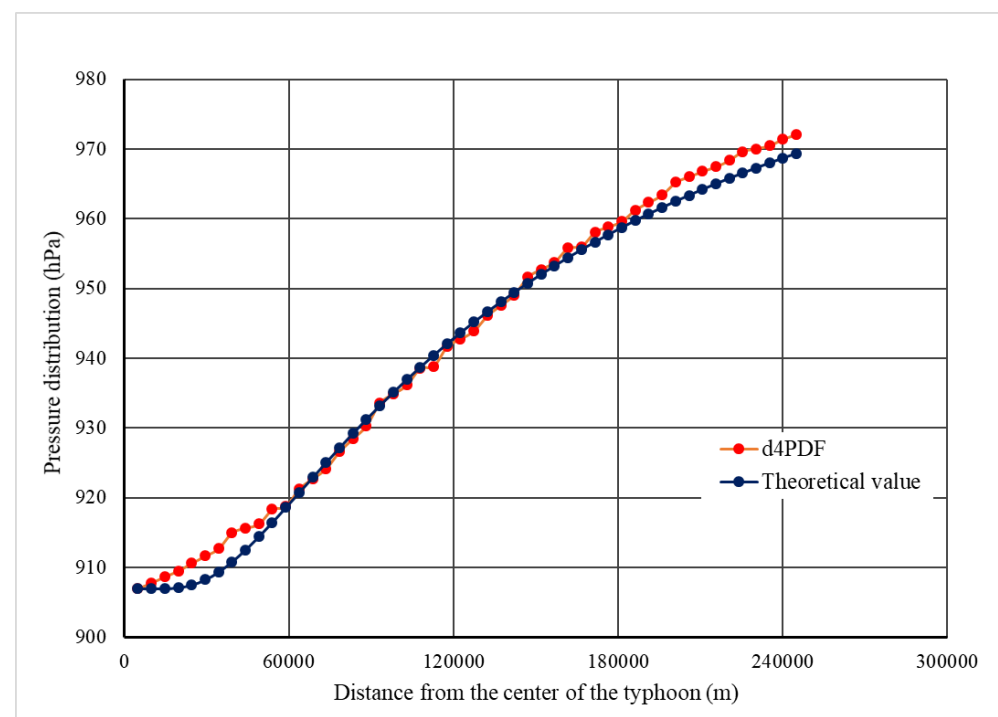

Figure 4.2.7 Verification on derived radius of maximum wind speed 


\subsection{Storm surge simulations with future typhoon using typhoon model 1) Damped effects of typhoons by passing through the land}

It is widely known that the intensity of typhoon is fading out while passing through land area due to the friction between land. Also in general, several hypothetical typhoons are created by shifting the original typhoon track in parallel and the simulations with them are performed for studying the worst typhoon path in the objective sea area. However, in the case that when translated typhoons are passing through land though the original track is going through only sea area, the damped effects of typhoon passing through the land is not included. Thus in order to improve this i.e. for including the typhoon fading in the typhoon model, the relationship between the rise of typhoon central pressure and total time of typhoon passing through land area was investigated by using BT which is available from 1951 to 2018 . The topographical data used for the investigation is as shown in Figure 4.3.1, which shows a ratio of land area in the area of a grid whose resolution is $20 \mathrm{~km} .1 .0$ means $100 \%$ land while 0.0 means $0 \%$ i.e. only sea. Typhoons using in the investigation were extracted from all BT data based on the same definition as 4.11 ).

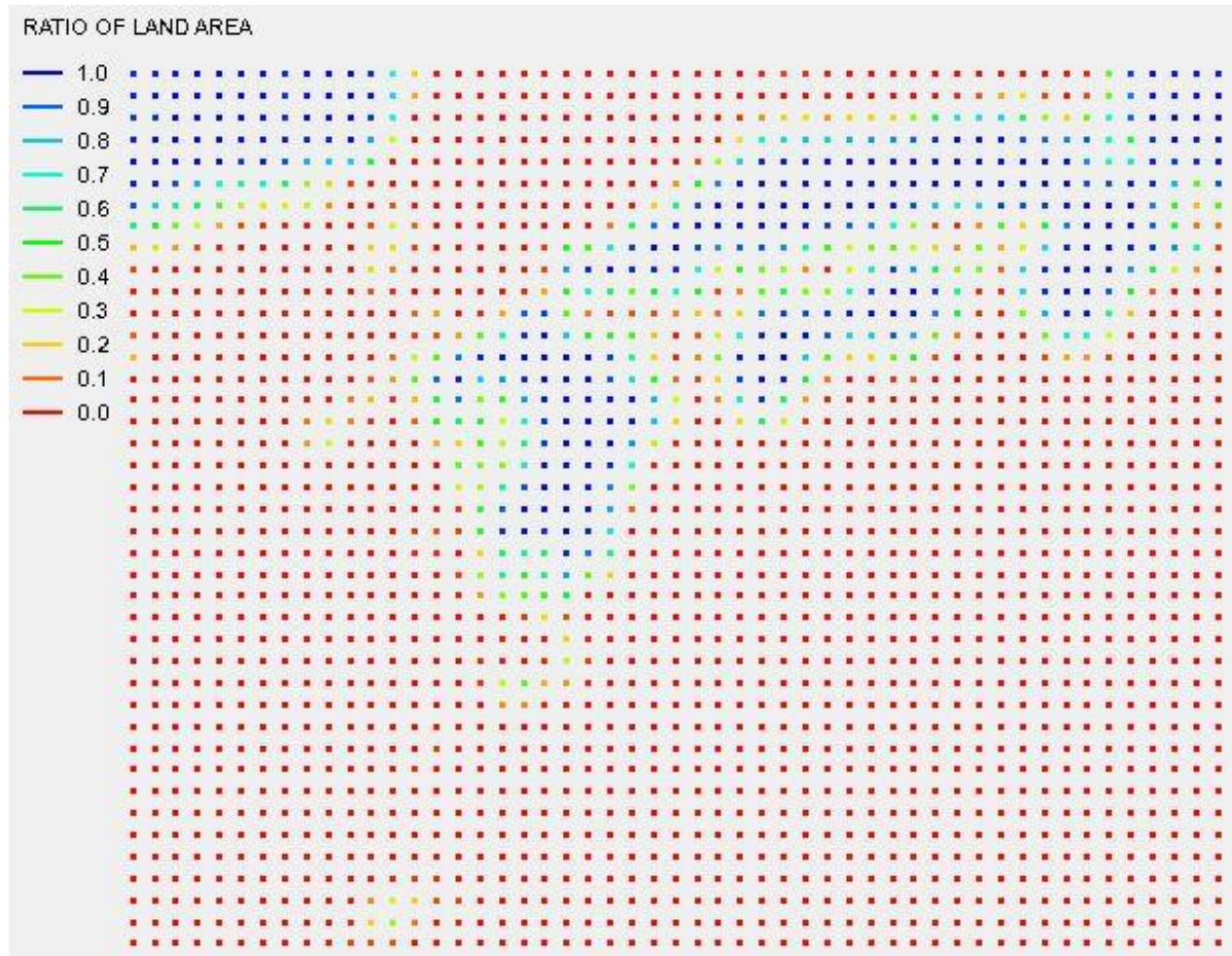

Figure 4.3.1 Topographical data used for the investigation on the damped effect of typhoons

Typhoon track data is existed every one hour and a land ratio of the grid which the typhoon was located was applied as the land ratio of each typhoon track point. And the ratio value was summed up when typhoon was in the range of north latitude 31 
34 degree. The summed up ratio value can be defined as total time of typhoon passing through land since the land ratio was added every one hour. In addition, the central pressure of typhoon at 31 degree of north latitude (the end of Kyushu island) was compared with the one at 34 degree of north latitude (the top of Kyushu island) and the rise of pressure was calculated for each typhoon. Figure 4.3.2 plots the derived amount of pressure rising for all objective typhoons; in total there are 207 typhoons to be analyzed.

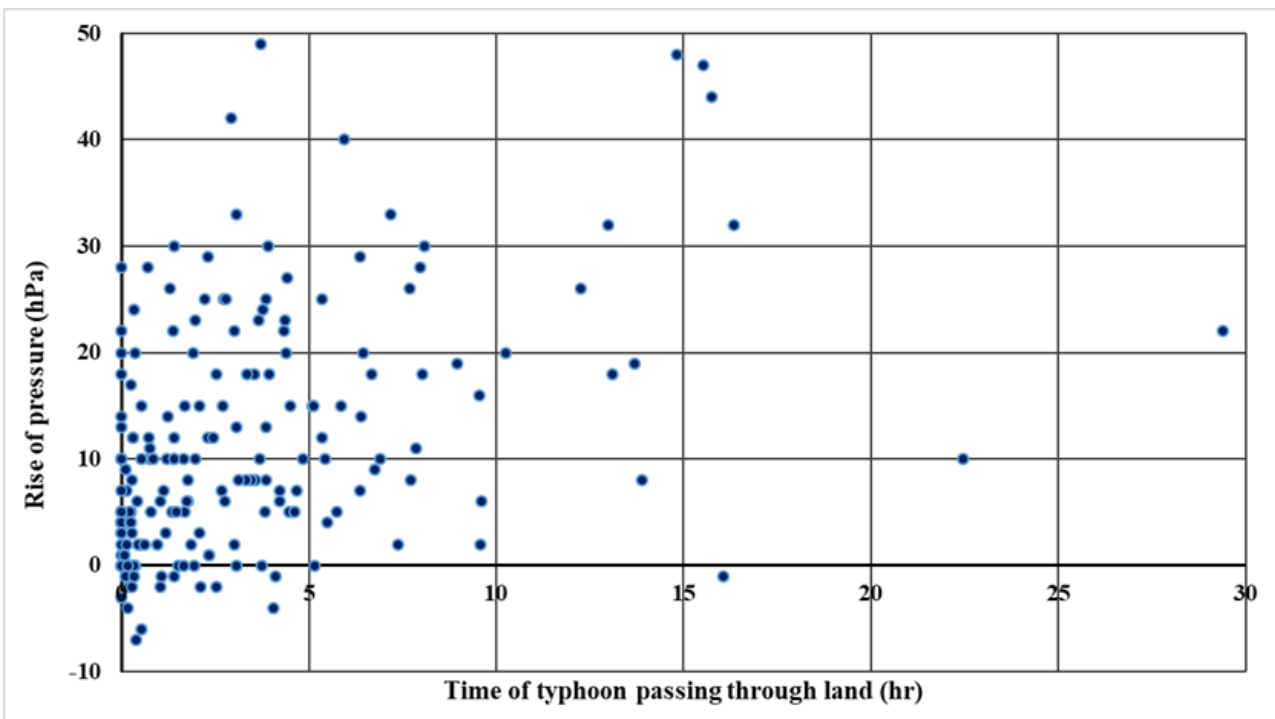

Figure 4.3.2 Plots on amount of central pressure rising with time axis of typhoon passing through land for all objective typhoons

In order to express the damped effect mathematically, the number of typhoons were counted for the specific time range and the rise of pressure was averaged for typhoons belonging to each time range. In order to determine the most suitable time rage to be averaged, some attempts were made as shown in Figure 4.3.3. Columns in the left of Figure 4.3.3 express the relationship the rise of pressure with time of typhoon passing through land and from box plots in the right of Figure 4.3.3 one can know the variation of the data in the time range. From the box plots, it is known that the variation of data increase when typhoon was on land longer. Moreover, Figure 4.3.2 tells that the number of sample is getting less as time passing thus it seems that one should analyze the typhoon data only which is in the range of $0 \sim$ around 10 hours on the land. Furthermore, since the time which typhoons were on land is not exactly correct due to the definition; the time was derived by adding the land ratio hourly which is the nearest to the typhoon at each time therefore the time must have a certain amount of errors. Hence it might be better not to separate the typhoons which have 0 hours as the time i.e. the ones going through only sea area. 

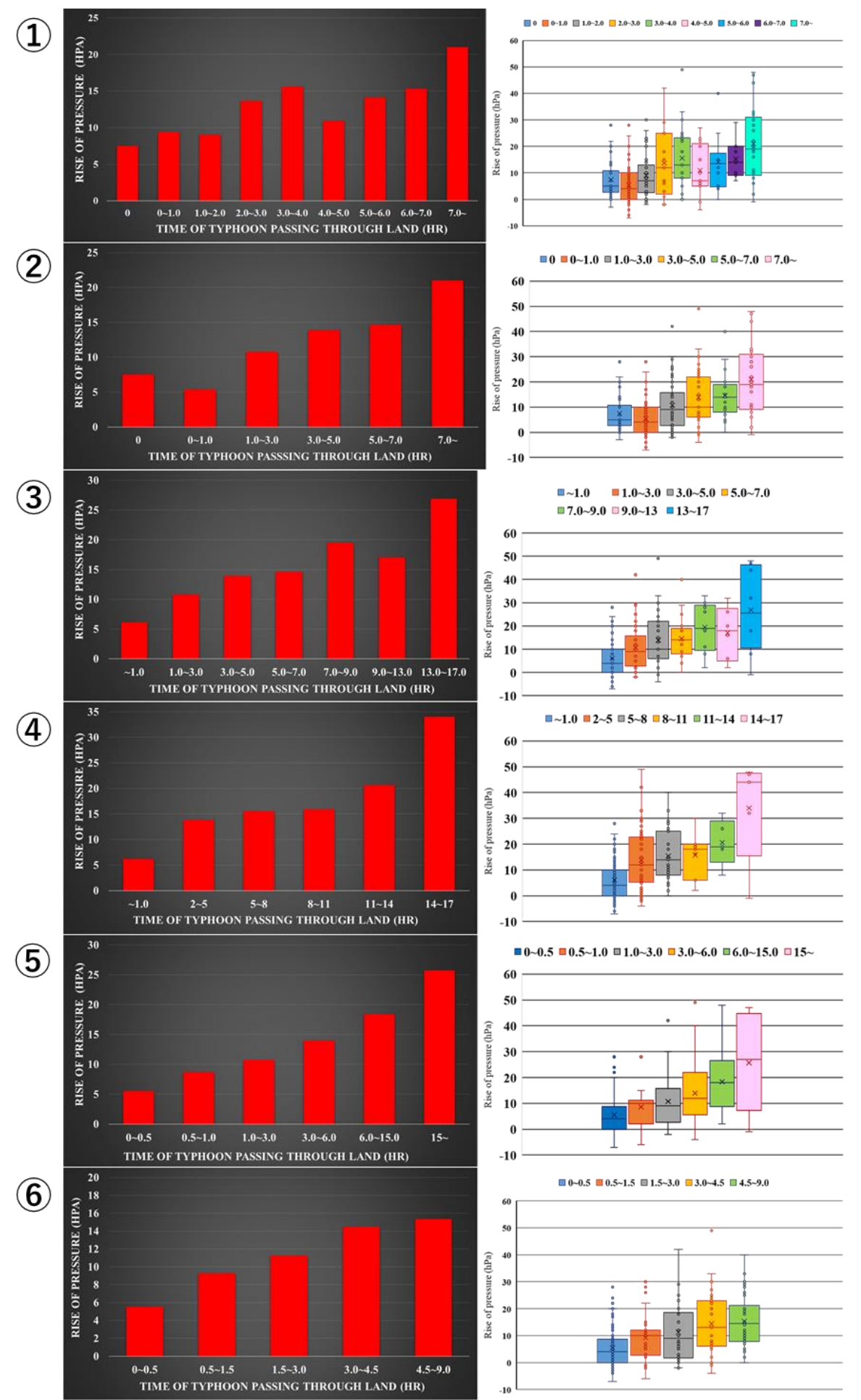

Figure 4.3.3 Relationship between the pressure rising and time of typhoon passing through land (left side), and its box plot (right side) 
Figure 4.3.4 shows approximate curves of Figure 4.3.3 within range of $0 \sim$ around 10 hours by power approximation which seems to fit the best with each plot. The approximation curves were created except for (1) and (2) in Figure 4.3.3. From Figure 4.3.4, it can be seen that almost similar coefficients are composing the approximation curve in each case. Table 4.3.1 tells how the data was divided in each case. Among the attempts, the one which was created for each time range to have the almost same number of samples (Number.6 in Figure 4.3.3 and 4.3.4) seems to be the best since all plots have almost same weight though the number of typhoons in 0 0.5 hours is doubled comparing the other time.

(3)

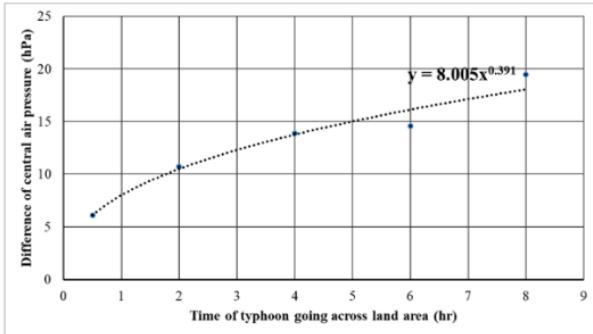

(5)

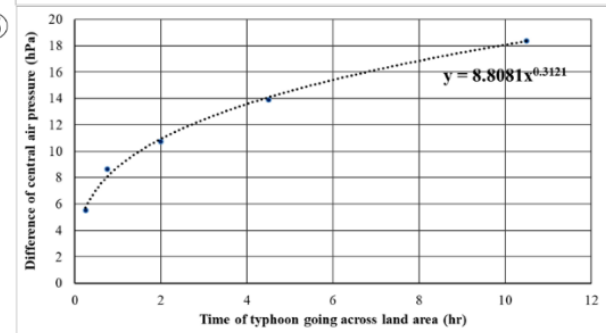

4

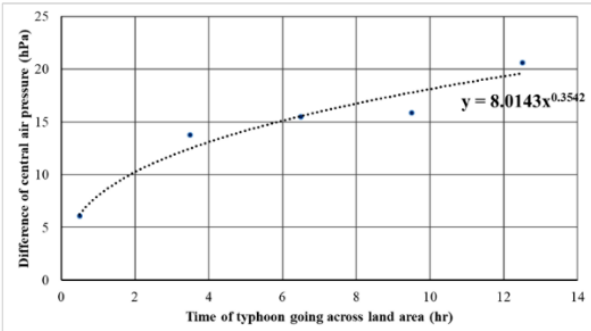

(6)

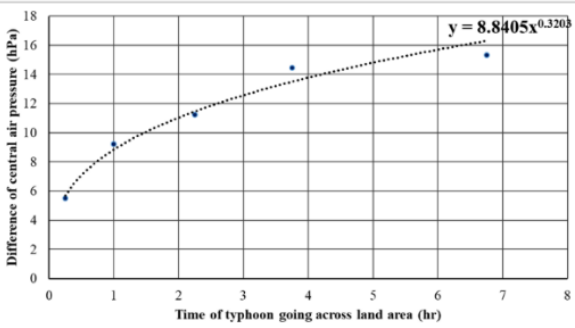

Figure 4.3.4 Approximate curves by power approximation

Table 4.3.1 Characteristics of each case

\begin{tabular}{|l|l|}
\hline Number & Characteristics \\
\hline 1 & Data is hourly and 0 hours (going through only sea area) is separated. \\
\hline 2 & $\begin{array}{l}\text { Data is every two hours except for the first one hour and 0 hours (going } \\
\text { through only sea area) is separated. }\end{array}$ \\
\hline 3 & Data is every two hours and 0 hours are included in first one hour. \\
\hline 5 & Data is every three hours and 0 hours are included in first one hour. \\
\hline 6 & $\begin{array}{l}\text { Data is divided randomly and 0 hours are included in first 0.5 hours. } \\
\text { samples and 0 hours are included in first } 0.5 \text { hours. }\end{array}$ \\
\hline
\end{tabular}

It was determined that the damped effect of typhoon going through land was considered by approximation curve of No.6 in Figure 4.3.4. However, one cannot use it directly since the first plot means the pressure decrease by not passing land area i.e. the natural typhoon's degradation so that the approximation curve needs to be 
subtracted the amount. Therefore, the equation within the red frame in Figure 4.3.5 expressing solid line is the one which should be used. According to the equation, the gradient of damped effect is decreasing as time of typhoon going across land area becomes longer.

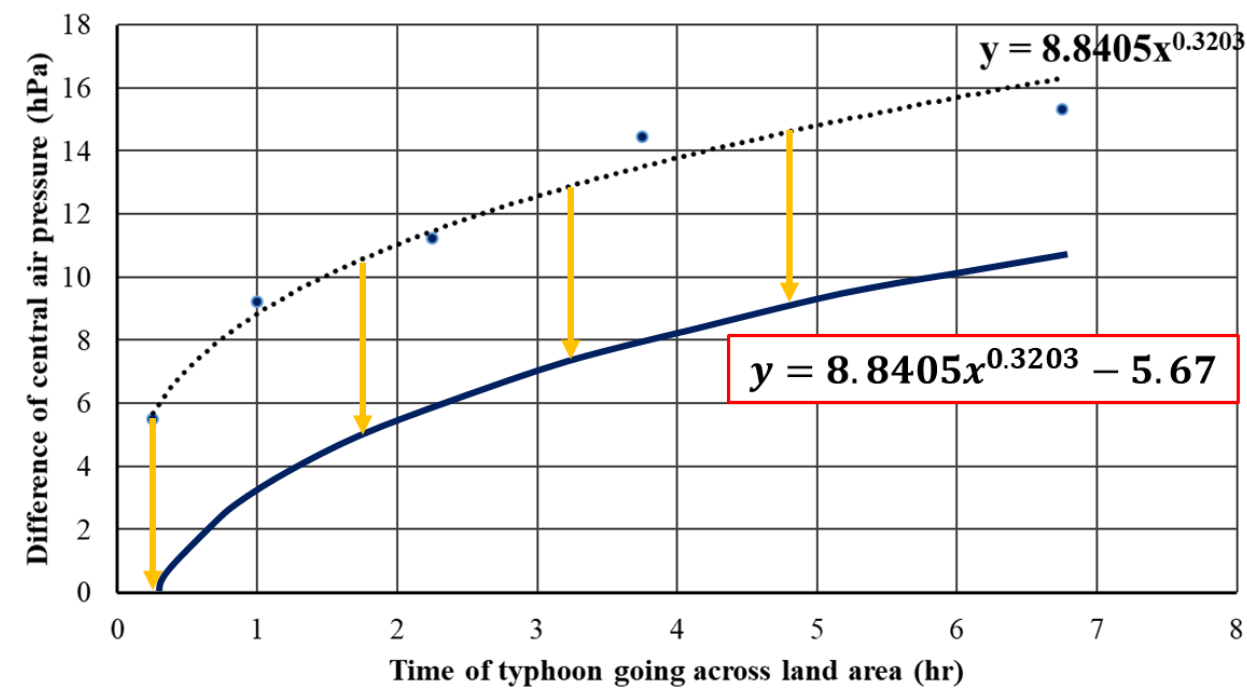

Figure 4.3.5 Corrected approximation curve (solid line) and equation (in red frame) on the damped effect of typhoon

\section{2) Simulations on future storm surge in Suo-nada Sea}

i) Comparison before and after the bias correction on central pressure of typhoon In chapter 3, it is shown that the storm surge simulaiton for the typhoons which is passing through west side of Suo-nada Sea have high accuracy. The both selected future typhoon have that kind of track thus the storm surge simulations using them should be comparatively precise.

\section{a) Fifth strongest typhoon}

Figure 4.3.6 shows the comparison of the results using the fifth strongest typhoon obtained by d4PDF and typhoon model at each station. According to the figure, it can be known that the storm surge height by d4PDF is much higher than the one by typhoon model. It is because that the simulation with typhoon model applied bias correction about central typhoon pressure and the intensity of the typhoon was degraded by around $10 \mathrm{hPa}$. And also the results by typhoon model does not have clear peak value comparing with the one by d4PDF. Moreover, there are some gaps between them on the time of the peak; typhoon model has peak values earlier at every stations. Figure4.3.7 shows all results of 10 stations (See Figure 4.3.8). From the figure, one can see that the speed of surge propagation is almost similar between them. 

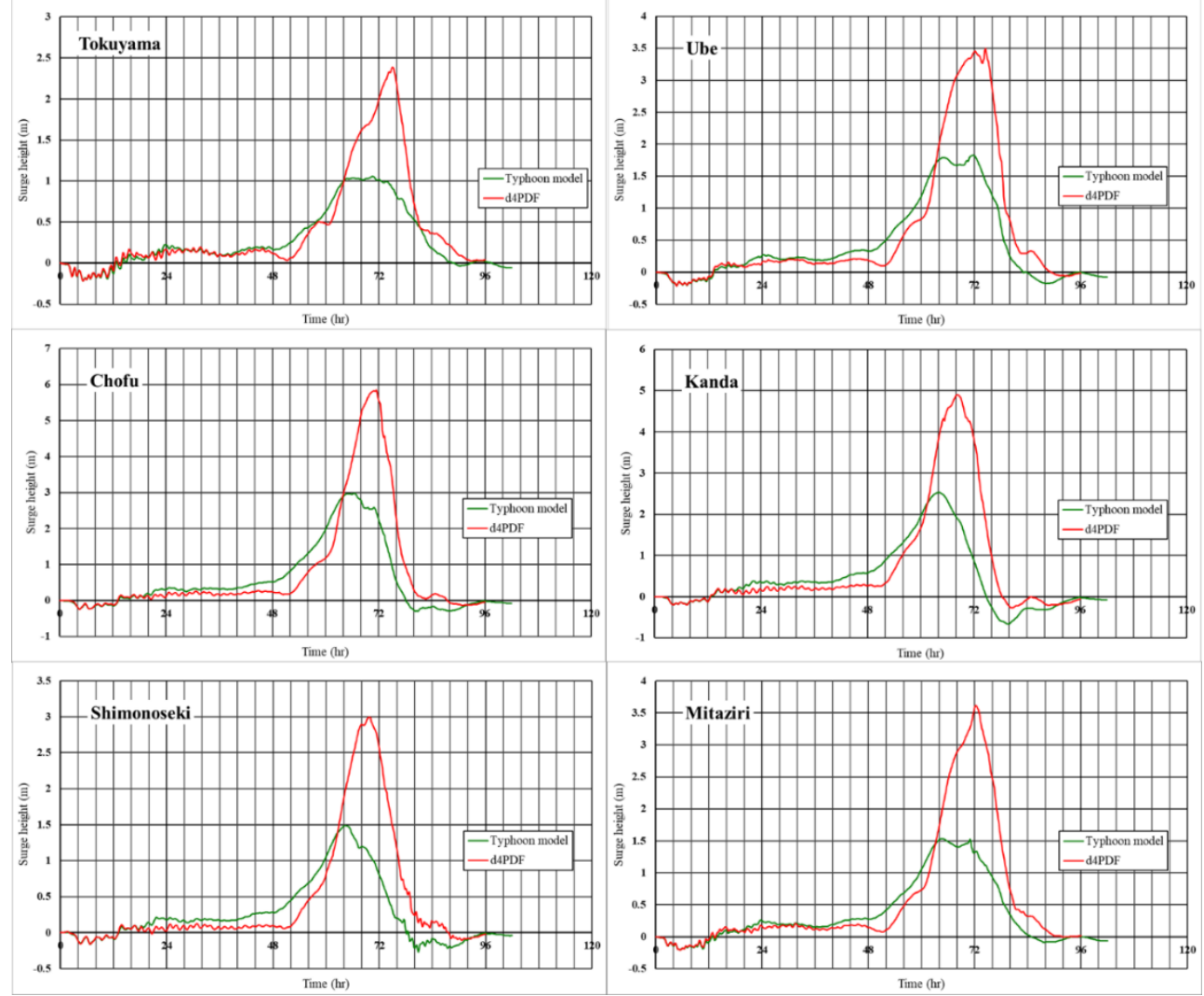

Figure 4.3.6 Comparison of the results by $d 4 P D F$ and typhoon model on the fifth strongest typhoon
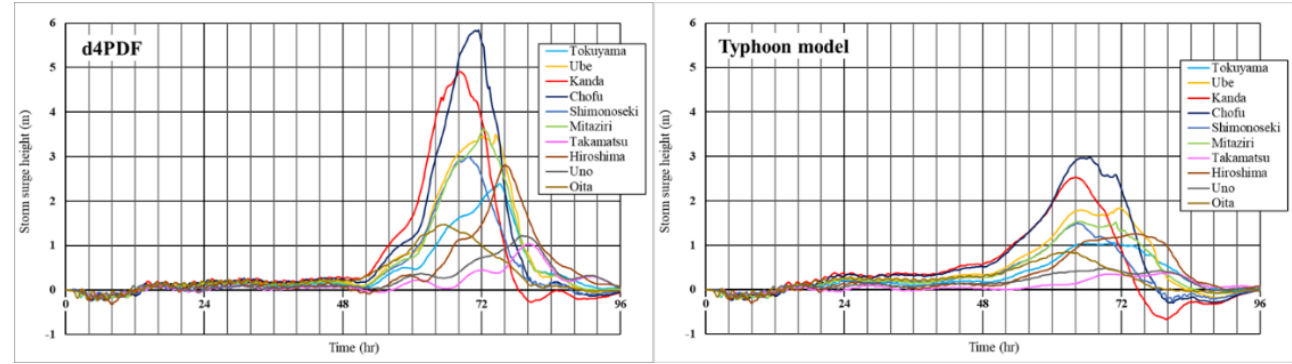

Figure 4.3.7 All results at 10 stations about both $44 P D F$ and typhoon model using the fifth strongest typhoon 


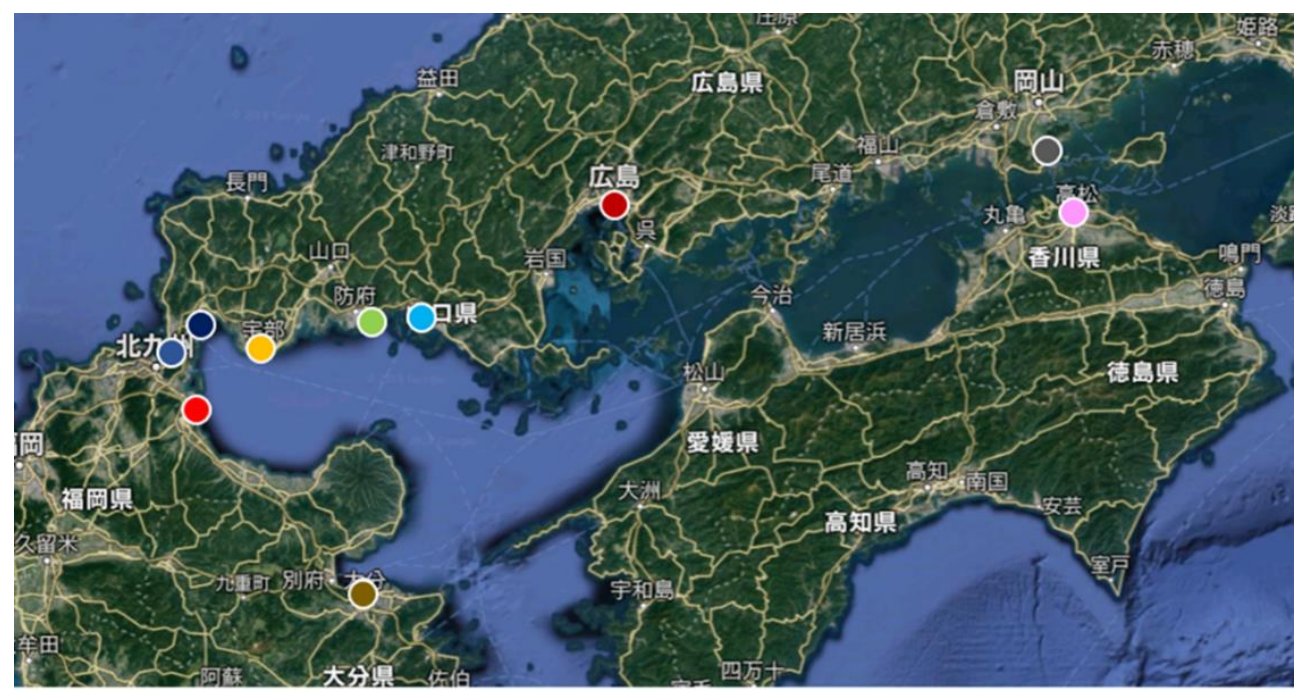

Figure 4.3.8 Location of the stations (the color of the point is corresponding to the line color in Figure 4.3.7 and Figure 4.3.10) (Google map, 2018)

\section{b) Strongest typhoon}

Figure 4.3.9 shows the results using the strongest typhoon by d4PDF and typhoon model. From the figure, it is seen that the time of the peak by typhoon model is almost same as the one by d4PDF while there were some gaps between them on the fifth strongest typhoon. Furthermore, the difference on the surge height of the fifth strongest typhoon is much larger than the strongest one; around $3.0 \mathrm{~m}$ is the maximum gap on the fifth strongest typhoon while around $0.5 \mathrm{~m}$ on the strongest one. It might be because that the strongest typhoon is much far from Suo-nada Sea comparing to the fifth strongest one hence the influence on the difference of external forces was less than the fifth one. Also the results by typhoon model have two peaks, there is the one before the highest at every stations. As a reason of the first peak, one can point out that the radius of maximum wind speed became smaller around the time of the first peak, (See Figure 4.2.6, yellow line) and accompanying with it, the range of an area blowing strong wind might become smaller. Hence it might be happened that the wind velocity around Suo-nada Sea became weak around that time and it would lead to the drop of the storm surge.

The results by typhoon model is stopped immediately after the peak. This is because that the typhoon track extracted from d4PDF disappeared soon after approaching to Suo-nada Sea (See Figure 4.2.2) though still the typhoon has $907.10 \mathrm{hPa}$ as the central pressure. Future typhoon track data was extracted from d4PDF when it was under the specific conditions defined as typhoon (Hiroyuki, et al., 2012). Thus the next points subsequent to the latest one (on August 17 ${ }^{\text {th }}$ in 2066) were out of the conditions and they were regarded as not typhoon hence the data was absence. Therefore, typhoon model could not be created after 0:00 on August 17 $7^{\text {th }}$ in 2066.

Also the results by d4PDF includes oscillations after around 104 hours from the start; its intensity depends on the location, and especially at Shimonoseki it became intense and the calculation seems to be unstable. 

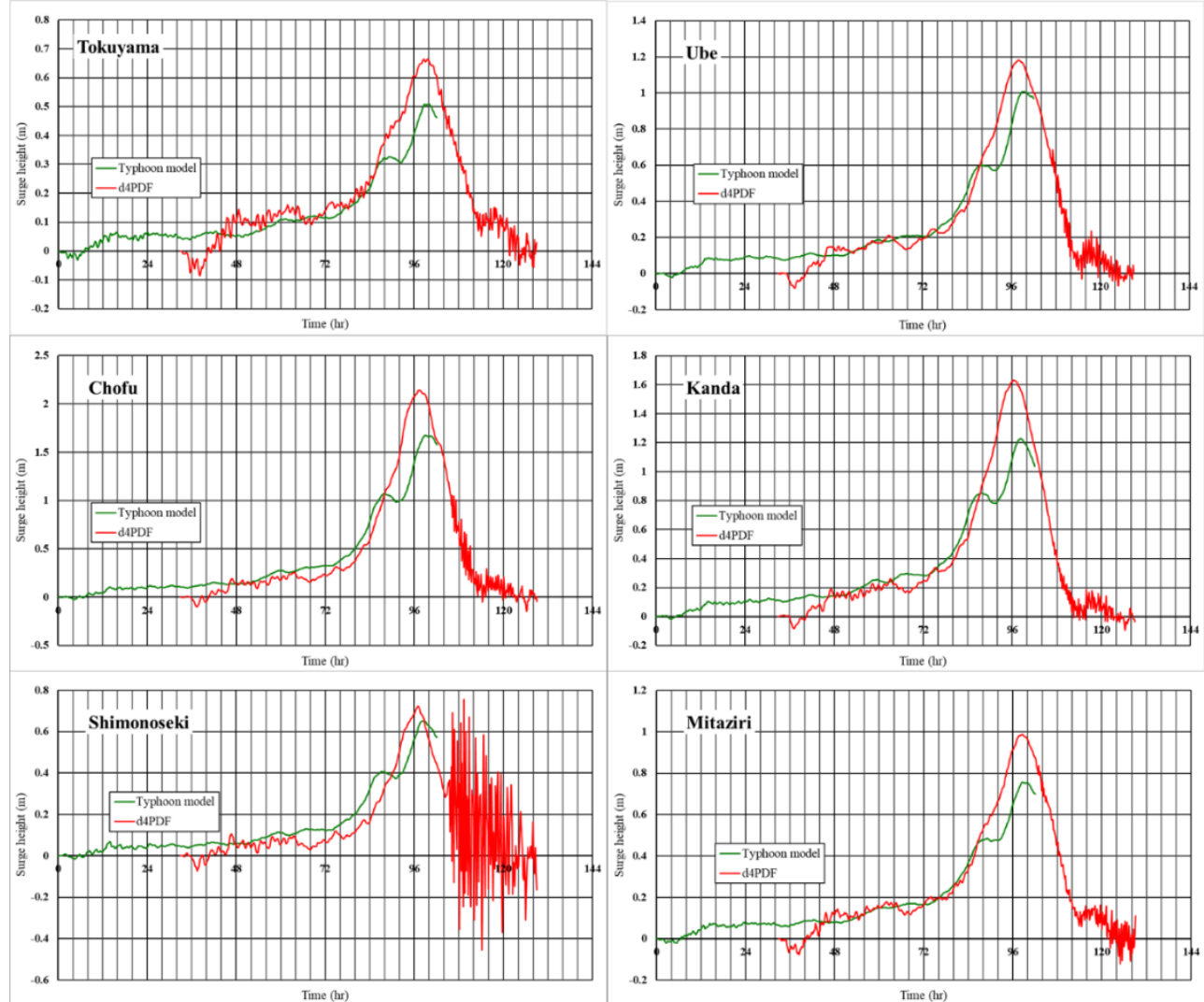

Figure 4.3.9 Comparison of the results by d4PDF and typhoon model on the strongest typhoon
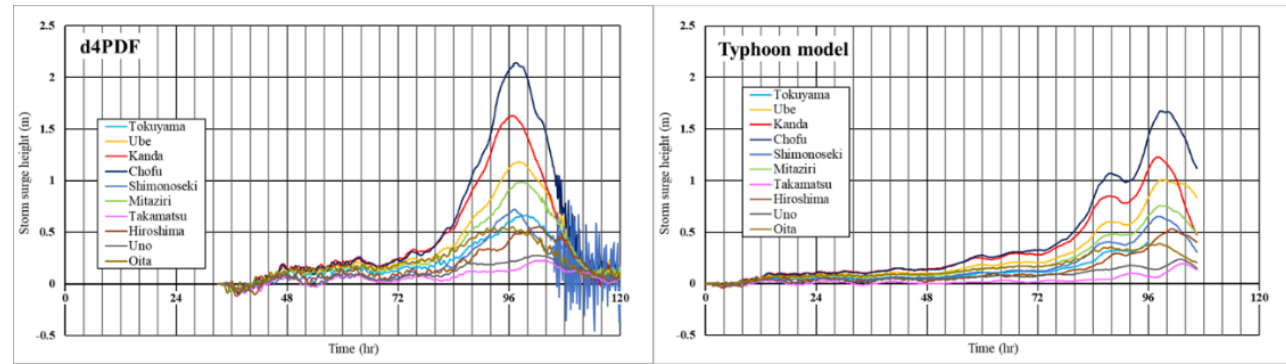

Figure 4.3.10 All results at 10 stations about both $44 P D F$ and typhoon model using the strongest typhoon (See Figure 4.3.8 about the locations of the stations) 


\section{ii) Simulations using hypothetical tracks with considering damped effect of typhoons}

In order to investigate the future storm surge in Suo-nada Sea more in detail, storm surge simulations were performed by using the empirical typhoon model for making hypothetical typhoon tracks which were created by parallel shift of the original one. As the original typhoon track, the strongest typhoon was selected. Since it is passing through only sea area, when the hypothetical tracks come to go across land as a result of parallel translation, the damped effect of typhoon was included in the simulations. Typhoon tracks used in simulations are as shown in Figure 4.3.11. Red line is the original track and the others are created based on the original. There are 7 hypothetical tracks in total situated every 0.5 degree from the first one which was shifted 1.5 degree from the original.

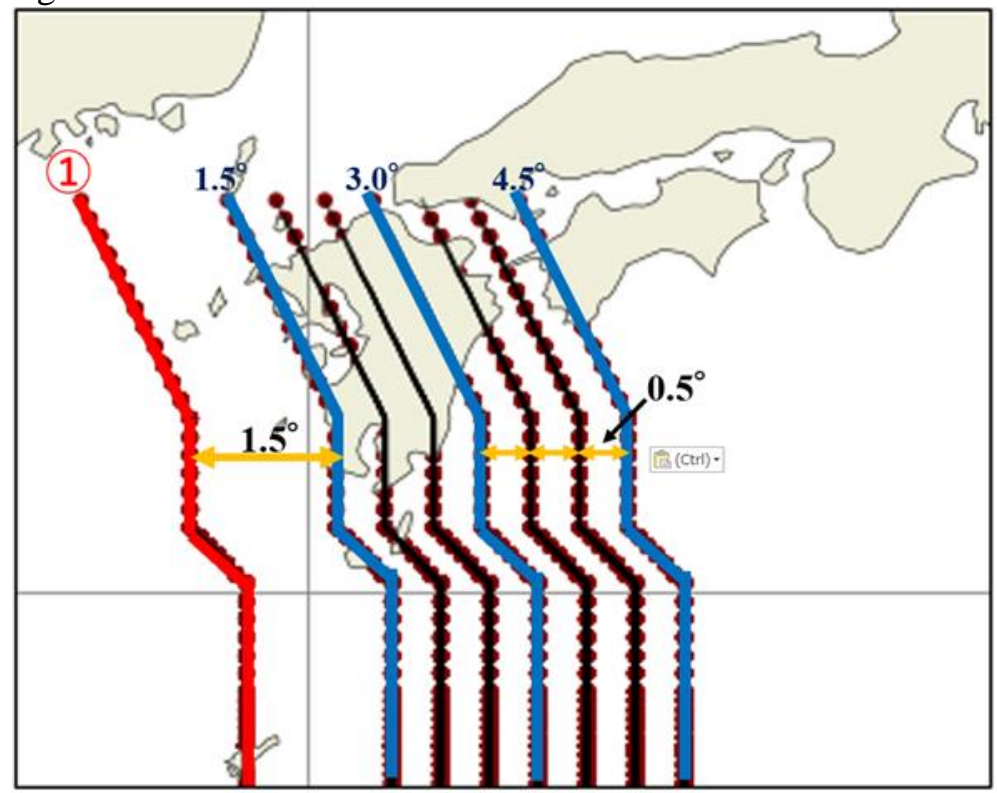

Figure 4.3.11 Typhoon tracks used for the future storm surge simulations

The results of the simulations are shown in Figure 4.3.12 and also one can check typhoon track of the results by Figure 4.3.13. In addition, Figure 4.3.14 shows the highest surge height and the typhoon leading to the surge at 6 points in Suo-nada Sea. From Figure 4.3.14, it can be known that typhoons created by 2.5 or 3.0 degrees' parallel shifted seem to be the dangerous to the sea area. Especially at inner part of Suo-nada Sea; Chofu, Kanda and Shimonoseki, typhoon shifted 2.5 degrees gave the highest surge height, almost $3.0 \mathrm{~m}$ at Chofu and Kanda. And Figure 4.3.12 indicates that at almost all stations, typhoon shifted 3.5 degree which is passing above Suo-nada Sea is as a border, the surge height is getting smaller as typhoon shifting to the east. Besides, when typhoon going through west side of Suo-nada Sea, the peak time comes earlier comparing to the typhoon passing through east side. Since the simulations included the damped effect of typhoon passing through land, if future storm surge was estimated by a traditional way, the results might be larger than the ones in Figure 4.3.12. 

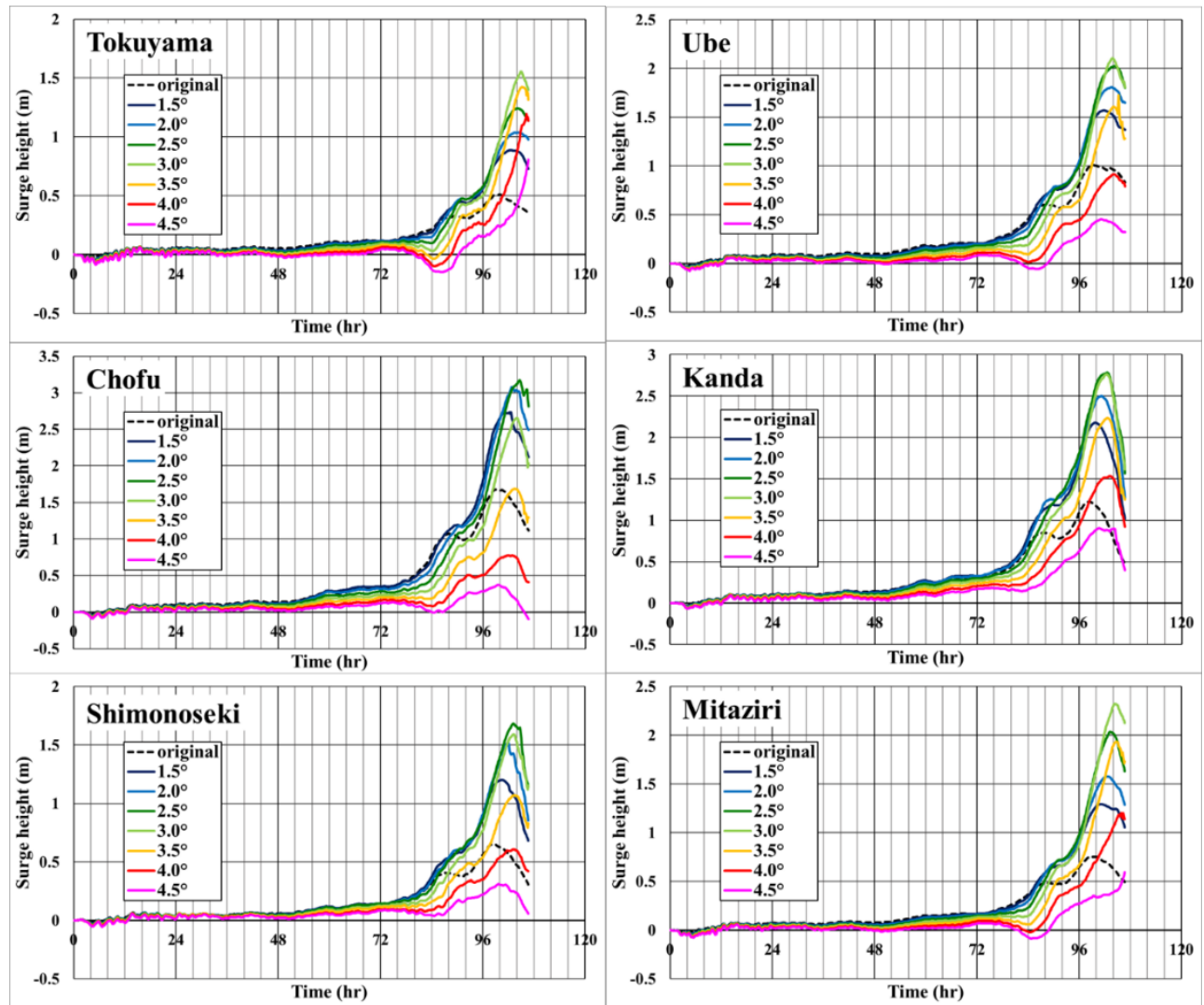

Figure 4.3.12 Future storm surge caused by the original and seven hypothetical typhoon tracks

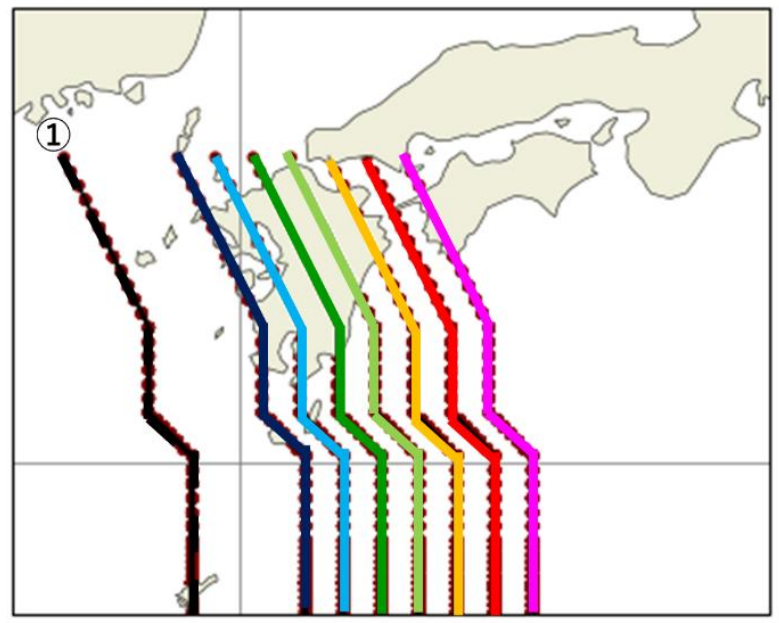

Figure 4.3.13 Typhoon tracks of the results in Figure 4.3.12 (Color of the lines is corresponding to the one of the results in Figure 4.3.12. Typhoon going through west side of Suo-nada Sea is expressed by cold color while warm color is used for the one going through east side.) 


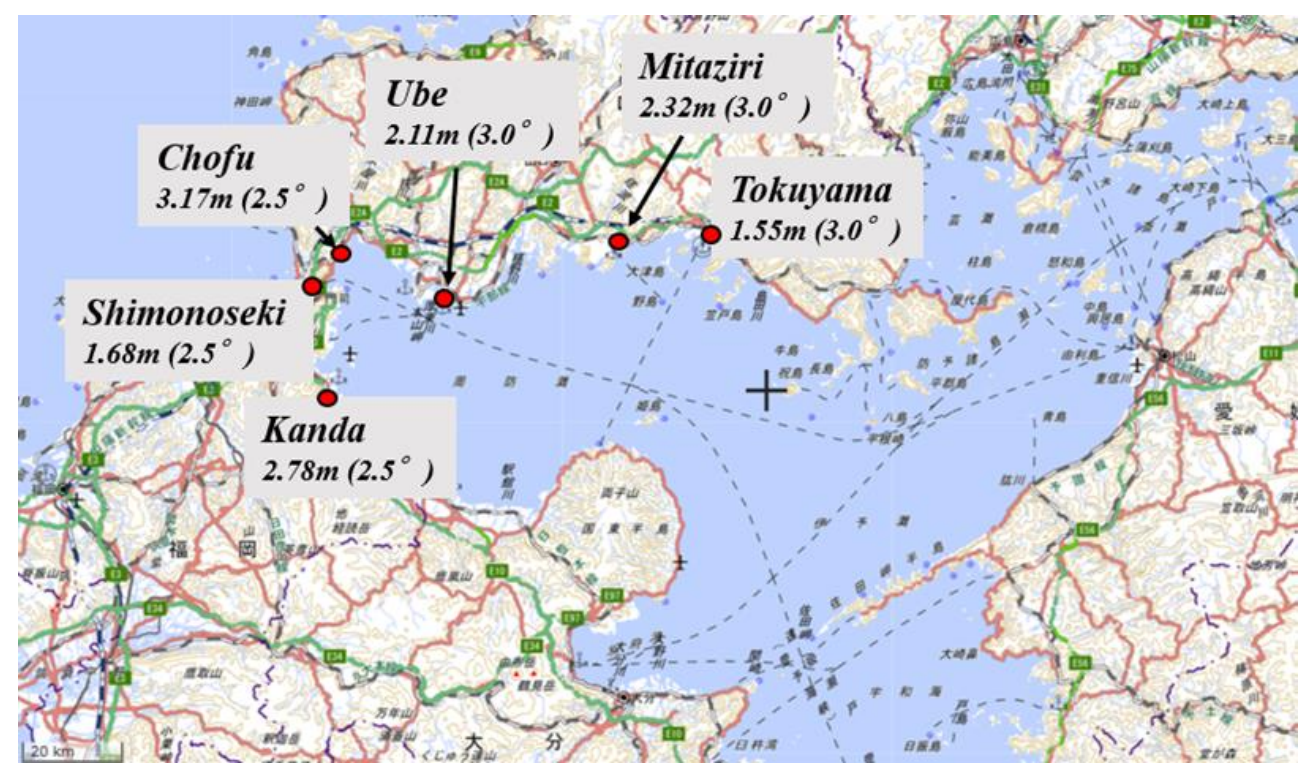

Figure 4.3.14 Highest surge height and typhoons caused the surge at 6 points in Suonada Sea (Geospatial Information Authority of Japan, 2018)

Figure 4.3.15 shows the maximum storm surge distribution obtained by each typhoon. Left side is the results by the typhoons passing through west side of Suo-nada Sea whereas right side is by the typhoons which is going through east side of the sea area. From the figures, it can be seen that the site where high storm surge occurred is moving from the northwest part of Suo-nada Sea to the southwest part of Suo-nada Sea as typhoon is shifting to the east.

Using the danger typhoons i.e. typhoons created by the original track shifted 2.5 or 3.0 degree, the several simulations were added without including typhoon's fade by passing through land in order to evaluate the damped effect. Figure 4.3.16 and 4.3.17 shows the pressure and wind speed distribution of the typhoons before and after considering the effect at the time when storm surge became high almost everywhere in Suo-nada Sea. About both pressure and wind distribution contours, as the color is getting similar to red, the intensity is getting stronger. Hence one can know that the typhoon got much weaker after including the damped effects in the simulations. Moreover, wind velocity of the typhoon shifted 3.0 degree was weaker than the one of the typhoon shifted 2.5 degree because the center of the 3.0 shifted typhoon was passing closer to Suo-nada Sea in contrast with the other one. Generally speaking, when typhoon is going across with the almost same distance as the radius of maximum wind speed, the storm surge is developed as the highest. In this case, typhoon has around $130 \mathrm{~km}$ as the radius hence the typhoon shifted 2.5 degree is the most dangerous from the hypothetical perspective as well. 


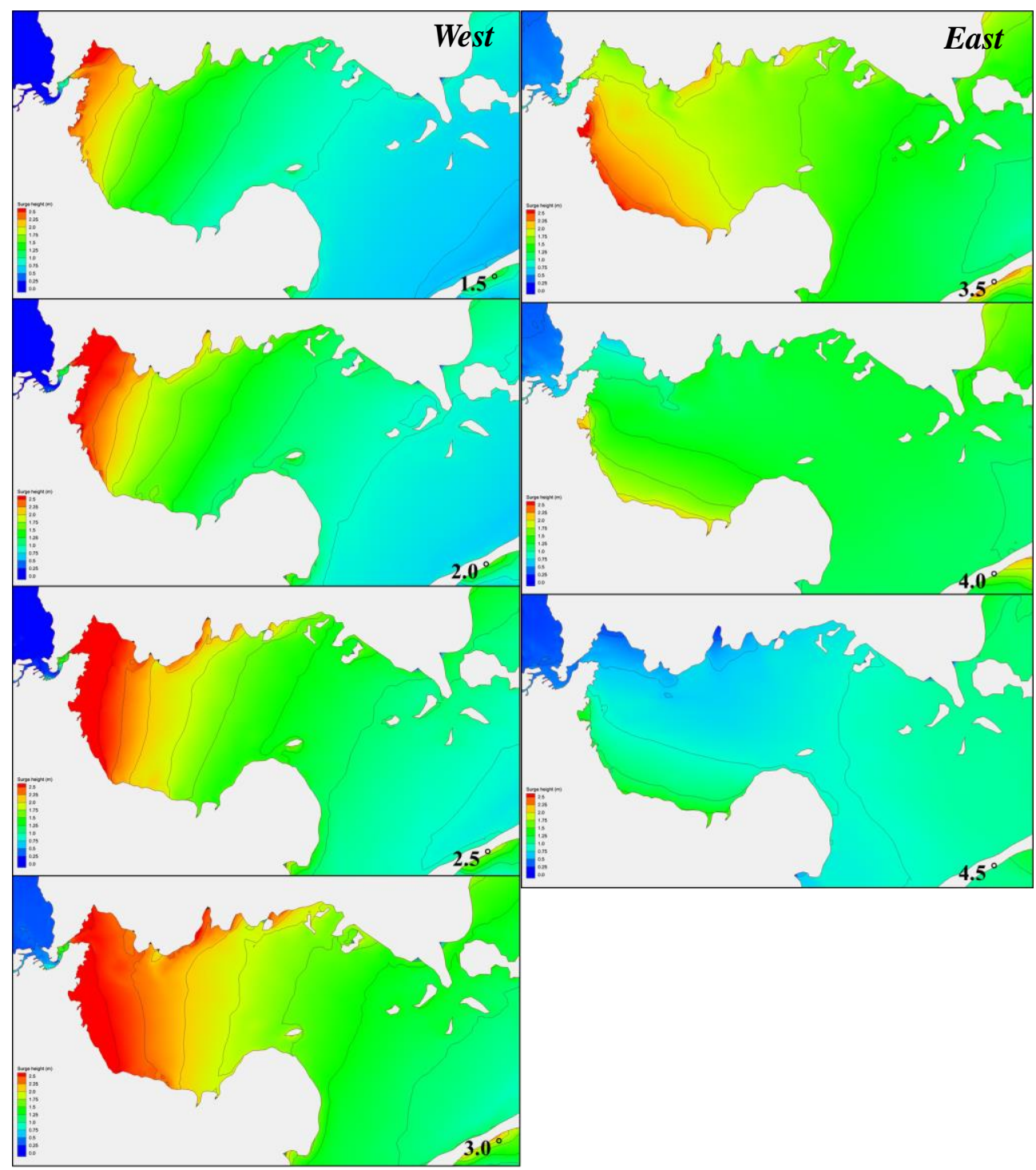

Figure 4.3.15 Maximum storm surge distribution of each typhoon (left side is the result obtained by using the typhoons passing through west side of Suo-nada Sea whereas right side is by the ones passing through east side of the sea area.) 


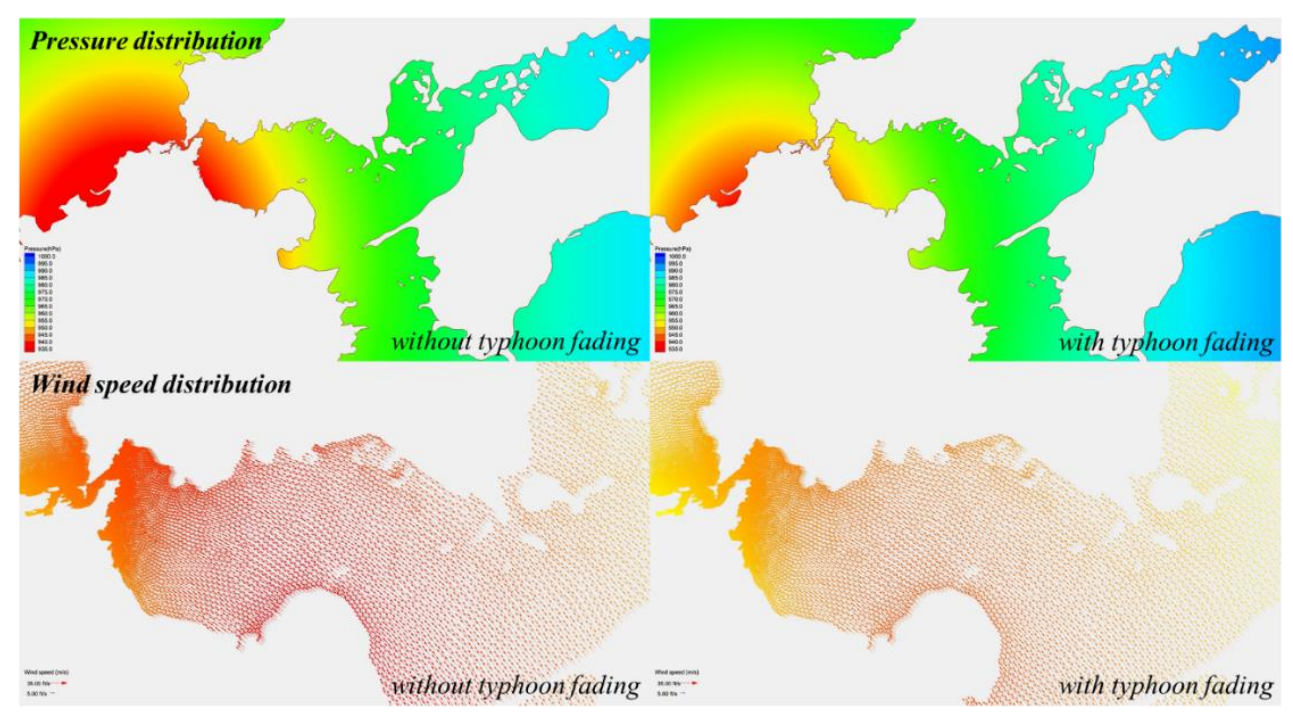

Figure 4.3.16 Pressure and Wind velocity distribution of typhoon shifted 2.5 degree when considering with and without typhoon fading

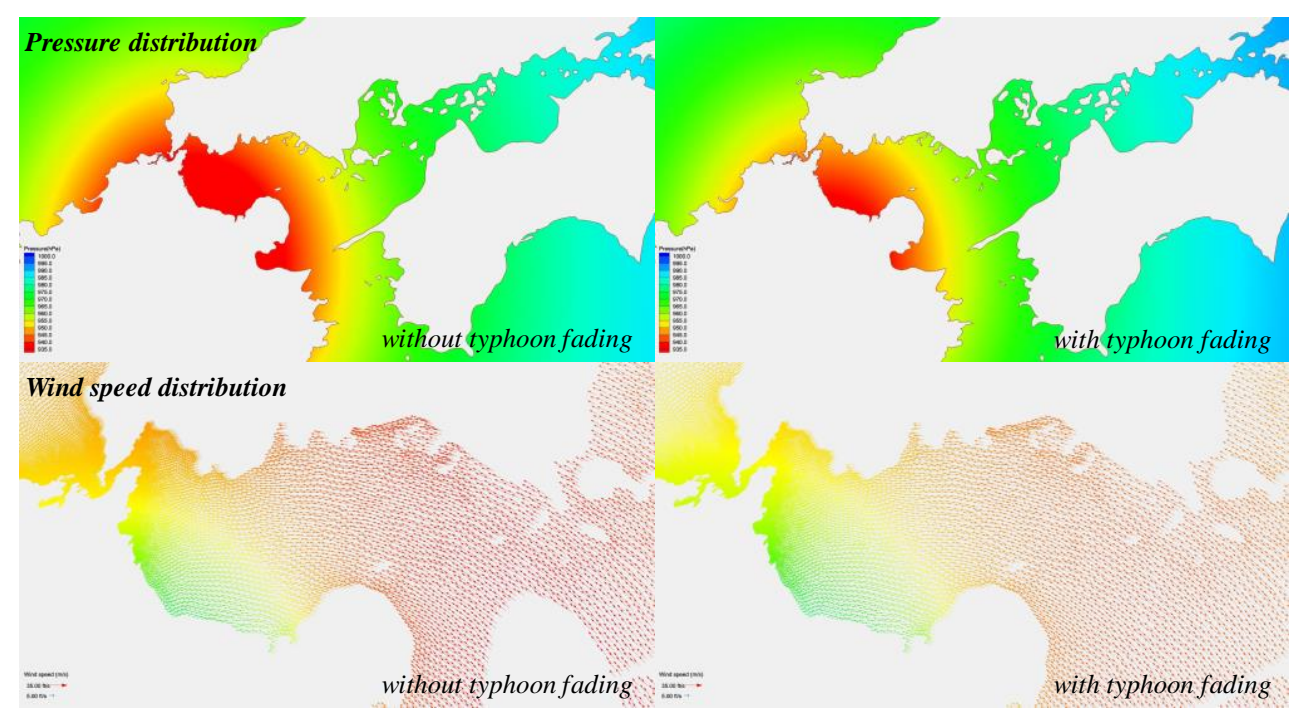

Figure 4.3.17 Pressure and Wind velocity distribution of typhoon shifted 3.0 degree when considering with and without typhoon fading 
The results are shown in Figure 4.3.18 with their tracks in Figure 4.3.19 and the details are in Table 4.3.2 4.3.4. As shown in Table 4.3.2, the time of typhoon going through land was determined as 11.12 hours for the typhoon shifted 2.5 degree and 9.03 hours for the one shifted 3.0 degree respectively. Thus the degradation of the typhoon central pressure could be calculated and $13.45 \mathrm{hPa}$ was subtracted in total from the one 2.5 degree shifted while $12.22 \mathrm{hPa}$ was for the one 3.0 degree shifted. They have only $1.23 \mathrm{hPa}$ difference since a power function was applied in making the approximation curve and the difference is getting smaller as $\mathrm{x}$-axis (in this case $\mathrm{x}$-axis is time that typhoon was on the land area) becomes larger. From Table 4.3.3 and 4.3.4, one can know that surge height became lower at every stations with almost same amount; around $14 \%$ minus for the 2.5 degree shifted typhoon whereas around $10 \%$ minus for the one 3.0 degree shifted. Chofu and Kanda are located on the inner apart of Suonada Sea and have a long fetch comparing with other sites. Hence the surge height there developed more than others for the two typhoons though the amount of surge declining is also large when the gaps are considered as meter. However, when one considers the declining pressure as ratio, the one at Kanda is the lowest among 6 stations. Moreover, the point which have highest declining ratio is Mitaziri and also it might be able to say that the storm surge at north part of Suo-nada Sea (Mitaziri, Tokuyama and Ube) subject to the change of typhoon's intensity. Furthermore, focusing on the results at Ube the highest storm surge height was caused by different typhoon before and after considering the damped effect. Before including the damped effect, the highest storm surge was generated by the typhoon shifted 2.5 degree whereas it changed to be the other one after including the effect although the difference between the surge by the typhoon 2.5 degree shifted and 3.0 degree shifted is slight. At Kanda before considering the damped effect, the highest surge was caused by the typhoon 2.5 degree shifted and there were $0.16 \mathrm{~m}$ gaps between the one caused by 3.0 degree shifted, however, their surge height became almost same after including the effect. 

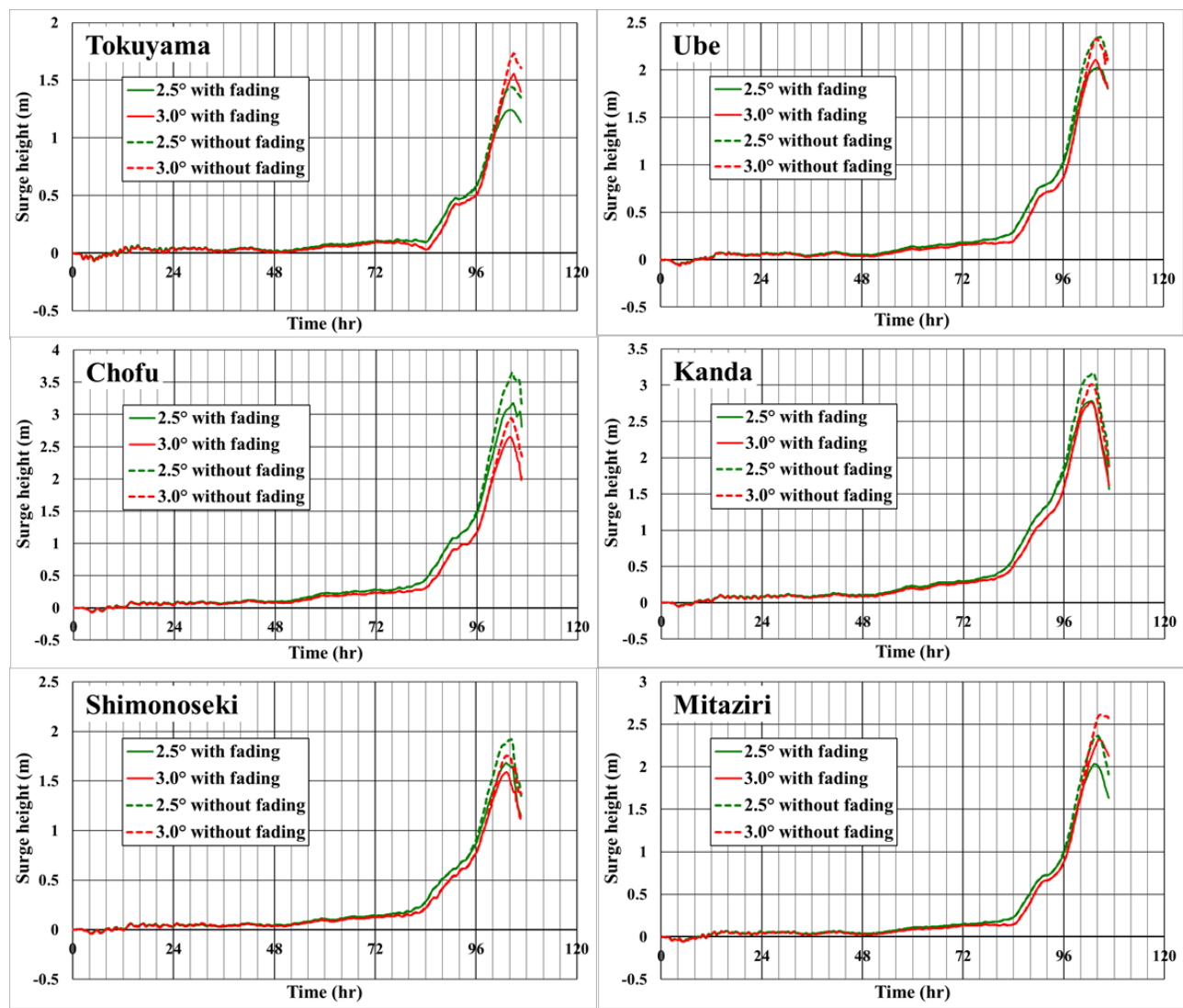

Figure 4.3.18 Comparison of the results with and without considering typhoon's fade

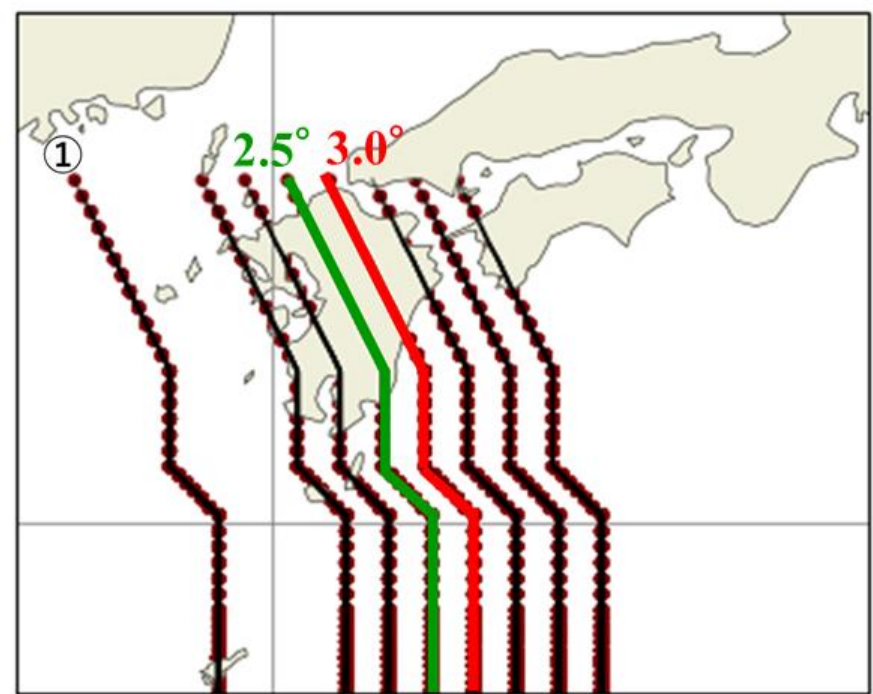

Figure 4.3.19 Typhoon tracks using the simulations 
Table 4.3.2 Time of each typhoon passing through land and the degraded pressure

\begin{tabular}{|l|c|c|}
\hline & 2.5 degree & 3.0 degree \\
\hline Total time typhoon passing though land & 11.12 hours & 9.03 hours \\
\hline Drop of central pressure of typhoon & $13.45 \mathrm{hPa}$ & $12.22 \mathrm{hPa}$ \\
\hline
\end{tabular}

Table 4.3.3 Comparison of surge height between with and without considering typhoon's fading (2.5 degree)

\begin{tabular}{|l|l|l|l|l|l|l|}
\hline & Tokuyama & Ube & Kanda & Shimonoseki & Chofu & Mitaziri \\
\hline $\begin{array}{l}\text { Without } \\
\text { fading }\end{array}$ & $1.44 \mathrm{~m}$ & $2.35 \mathrm{~m}$ & $3.17 \mathrm{~m}$ & $1.92 \mathrm{~m}$ & $3.65 \mathrm{~m}$ & $2.36 \mathrm{~m}$ \\
\hline $\begin{array}{l}\text { With } \\
\text { fading }\end{array}$ & $1.24 \mathrm{~m}$ & $2.02 \mathrm{~m}$ & $2.78 \mathrm{~m}$ & $1.68 \mathrm{~m}$ & $3.17 \mathrm{~m}$ & $2.03 \mathrm{~m}$ \\
\hline $\begin{array}{l}\text { Decline } \\
\text { of storm } \\
\text { surge }\end{array}$ & $\begin{array}{l}0.2 \mathrm{~m} \\
(-14 \%)\end{array}$ & $\begin{array}{l}0.33 \mathrm{~m} \\
(-14 \%)\end{array}$ & $\begin{array}{l}0.39 \mathrm{~m} \\
(-12 \%)\end{array}$ & $\begin{array}{l}0.24 \mathrm{~m} \\
(-13 \%)\end{array}$ & $\begin{array}{l}0.48 \mathrm{~m} \\
(-13 \%)\end{array}$ & $\begin{array}{l}0.33 \mathrm{~m} \\
(-14 \%)\end{array}$ \\
\hline
\end{tabular}

Table 4.3.4 Comparison of surge height between with and without considering typhoon's fading (3.0 degree)

\begin{tabular}{|l|l|l|l|l|l|l|}
\hline & $\begin{array}{l}\text { Tokuyam } \\
\mathrm{a}\end{array}$ & Ube & Kanda & Shimonoseki & Chofu & Mitaziri \\
\hline $\begin{array}{l}\text { Without } \\
\text { fading }\end{array}$ & $1.73 \mathrm{~m}$ & $2.33 \mathrm{~m}$ & $3.01 \mathrm{~m}$ & $1.75 \mathrm{~m}$ & $2.94 \mathrm{~m}$ & $2.61 \mathrm{~m}$ \\
\hline $\begin{array}{l}\text { With } \\
\text { fading }\end{array}$ & $1.55 \mathrm{~m}$ & $2.11 \mathrm{~m}$ & $2.77 \mathrm{~m}$ & $1.59 \mathrm{~m}$ & $2.65 \mathrm{~m}$ & $2.32 \mathrm{~m}$ \\
\hline $\begin{array}{l}\text { Decline } \\
\text { of storm } \\
\text { surge }\end{array}$ & $\begin{array}{l}0.18 \mathrm{~m} \\
(-10 \%)\end{array}$ & $\begin{array}{l}0.22 \mathrm{~m} \\
(-9.4 \%)\end{array}$ & $\begin{array}{l}0.24 \mathrm{~m} \\
(-8.0 \%)\end{array}$ & $\begin{array}{l}0.16 \mathrm{~m} \\
(-9.1 \%)\end{array}$ & $\begin{array}{l}0.29 \mathrm{~m} \\
(-9.9 \%)\end{array}$ & $\begin{array}{l}0.29 \mathrm{~m} \\
(-11 \%)\end{array}$ \\
\hline
\end{tabular}




\section{3) Discussion on future storm surge in Suo-nada Sea}

From the investigation on future typhoon trend, it can be known that the usual typhoon track might change in the future from going towards north-east to north. The way of storm surge developing in Seto-Inland Sea which is an enclosed coastal sea strongly depends on the typhoon tracks and its slight shifting to east or west will lead to a big difference even the pattern of the tracks is similar. When typhoon which have a track like T0416 i.e. when typhoon traveling from south-west to north-east, the tidal level at the areas on east part of Seto-Inland Sea such as Himezi and Kobe tends to be promoted to rise more by the propagated high wave from west part (Moemi, et al., 2007). Also K.Komai, et al., (2005) said that when typhoon approaching Kyushu island from southern sea area, the propagation of storm surge to an inland sea mainly from Bungo-Channel can be seen and scale of storm surge amplifies when it proceeding to east. Hence the usual storm surge trend in Suo-nada Sea also might change accompanied with typhoon tracks. Furthermore, if an unusual typhoon which moves from south-east to north-west is generated, the high tidal level led by large amount of sea water supplied through Kii-Channel is propagated from east side of Seto-Inland Sea to Suo-nada Sea and can make storm surge higher than expected around the region along Suo-nada Sea i.e. opposite phenomenon of the present can be happened in the future. On the other hands, in the present, the usual typhoon around the region; going from south-west to north-east is traveling above Seto-inland Sea for long time and it is one of the main reasons that the time of storm surge's peak coincides with high tide and can cause the severe damages (Moemi, et al., 2007). However, if the typhoon track trend changes to going north, the time when typhoons are around Seto-Inland Sea will be shorter hence it can be said that the risk of storm surge clashing against high tide might be less than present. Typhoon traveling speed is also related to the storm surge developing and as it becomes faster, the storm surge will rise more especially at the north coast of Suo-nada Sea (Haruyuki and Hisato, 2002). Therefore, the moving speed of future typhoon also might need to be studied for evaluating the risk of future storm surge.

In this study, the future typhoons were used for future storm surge simulations with some hypothetical tracks. The simulated typhoon is the one passing through west side of Suo-nada Sea towards north. From the chapter 3, it was shown that the simulations with typhoon going west side of Suo-nada have some accuracy even with typhoon model. Besides, Haruyuki and Hisato (2002) reported that they also used typhoon model for estimating storm surge with typhoon running through Kyushu Island towards north and could obtain good results. Thus it can be said that at least the simulations with typhoons shifted $1.5 \sim 3.0$ degree should have accuracy to some extent although the surge height still tends to be underestimated somewhat.

Table 4.3.5 shows the past outstanding surge height around the region along Suo-nada Sea as a reference. The highest ones at each point were marked with * in the table. Comparing with the past storm surge height, the ones obtained by future storm surge simulations with the typhoon's damped effect (See Table 4.3.6) became higher except for Ube and Tokuyama though at Ube the highest surge in the past is almost same as the simulated value, only $0.04 \mathrm{~m}$ gaps. 
Table 4.3.5 Outstanding surge height in the past around the region along Suo-nada Sea

\begin{tabular}{|l|l|l|l|l|l|}
\hline $\begin{array}{l}\text { Name of } \\
\text { typhoon }\end{array}$ & Kanda & Chofu & Ube & Mitaziri & Tokuyama \\
\hline $\begin{array}{l}\text { T4216 } \\
\text { Suo-nada } \\
\text { typhoon) }\end{array}$ & $1.50 \mathrm{~m}$ & & $1.63 \mathrm{~m}$ & & \\
\hline T5415 & & & $0.62 \mathrm{~m}$ & $1.29 \mathrm{~m}$ & $1.13 \mathrm{~m}$ \\
\hline T5522 & & & $1.58 \mathrm{~m}$ & & $1.53 \mathrm{~m}$ \\
\hline T9119 & $1.90 \mathrm{~m}$ & $2.81 \mathrm{~m} *$ & $1.93 \mathrm{~m}$ & & $1.62 \mathrm{~m}$ \\
\hline T9918 & $2.07 \mathrm{~m} *$ & $2.20 \mathrm{~m}$ & $2.11 \mathrm{~m}$ & $2.08 \mathrm{~m}^{*}$ & $1.95 \mathrm{~m} *$ \\
\hline T0416 & & $1.07 \mathrm{~m}$ & $1.77 \mathrm{~m}$ & $1.94 \mathrm{~m}$ & $1.69 \mathrm{~m}$ \\
\hline T0418 & & $0.88 \mathrm{~m}$ & $2.15 \mathrm{~m} *$ & $1.94 \mathrm{~m}$ & $1.75 \mathrm{~m}$ \\
\hline
\end{tabular}

Table 4.3.6 Surge height by future storm surge simulations considering typhoon's damped effect

\begin{tabular}{|l|l|l|l|l|l|}
\hline Location & Kanda & Chofu & Ube & Mitaziri & Tokuyama \\
\hline Surge height & $2.78 \mathrm{~m}$ & $3.17 \mathrm{~m}$ & $2.11 \mathrm{~m}$ & $2.32 \mathrm{~m}$ & $1.55 \mathrm{~m}$ \\
\hline
\end{tabular}

Furthermore, Tomihide, et al., (2004) proposed the new sea wall level around the regions along Suo-nada Sea on the basis of probabilistic estimates on storm surge with T9918 and hypothetical tracks created by T9918 parallel shifted. Among the sites they proposed new sea wall level, only Chofu and Ube were overlapped with the points where there are results in this study (See Table 4.3.8). Thus at the two points, on the basis of the results on storm surge in the study, a height of levee freeboard was calculated in accordance with the way of the past study and the results were compared with it (See Table 4.3.8). High water level (HWL) and wave height in front of the embankment were used the same value as the past study and the way of deriving each factor in Table 4.3.8 is as shown in Table 4.3.7.

Table 4.3.7 Description of each factor in Table 4.3.8

\begin{tabular}{|c|c|c|c|c|c|c|}
\hline $\begin{array}{c}\text { Surge height } \\
(\mathrm{m})\end{array}$ & $\begin{array}{c}\text { HWL } \\
(\mathrm{m})\end{array}$ & $\begin{array}{c}\text { Estimated } \\
\text { tidal level } \\
(\mathrm{m})\end{array}$ & $\begin{array}{c}\text { Wave height } \\
\text { in front of the } \\
\text { embankment } \\
(\mathrm{m})\end{array}$ & $\begin{array}{c}\text { Proposed } \\
\text { height of } \\
\text { levees } \\
(\mathrm{m})\end{array}$ & $\begin{array}{c}\text { Present } \\
\text { height of } \\
\text { levees } \\
(\mathrm{m})\end{array}$ & $\begin{array}{c}\text { Lack of } \\
\text { the } \\
\text { levees } \\
\text { height } \\
(\mathrm{m})\end{array}$ \\
\hline $\begin{array}{c}\text { Results of } \\
\text { the } \\
\text { simulations }\end{array}$ & $\begin{array}{c}\text { Fixed } \\
\text { value } \\
\text { depending } \\
\text { on the site }\end{array}$ & $\begin{array}{c}\text { Surge } \\
\text { height } \\
+ \\
\text { HWL }\end{array}$ & $\begin{array}{c}\text { Fixed value } \\
\text { depending on } \\
\text { the site }\end{array}$ & $\begin{array}{c}\text { Estimated } \\
\text { tidal level } \\
+ \\
\text { ave height in } \\
\text { front of the } \\
\text { embankment }\end{array}$ & $\begin{array}{c}\text { Present } \\
\text { height of } \\
\text { levees at } \\
\text { each site }\end{array}$ & $\begin{array}{c}\text { Propose } \\
\text { d height } \\
\text { of levees } \\
- \\
\text { Present } \\
\text { one }\end{array}$ \\
\hline
\end{tabular}


Table 4.3.8 Investigation on levee freeboard at Chofu and Ube (Comparison the proposed height of levee freeboard in the past study by Tomihide, et al., (2004) with the one in this study)

\begin{tabular}{|c|c|c|c|c|c|c|c|}
\hline Chofu & $\begin{array}{c}\text { Surge } \\
\text { hight } \\
(\mathrm{m})\end{array}$ & $\begin{array}{c}\text { HWL } \\
(\mathrm{m})\end{array}$ & $\begin{array}{c}\text { Estimated } \\
\text { tidal level } \\
(\mathrm{m})\end{array}$ & $\begin{array}{c}\text { Wave height } \\
\text { in front of the } \\
\text { embankment } \\
(\mathrm{m})\end{array}$ & $\begin{array}{c}\text { Propose } \\
\text { d height } \\
\text { of leves } \\
(\mathrm{m})\end{array}$ & $\begin{array}{c}\text { Present } \\
\text { height of } \\
\text { levees } \\
(\mathrm{m})\end{array}$ & $\begin{array}{c}\text { Lack of } \\
\text { the leves } \\
\text { height } \\
(\mathrm{m})\end{array}$ \\
\hline $\begin{array}{c}\text { Past } \\
\text { study }\end{array}$ & 2.50 & 3.90 & 6.40 & 1.99 & 8.39 & 8.30 & 0.09 \\
\hline $\begin{array}{c}\text { This } \\
\text { study }\end{array}$ & 3.17 & 3.90 & 7.07 & 1.99 & 9.06 & 8.30 & 0.76 \\
\hline
\end{tabular}

\begin{tabular}{|c|c|c|c|c|c|c|c|}
\hline Ube & $\begin{array}{c}\text { Surge } \\
\text { hight } \\
(\mathrm{m})\end{array}$ & $\begin{array}{c}\text { HWL } \\
(\mathrm{m})\end{array}$ & $\begin{array}{c}\text { Estimated } \\
\text { tidal level } \\
(\mathrm{m})\end{array}$ & $\begin{array}{c}\text { Wave height } \\
\text { in front of the } \\
\text { embankment } \\
(\mathrm{m})\end{array}$ & $\begin{array}{c}\text { Propose } \\
\text { d height } \\
\text { of leves } \\
(\mathrm{m})\end{array}$ & $\begin{array}{c}\text { Present } \\
\text { height of } \\
\text { levees } \\
(\mathrm{m})\end{array}$ & $\begin{array}{c}\text { Lack of } \\
\text { the leves } \\
\text { height } \\
(\mathrm{m})\end{array}$ \\
\hline $\begin{array}{c}\text { Past } \\
\text { study }\end{array}$ & 2.10 & 3.70 & 5.80 & 3.34 & 9.14 & 8.00 & 1.14 \\
\hline $\begin{array}{c}\text { This } \\
\text { study }\end{array}$ & 2.11 & 3.70 & 5.81 & 3.34 & 9.15 & 8.00 & 1.15 \\
\hline
\end{tabular}

From Table 4.3.8, it can be seen that the surge height might be higher than the height of present levees in the future. Also the surge height at Chofu in the study is around $0.7 \mathrm{~m}$ higher than the estimated surge height in past study whereas at Ube the surge height in this study is almost same as the one of the past study. In either case, at both Chofu and Ube the present levees height is not enough for disaster prevention. Moreover, one thing needs to be considered is that the surge height in the past study by Tomihide, et al., (2004) was estimated by adopting T9918 which had one of the worst typhoon track for the region. On the other hands, the future typhoon used in the study is going towards north and is not necessarily the dangerous track for the region, it was selected due to the lowest central pressure when it is closest to the region. Therefore, the future typhoon which is traveling from south-west to north-east might lead to much higher storm surge than noted here due to its intensity.

And the storm surge estimation by numerical simulations have tendency of underestimating for somewhat hence the surge height might become higher to some extent than the simulated ones in this study in the future.

Hence as a conclusion of this study, it can be said that there is a high possibility that the storm surge around Suo-nada Sea can be more developed and cause more severe damages comparing to the present around the region in the future. 


\section{Summary}

In order to take precautions against future storm surge caused by more furious typhoon due to the global warming, the numerical simulations using Finite Volume Coastal Ocean Model (FVCOM) were performed with target for Suo-nada Sea. Suonada Sea has a vulnerability against storm surge though the sea area has topographical factors which makes storm surge estimations difficult. Indeed, the storm surge had been underestimated in the past study even if one could estimate wind velocity with high accuracy.

Firstly, the most suitable computational domain size was determined for optimizing the computations. Thereafter various kinds of data; GPV, WRF and an empirical typhoon model were used in estimating external forces i.e. pressure and wind speed distribution so as to verify the influence of using different data on the simulation accuracy. Also four typhoons which gave severe damages around the region along Suo-nada Sea; T9119, T9918, T0416 and T0418 were selected for using in the simulations. As a results, it was revealed that the simulations with typhoon passing through west side of Suo-nada Sea had enough accuracy. Moreover, when the estimations of external forces were carried out correctly, FVCOM could give accurate outputs on storm surge.

Furthermore, the change of typhoon trend in the future was investigated on the basis of Database for Policy Decision making for Future climate change (d4PDF). And it turns out that a usual typhoon track approaching to Suo-nada Sea might be changed in the future; from going towards north-east to going towards north. Moreover, the number of typhoons approaching Suo-nada Sea will decrease while the intensity of the typhoons will be strong.

As a last phase, by using future typhoons extracted from d4PDF, the future storm surge simulations were carried out with an empirical typhoon model. The simulations were performed for not only the original course but also several hypothetical courses created by parallel shift of the original one with considering the damped effect which typhoons were given by going through land area. The damped effect of typhoon was derived by comparing the typhoon central pressure between 31 and 34 degree of north latitude with Best Track data (BT). By including the typhoon fading, the intensity of the future typhoons was degraded by around $10 \sim 14 \%$ in the numerical simulations depending on the total time of typhoon traveling above land. Finally, it was confirmed that the height of storm surge led by a future typhoon became higher than the past remarkable storm surge even with considering the damped effect of typhoon.

Therefore, it can be concluded that due to the global warming, the typhoon trend around Suo-nada Sea might be changed besides the storm surge in Suo-nada Sea can be more developed and make more severe damages around the region along Suo-nada Sea in the future. 


\section{Appendices}

Appendix A: Additional outputs extracted from BT on the basis of the same definition as the investigation using d4PDF

Appendix B: Comparison of time series on wind speed with and without typhoon fading 


\section{Appendix A}

For BT also the same attempts on extracting typhoons were carried out. The results were as shown in Figure A-1. The typhoons which approached Suo-nada Sea used to travel towards north-east and this tendency is similar with the results by past experiments of d4PDF. Thus the results obtained from d4PDF could represent the past typhoon trend enough hence the credibility can be expected in the results obtained by using future experiments of d4PDF as well. Therefore, it can be said that the discussion on the change of typhoon trend in the future is valid. Figure A-2 shows the histogram on the number of typhoons which approached Suo-nada Sea in reality in the past and its central pressure.
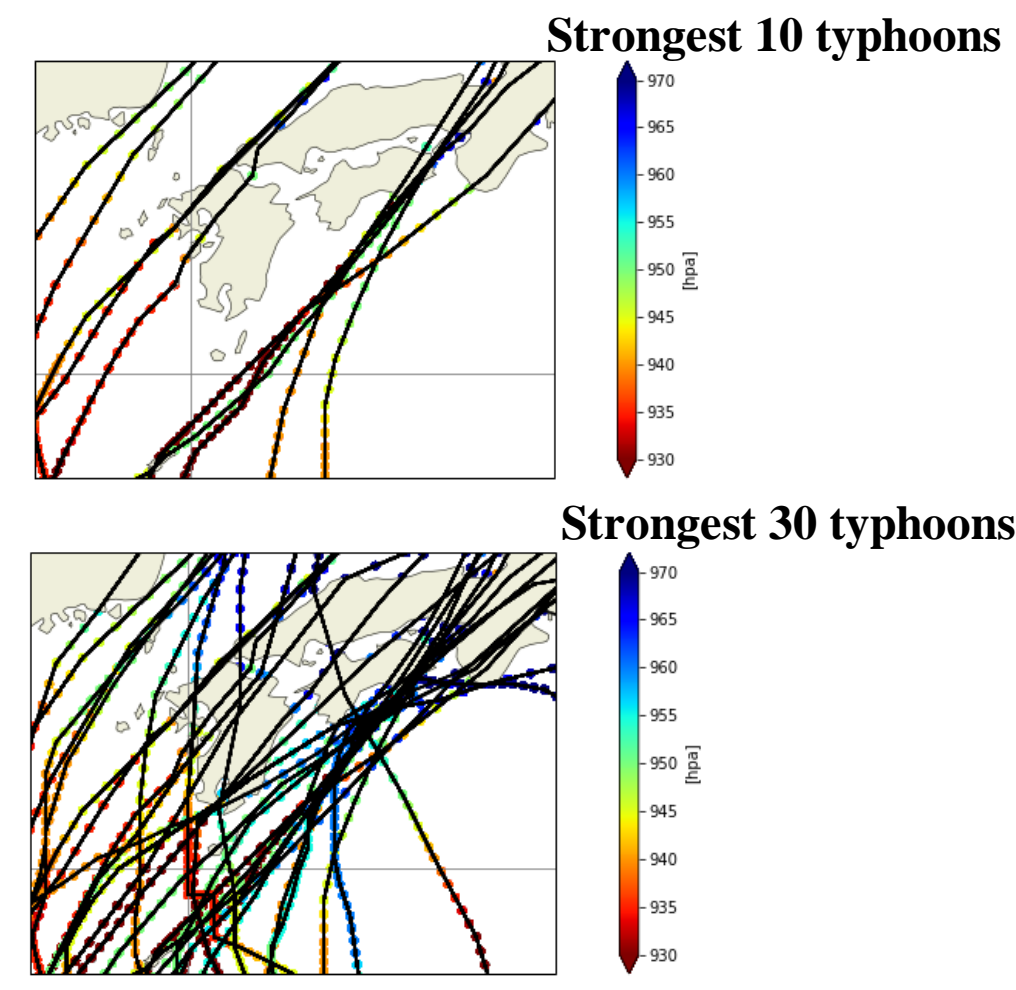

Strongest 50 typhoons

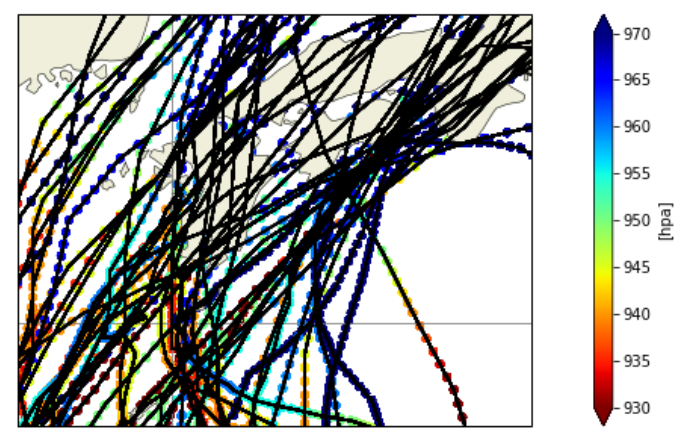

Figure A-1. Typhoon tracks extracted from BT which approached Suo-nada Sea in the past 


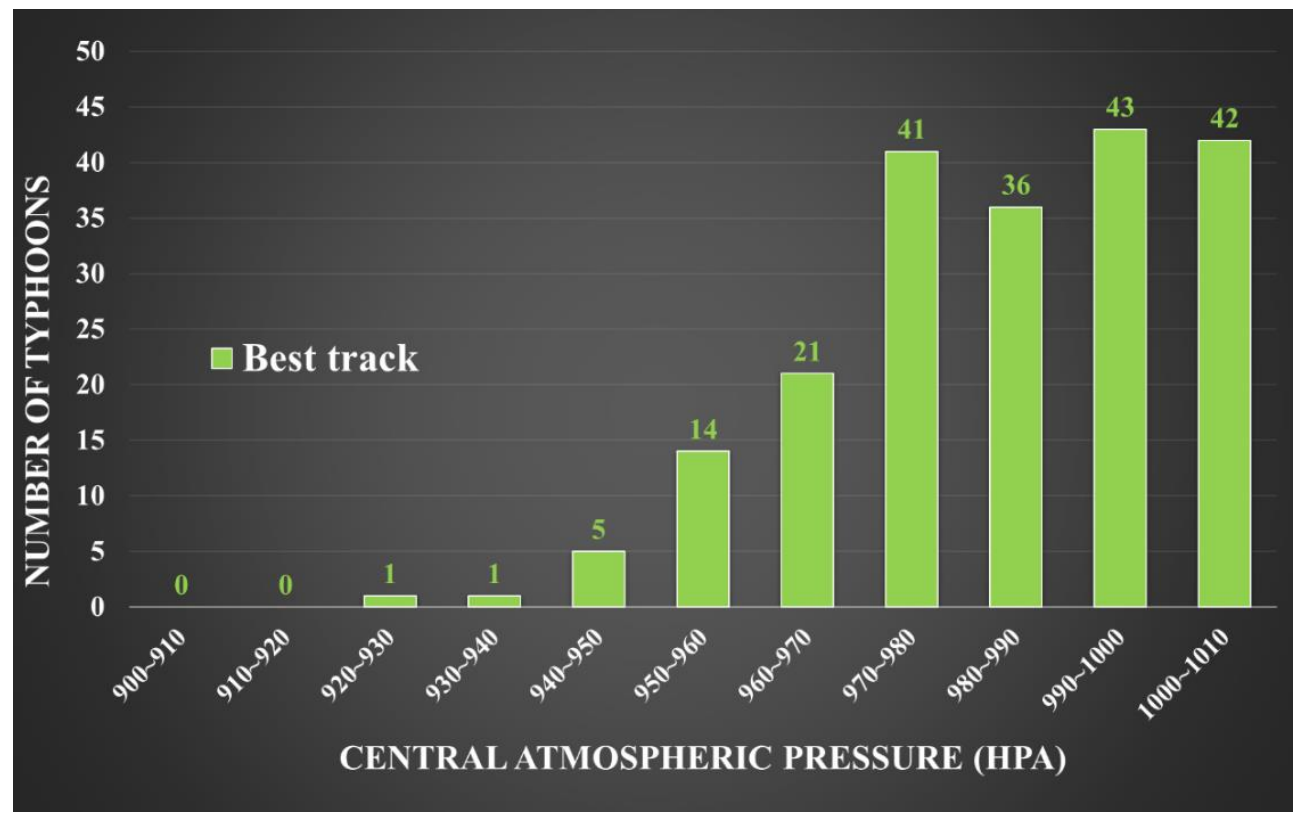

Figure A-2. Histogram on the relationship between the number of typhoons which approached to Suo-nada Sea in the past and its central pressure (BT)

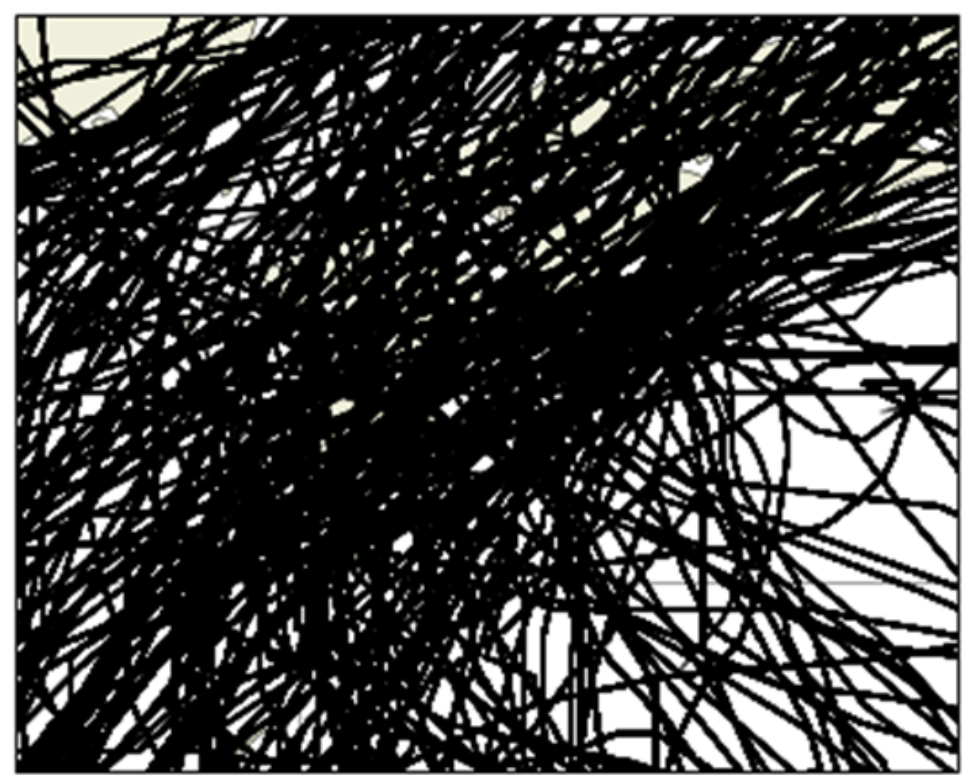

Figure A-3. 208 typhoons extracted from BT for investigation on the damped effect of typhoon passing through land area 


\section{Appendix B}
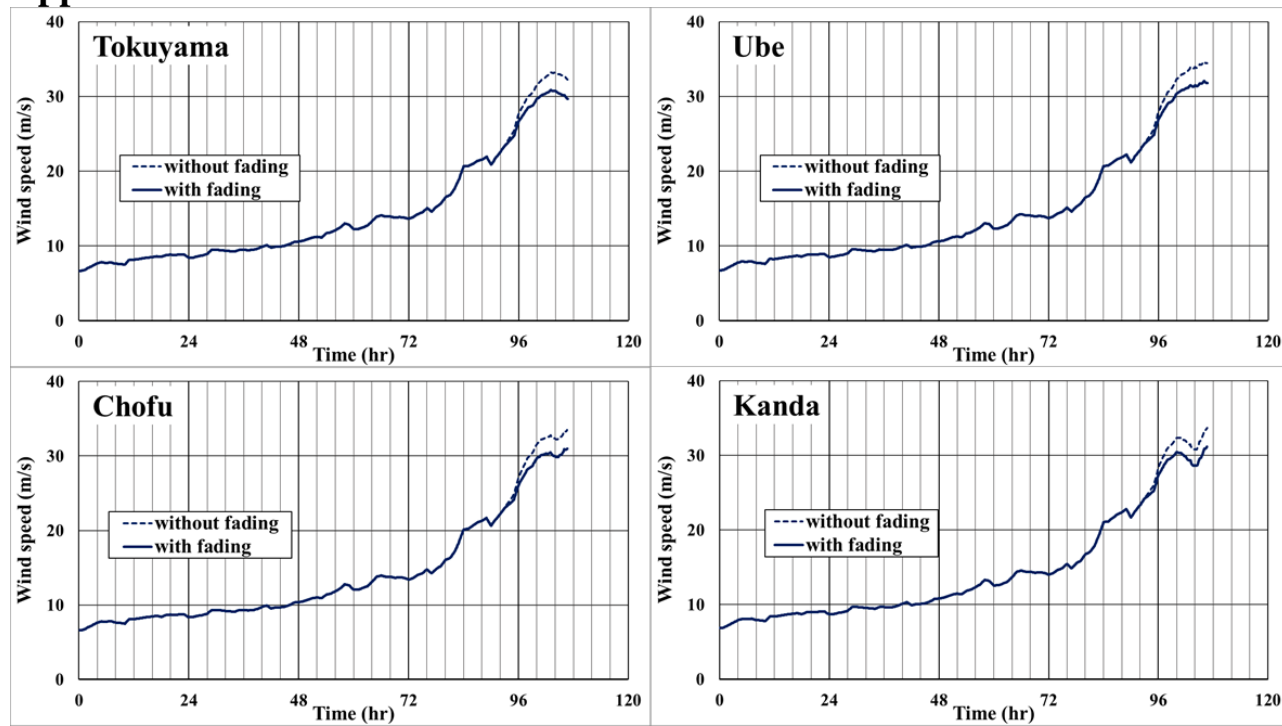

Figure B-1. Comparison on wind speed with and without typhoon fading using 2.5 degree shifted typhoon
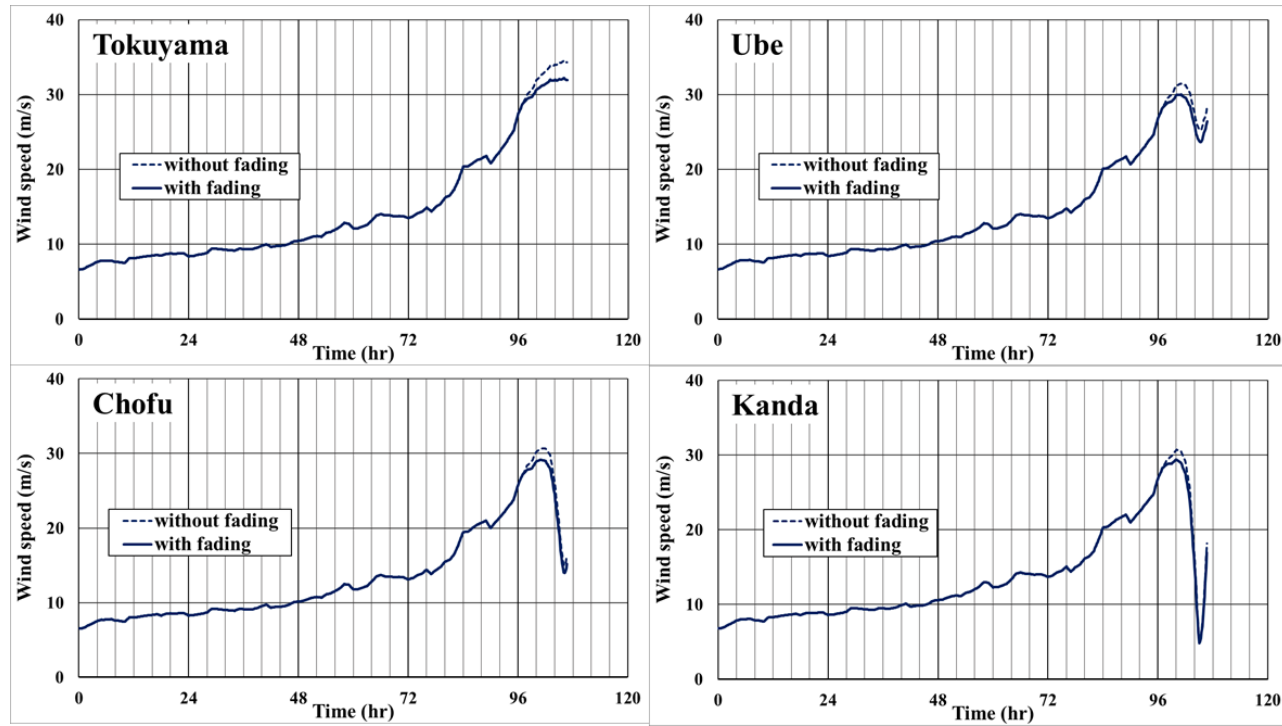

Figure B-2. Comparison on wind speed with and without typhoon fading using 3.0 degree shifted typhoon 


\section{Reference}

Chen, et al. (2013) An Unstructured Grid, Finite-Volume Community Ocean Model FVCOM User Manual, Fourth Edition, Marine Ecosystem Dynamics Modelling Laboratory

Marine Ecosystem Dynamics Modelling Laboratory, 2001-2019. FVCOM. [online] Available at: < http://fvcom.smast.umassd.edu/> [Accessed 9 January 2019]

Yamaguchi Prefectural Government, 2007. Yamaguchi ken no takashio saigai, [Disaster caused by storm surge in Yamaguchi Prefecture]. [pdf]Yamaguchi city: Yamaguchi Prefectural Government. Available through $<$ http://www.pref.yamaguchi.lg.jp/cms/a18700/takasiohm/top/apd1_3_2007021026145900.pdf>

[Accessed 19 July 2018].

Takamatsu Port Airport Technical Research Office, 2007. Taifu shinro ni sayu sareru Setonaikai Shikoku engan no takashio to takanami, [Storm surge and high wave controlled by typhoon course along Seto Inland Sea and Shikoku Island]. [pdf] Takamatsu Port Airport Technical Research Office, Shikoku Regional Development Bureau, Ministry of Land, Infrastructure, Transport and Tourism. Available at: < http://www.pa.skr.mlit.go.jp/general/region/tkgityou/publish/panf/panf_4.pdf > [Accessed 19 July 2018].

Nadao, K., Kazuo, K., Hiroaki, M., Yukihiro, I., Kazuhisa, H., Eichi, S., Yuichi, S., Akifumi, F., Yoshihiko, T., and Keiichi, T., (2006), The Mechanism of the Storm Surges in the Seto Inland Sea Caused by Typhoon Chaba (0416): TENKI, The bulletin journal of the Meteorological Society of Japan, Vol.53, pp.845-856 (in Japanese)

Ministry of Land, Infrastructure, Transport and Tourism, 2005. Assessment of Disaster Damaged in 2004. pp.22-23[pdf] Tokyo: Ministry of Land, Infrastructure, Transport and Tourism

Available at $:<$ http://www.mlit.go.jp/river/pamphlet_jirei/bousai/saigai/2005/22.pdf $>$

[Accessed 4 July 2018].

Ministry of Land, Infrastructure, Transport and Tourism, 2005. Assessment of Disaster Damaged in 2004. pp.24-25[pdf] Tokyo: Ministry of Land, Infrastructure, Transport and Tourism

Available at http://www.mlit.go.jp/river/pamphlet_jirei/bousai/saigai/2005/24.pdf>

[Accessed 6 July 2018].

Ministry of Construction, n.d., CLOSE UP THE DISASTER IN 1999, [online] Available

at: 
http://www.mlit.go.jp/river/pamphlet_jirei/bousai/saigai/1999/html/b004.htm> [Accessed 6 ${ }^{\text {th }}$ July 2018].

Tomihide, M., Tetsuya, H., Yoshihiro, U., Masahiro, M., Ikuo, O and Koji, N., 2003. CHARACTERISTICS OF STORM SURGE DAMAGES CAUSED BY TYPHOON 9918 IN SUO-NADA SEA.:JSCE, Vol.66, No.1, pp.226-230 (in Japanese)

Yoshiaki, S., Hidenori, S., 2010. Tidal Simulation around Japanese Coastal Region with a Global Ocean Tide Model: Proceedings of Coastal Engineering, JSCE, Vol.66, No.1, pp.226-230 (in Japanese)

Masamori, M., 2003. 高潮の研究その実例とメカニズム. Tokyo: SEIZANDOSHOTEN CO.,LTD.

Ogata, T., Mizuta, R., Adachi Y., Murakami, H. and Ose, T., 2015. Effect of air-sea coupling on the frequency distribution of intense tropical cyclones over the northwestern Pacific: Geophysical Research Letters, Vol.42, pp. 10415-10421

Yoshihiko IDE, Naoyuki NAKAO, Mitsuyoshi KODAMA, Noriaki HASHIMOTO and Masaru YAMASHIRO., 2018.STUDY ON DIFFERENCES IN TYPHOON CHARACTERISTICS DUE TO SEA SURFACE TEMPERATURE PATTERNS UNDER NEAR-FUTURE CLIMATE: Proceedings of civil engineering in the ocean, Vol.74, No.2 (in Japanese)

Hiroyasu KAWAI., 2000. Field Investigation of Characteristic of Storm Surge in Suonada Sea: Port and Harbour Research Institute, Ministry of Land, Infrastructure and Transport, 海と空, 76(4), pp197-201

Haruyuki KOJIMA and Hisato FUJII., 2002. STORM SURGE CHARACTERISTICS ALONG THE COASTS OF THE SUO, GENKAI AND HIBIKI SEAS: Proceedings of civil engineering in the ocean, Vol.18, pp.227-232 (in Japanese)

Moemi, M., Kazuo, M., Hideyuki, S., (2006), Numerical Simulations of Storm Surge and Typhoon Wind Profile with Super Gradient Wind: Annual Journal of Coastal Engineering, JSCE, Vol.53, pp206-210 (in Japanese)

Veltcheva, A.D, Hiroyasu, H., (2002), Storm Surge Estimation by Considering the Distortion of Pressure Distribution and Super Gradient Winds: Proceedings of Coastal Engineering, JSCE, Vol.49, pp.241-245 (in Japanese)

Moemi MATOBA, Shinga FUKUHARA, Kazuo MURAKAMI and Hidenori SHIBAKI., 2007. Characteristics of Storm Surge in the Seto Inland Sea with Consideration of Typhoon Tracks: Proceedings of Coastal Engineering, JSCE, Vol.54, pp.291-295 (in Japanese) 
K.Komai, T.Hibino, H.Matsumoto., 2005. Characteristics of Propagation and Generation of Storm Surge in the Seto Inland Sea -Analysis of TY0416 and TY0418- : Proceedings of Coastal Engineering, JSCE, Vol.52, pp.221-225 (in Japanese)

Hiroyasu KAWAI, Tetsuya HIRAISHI, Haruhiro MARUYAMA, Toshio TANAKA., 2000. Field Investigation and Numerical Simulation of Storm Surge by Typhoon No.9918: TECHNICAL NOTE OF THE PORT AND HARBOUR RESEARCH INSTITUTE MINISTRY OF TRANSPORT, JAPAN, No.971 (in Japanese)

Kanmon waterway Office (関門航路事務所), 2008. Tide and tidal currents in Kanmon Strait (関門海峡の潮位・潮流). [online]

Available at: < https://www.pa.qsr.mlit.go.jp/kanmon/2kanmon/index2-1.html > [Accessed 6 February 2019].

Tomihide, M., Tetsuya, H., Yoshihiro, U., Fusanori, M. and Koji, N., 2004. THE DEFENSIVE STANDARD FOR STORM SURGE IN SUO-NADA SEA: Proceedings of JSCE (775), pp.69-80 (in Japanese)

Murakami, H., Wang, Y., Yoshimura, H., Mizuta, R., Sugi, M., Shindo, E., Yukimoto, S., Hosaka, M., Kusunoki, S., Ose, T., and Kitoh, A., 2012. Future changes in tropical cyclone activity projected by the new high-resolution MRIAGCM, Journal of Climate, 25(9), 3237-3260, 2012

Tsumoto, K., T. Takanezawa, and M. Ooe., 2000: Ocean Tide Models Developed by Assimilating TOPEX/POSEIDON Altimeter Data into Hydrodynamical Model: A Global Model and a Regional Model Around Japan, Journal of Oceanography, Vol.56, pp567-581 3

Ministry of Education, Culture, Sports, Science and Technology, Japan Meteorological Agency Meteorological Research Institute, Tokyo University, Kyoto University, National Institute for Environmental Studies, Tsukuba University, Japan Agency for Marine-Earth Science and Technology, 2015. 地球温暖化対策に資す るアンサンブル気候予測データベース database for Policy Decision making for Future climate change (d4PDF) 利用手引き (抜粋) .[image online]

Available at: < http://www.mirocgcm.jp/ pub/d4PDF/img/d4PDF_Chap1_20151214.pdf>

[Accessed 27 February 2019] 